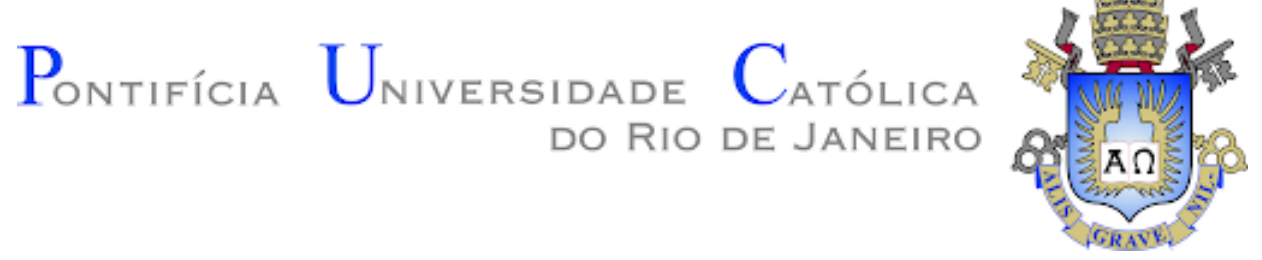

Waleska Yone Yamakawa Zavatti Campos

Efeitos da Liderança Servidora e Empreendedora no Fomento da Inovação no Setor Público

Dissertação de Mestrado

Dissertação apresentada como requisito parcial para obtenção do grau de Mestre pelo Programa de Pósgraduação em Administração de Empresas do Departamento de Administração da PUC-Rio.

Orientadora: Prof ${ }^{-}$Flavia de Souza Costa Neves Cavazotte 


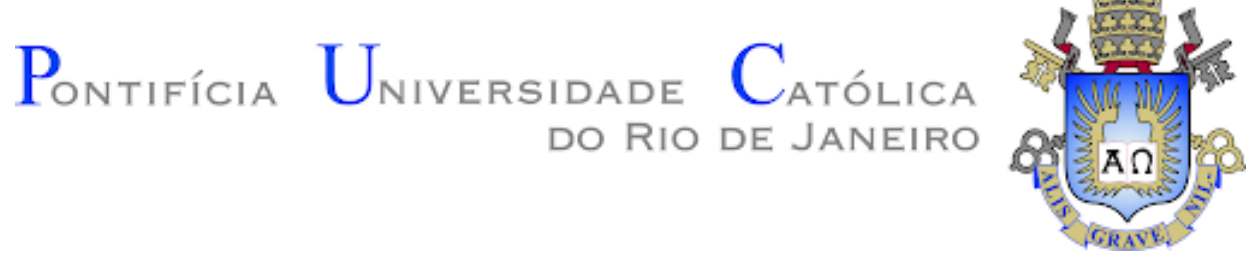

Waleska Yone Yamakawa Zavatti Campos

\section{Efeitos da Liderança Servidora e Empreendedora no Fomento da Inovação no Setor Público}

Dissertação apresentada como requisito parcial para obtenção do grau de Mestre pelo Programa de Pósgraduação em Administração de Empresas da PUC-Rio. Aprovada pela Comissão Examinadora abaixo.

Prof. - Flavia de Souza Costa Neves Cavazotte

Orientadora

Departamento de Administração - PUC-Rio

Prof.- Ana Heloísa da Costa Lemos Departamento de Administração - PUC-Rio

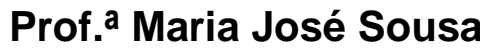

Departamento de Ciência Política e Políticas Públicas - ISCTE-IUL Portugal

Prof. Valter de Assis Moreno Jr. IBMEC 
Todos os direitos reservados. É proibida a reprodução total ou parcial do trabalho sem autorização da universidade, da autora e da orientadora.

\section{Waleska Yone Yamakawa Zavatti Campos}

Graduou-se em Pedagogia pela Universidade de São Paulo em 2008. Graduou-se em Bacharelado em Administração pela Universidade Federal de Goiás em 2020. Participou de curso de curta duração no exterior com bolsa da Capes, pelo Programa Capes/Print - Programa de Internacionalização no Instituto Universitário de Lisboa - ISCTE/IUL, Portugal. Cursou MBA em Gestão de Pessoas-Magistério Superior em 2012 (LFG). Cursou especialização em Gestão Pública em 2014 (Universidade Católica Dom Bosco). Cursou especialização em Controle Externo e Governança Pública em 2017 (Instituto Brasiliense de Direito Público). É Analista de Controle Externo-Especialidade Gestão de Pessoas do Tribunal de Contas do Estado de Goiás. Atualmente é integrante dos grupos de pesquisa: Gestão da Inovação e Tecnologia da Universidade Federal de Rondônia (GEITEC) e Centro de Pesquisa em Empreendedorismo e Inovação (MAGIS/PUC-Rio).

Ficha Catalográfica

Campos, Waleska Yone Yamakawa Zavatti

Efeitos da liderança servidora e empreendedora no fomento da inovação no setor público / Waleska Yone Yamakawa Zavatti Campos ; orientadora: Flavia de Souza Costa Neves Cavazotte. 2021.

106 f. : il. color. ; $30 \mathrm{~cm}$

Dissertação (mestrado)-Pontifícia Universidade Católica do Rio de Janeiro, Departamento de Administração, 2021.

Inclui bibliografia

1. Administração - Teses. 2. Liderança servidora. 3. Liderança empreendedora. 4. Empoderamento psicológico. 5. Engajamento. 6. Comportamento inovador no trabalho. I. Cavazotte, Flavia de Souza Costa Neves. II. Pontifícia Universidade Católica do Rio de Janeiro. Departamento de Administração. III. Título. 
Aos meus pais, Lourival e Marina (in memoriam) pela valorização de minha formação. 


\section{Agradecimentos}

À Deus, pela saúde e pela oportunidade. Ao meu pai Lourival Zavatti, e minha mãe, Marina Yochiko Yamakawa Zavatti (in memoriam), por viabilizarem os meios para meu desenvolvimento. Ao meu esposo Felipe Campos, pelo apoio incondicional. Às irmãs Vanessa, Valquíria e Viviane Zavatti e à minha madrasta Leonor Lima, um agradecimento especial.

Ao TCE-GO pela concessão da licença-mestrado, a partir da qual pude produzir conhecimentos com o escopo de auxiliar a sociedade.

À Prof ${ }^{a}$ Flávia Cavazotte, pela generosidade. Agradeço, também, por me indicar a concorrer à bolsa CAPES-Print, a partir da qual, após aprovação, pude participar de curso na ISCTE-IUL/Portugal (Proc. $n^{\circ} 88887.583269 / 2020-00$ ). Por fim, obrigada por acreditar no nosso trabalho aprovado no Academy of Management 2021.

Aos Professores Luiz Brandão, Marcos Cohen, Ana Heloísa Lemos, Martius Rodriguez, Luciana Barbieri, Estela Najberg, Maria Sousa, Carolina Rodrigues, e Raul Pommer, obrigada por auxiliarem em meu desenvolvimento acadêmico.

A Elton de Oliveira, Larissa Lourenço, Maria Clarice e Carmem Eleonora, obrigada pela amizade e apoio. Um agradecimento especial a: Lucyanne Mendonça, Rodrigo Utino, Hugo Brito, Carolina Pante, Rosana Smék, Carla Oliveira, Paula Polidoro, Marcelo Quintão, Michelle Pacheco, Alexandre Silva e Carolina Brandão.

O presente trabalho foi realizado com apoio da Coordenação de Aperfeiçoamento de Pessoal de Nível Superior - Brasil (CAPES) - Código de Financiamento 001.

À PUC-Rio e ao CNPq, pelos auxílios concedidos, sem os quais este trabalho não poderia ter sido realizado. 


\section{Resumo}

Campos, Waleska Yone Yamakawa Zavatti; Cavazotte, Flavia de Souza Costa Neves (Orientadora). Efeitos da Liderança Servidora e Empreendedora no Fomento da Inovação no Setor Público. Rio de Janeiro, 2021. 106 p. Dissertação de Mestrado - Departamento de Administração, Pontifícia Universidade Católica do Rio de Janeiro.

Este estudo examina as associações de liderança servidora e liderança empreendedora com o comportamento inovador no contexto do setor público. Além disso, foi verificado se as relações são mediadas pelo empoderamento psicológico e pelo engajamento, respectivamente. O cerne das hipóteses é de que esses tipos de liderança auxiliam os funcionários a serem mais engajados, empoderados psicologicamente e inovadores. Para testar as hipóteses, foi aplicada modelagem de equações estruturais de mínimos quadrados parciais com dados de uma amostra de 135 servidores públicos de Tribunais de Contas oriundos de 14 Estados brasileiros, obtidas por meio de questionário eletrônico. Para estimar e remover o viés do método comum, foi utilizada a técnica de variável marcadora. Os resultados mostram que os efeitos da liderança servidora no comportamento inovador são totalmente mediados pelo empoderamento psicológico. Além disso, os resultados evidenciam que a liderança empreendedora tem associação direta e positiva com o comportamento inovador, de modo que esses efeitos são parcialmente mediados pelo engajamento. $\mathrm{O}$ estudo contribui para o entendimento dos efeitos da liderança servidora e empreendedora, bem como de atributos individuais, no fomento da inovação no setor público. Por fim, são discutidas implicações para a teoria e para a prática de gestão.

\section{Palavras-chave}

Liderança Servidora; Liderança Empreendedora; Empoderamento Psicológico; Engajamento; Comportamento Inovador no Trabalho. 


\section{Abstract}

Campos, Waleska Yone Yamakawa Zavatti; Cavazotte, Flavia de Souza Costa Neves (Advisor). Effects of Servant and Entrepreneurial Leadership in Fostering Innovation in the Public Sector. Rio de Janeiro, 2021. 106 p. Dissertação de Mestrado - Departamento de Administração, Pontifícia Universidade Católica do Rio de Janeiro.

This study examines the associations of servant leadership and entrepreneurial leadership with innovative behavior in the context of the public sector. Furthermore, it was verified whether the relationships are mediated by psychological empowerment and engagement, respectively. The core of the hypothesis is that these leadership styles help employees to be more engaged, psychologically empowered and innovative. To test the hypotheses, partial least squares structural equation modeling was applied with data from a sample of 135 public servants from the Courts of Auditors from 14 Brazilian states, obtained through an electronic questionnaire. To estimate and remove the common method bias, a marker variable technique is used. The results demonstrate that the effects of servant leadership on innovative behavior are fully mediated by psychological empowerment. Furthermore, the results show that entrepreneurial leadership has a direct and positive association with innovative behavior, so that these effects are partially mediated by engagement. The study contributes to the understanding of the effects of servant and entrepreneurial leadership, as well as individual attributes, in fostering innovation in the public sector. Finally, contributions to management theory and practice are discussed.

\section{Keywords}

Servant Leadership; Entrepreneurial Leadership; Psychological Empowerment; Engagement; Innovative Work Behavior. 


\section{Sumário}

1 Introdução 13

$\begin{array}{ll}1.1 \text { Objetivo geral } & 15\end{array}$

$\begin{array}{ll}1.2 \text { Objetivos específicos } & 15\end{array}$

$\begin{array}{ll}1.3 \text { Delimitação do estudo } & 16\end{array}$

1.4 Relevância e justificativa do estudo 16

2 Referencial teórico $\quad 19$

2.1 Revisão sistemática da literatura 19

2.1.1 Método da revisão sistemática da literatura 19

2.1.2 Abordagens nos estudos sobre liderança, criatividade e inovação no setor público $\quad 20$

2.1.3 Moderadores e mediadores $\quad 22$

2.2 Comportamento inovador no trabalho 23

2.3 Liderança servidora $\quad 26$

2.3.1 Teoria da autodeterminação nas relações entre liderança servidora e comportamento inovador no trabalho 33

2.3.2 Liderança servidora e comportamento inovador no trabalho 35

$\begin{array}{ll}\text { 2.3.3 Mecanismos de influência } & 37\end{array}$

2.3.4 Liderança servidora, empoderamento psicológico e comportamento inovador no trabalho $\quad 37$

2.4 Liderança empreendedora 40

2.4.1 Teoria social cognitiva na relação entre liderança empreendedora e comportamento inovador no trabalho 43

2.4.2 Liderança empreendedora e comportamento inovador no trabalho $\quad 44$

2.4.3 Mecanismos de influência $\quad 46$

2.4.4 Liderança empreendedora, engajamento e comportamento inovador no trabalho 46

2.5 Modelo conceitual e hipóteses 50

3 Método 52

3.1 Desenho da pesquisa e participantes 52

3.2 Escalas $\quad 55$

3.2.1 Liderança servidora $\quad 56$

3.2.2 Liderança empreendedora $\quad 56$

3.2.3 Empoderamento psicológico $\quad 57$ 
3.2.4 Engajamento 57

3.2.5 Comportamento inovador no trabalho 58

3.2.6 Variáveis demográficas e de controle $\quad 58$

3.3 Procedimentos para análise de dados da pesquisa 59

4 Resultados $\quad 60$

4.1 Análise descritiva dos dados demográficos da amostra $\quad 60$

4.2 Testes de normalidade 63

4.3 Análise Fatorial Exploratória 65

4.3.1 Comportamento inovador no trabalho 65

4.3.2 Empoderamento psicológico $\quad 66$

4.4 Avaliação do modelo de mensuração 68

4.5 Teste de correlação $\quad 72$

4.6 Avaliação do viés do método comum 74

4.7 Avaliação do modelo estrutural $\quad 74$

4.7.1 Avaliação do Modelo 1

4.7.2 Avaliação do Modelo $2 \quad 77$

4.7.3 Avaliação do Modelo $3 \quad 80$

4.8 Mapa de importância-desempenho 84

5 Discussão e conclusão 86

5.1 Discussão 86

5.2 Limitações do estudo e agenda de pesquisa $\quad 89$

6 Referências 91

$\begin{array}{ll}\text { Anexo } & 105\end{array}$ 


\section{Índice de Figuras}

Figura 1 - Método da revisão sistemática da literatura 20

Figura 2 - Rol de variáveis mediadoras e moderadoras 22

Figura 3 - Dimensões da liderança servidora 29

Figura 4 - Análise fatorial confirmatória de segunda ordem 31

Figura 5 - Continuum de autodeterminação 34

Figura 6 - Fenômeno do empreendedorismo 42

Figura 7 - Teoria social cognitiva 44

Figura 8 - Modelo conceitual do estudo 50

Figura 9 - Detecção de potenciais outliers 54

Figura 10 - Detecção de potenciais outliers 55

Figura 11 - Distribuição de gêneros, em números absolutos 60

Figura 12 - Formação acadêmica, em números absolutos $\quad 61$

Figura 13 - Tempo de trabalho na organização e com o líder 61

Figura 14 - Distribuição de respondentes por Estado brasileiro 62

Figura 15 - Bem-estar e intenção de permanecer no teletrabalho 63

Figura 16 - Gráfico QQ-Plot para análise de normalidade 64

Figura 17 - Gráfico de distribuição para análise de normalidade $\quad 64$

Figura 18 - Resultados estruturais do Modelo $2 \quad 77$

Figura 19 - Resultados estruturais do Modelo $3 \quad 80$

Figura 20 - Mapa de importância-desempenho 84 


\section{Índice de Quadros}

Quadro 1 - Características metodológicas - criatividade 21

Quadro 2 - Características metodológicas - comportamento inovador 21

Quadro 3 - Limitações das escalas de criatividade e inovação 25

Quadro 4 - Sumarização das hipóteses 51

Quadro 5 - Fontes dos questionários e métricas 55

Quadro 6 - Variáveis demográficas e de controle 58

Quadro 7 - Avaliação do modelo de mensuração 69

Quadro 8 - Modelos do estudo $\quad 74$

Quadro 9 - Sumarização das hipóteses - Modelo $2 \quad 79$

Quadro 10 - Sumarização das hipóteses - Modelo 3 


\section{Índice de Tabelas}

Tabela 1 - Cálculo da amostra mínima da pesquisa 53

Tabela 2 - Possibilidades de respondentes $\quad 54$

Tabela 3 - Testes de normalidade dos resíduos 64

Tabela 4 - Teste KMO e de Barlett 65

Tabela 5 - Matriz padrão 66

Tabela 6 - Teste KMO e de Barlett $\quad 67$

Tabela 7 - Matriz padrão $\quad 67$

Tabela 8 - Alfa de Cronbach - empoderamento psicológico 68

Tabela 9 - Validade discriminante, convergente e confiabilidade $\quad 69$

Tabela 10 - Cargas cruzadas 71

Tabela 11 - Correlação de Pearson entre as variáveis latentes 73

Tabela 12 - Modelos estruturais preditores do comportamento inovador 76

Tabela 13 - Valores de importância e desempenho 85 


\section{1 \\ Introdução}

A liderança é considerada peça-chave no desenvolvimento da criatividade e inovação dos funcionários, do time e da organização pela sua capacidade de moldar o ambiente, alocar recursos e influenciar o comportamento dos liderados (Hughes et al., 2018; Lee et al., 2020).

No setor público, a liderança para a inovação ganha ainda mais relevo devido aos impactos sociais que inovações podem trazer para o progresso da humanidade, em um contexto marcado por austeridade e limitação de recursos (Bolden \& O'Regan, 2018). Com isso, a inovação é caminho profícuo para a entrega de melhores serviços públicos a um menor custo, bem como para enfrentamento de desafios sociais, ambientais, e tecnológicos (H. Qiu \& Chreim, 2021).

Especificamente, as discussões acerca da inovação chegaram ao setor público como respostas governamentais às necessidades sociais em busca de eficiência e às demandas crescentes por novos ou melhores produtos e serviços, por novas formas de comunicação e por formas alternativas de interagir com os cidadãos, com foco primordial na melhoria do desempenho (Clausen et al., 2020; Lewis et al., 2018).

Estudiosos argumentam que a inovação é fundamental para que o setor público responda a esses diversos desafios (Reiter \& Klenk, 2019). Uma das saídas para que o setor público inove é a implementação do denominado pós-New Public Management, marcado pela racionalização da máquina pública via melhoria de processos de liderança e criação de novos produtos e serviços, com foco primordial na eficiência pública (Osborne \& Brown, 2011; Reiter \& Klenk, 2019).

Nesse sentido, a relação entre líderes e liderados não configura apenas uma relação na qual são perseguidas soluções para problemas, mas envolve também a criação de um grupo para atingimento de objetivos pré-determinados (Antonakis \& Day, 2018), como por exemplo, a busca pelo bem comum por meio da exploração de oportunidades e implementação de inovações. Assim, a criação de uma equipe deve ser pautada pela premissa de que a coordenação visa o encadeamento de 
esforços e cooperação (Pietraszewski, 2020). Tais esforços podem ser dotados de uma postura instrumental, voltada à mera realização de tarefas técnicas (Antonakis $\&$ House, 2014) ou ainda, de uma postura proativa e criativa por parte da liderança e dos liderados (Makri \& Scandura, 2010). Do ponto de vista dos atuais desafios sociais e organizacionais, os líderes públicos mais eficazes do século XXI devem ser capazes de coordenar esforços e realizar a mudança por meio de processos criativos e inovadores (Basadur, 2004).

Embora o papel dos funcionários no processo de criação, promoção e implementação de ideias novas no trabalho tenha sido objeto de destaque, estudos recentes têm demonstrado a existência de crescente interesse em descortinar os fatores que incentivam o comportamento de inovação de funcionários, dentre os quais destacam-se tipos de liderança, componentes motivacionais, cognitivos e organizacionais (Hughes et al., 2018; Lee et al., 2020).

Nesse sentido, e sem a intenção de esgotar a discussão, muito tem sido pesquisado acerca dos fatores que estimulam o comportamento de inovação, como empoderamento psicológico (Khan et al., 2021), recompensas e clima organizacional (Volery \& Tarabashkina, 2021), capital psicológico (Y. Wang et al., 2021) e engajamento (Agarwal et al., 2012). Além disso, barreiras ao comportamento de inovação foram relatadas, como a burocracia no setor público, que ao levar a mais regras, hierarquia e procedimentos, diminui a autonomia, afetando, por sua vez, a inovação (van Acker et al., 2018).

Estudiosos também evidenciam que determinados tipos de liderança têm impactos importantes no fomento da criatividade e da inovação, como por exemplo a liderança servidora (Yoshida et al., 2014) e a liderança empreendedora (Newman et al., 2018). Além disso, o setor público é lócus de análise de estudos recentes, especialmente, devido suas particularidades como burocracia, estrutura organizacional e seus impactos para a sociedade (Miao et al., 2018; Mutonyi et al., 2020; Suseno et al., 2020).

Diante desse cenário, foram elencadas as seguintes questões de pesquisa:

- Quais as associações entre liderança servidora e comportamento inovador no trabalho no contexto do setor público?

- Qual as associações entre liderança empreendedora e comportamento inovador no contexto do setor público? 
Para responder às questões de pesquisa, foram delineados objetivos gerais e específicos discutidos na subseção a seguir.

\section{1}

\section{Objetivo geral}

O objetivo geral deste trabalho é investigar as associações de liderança servidora e liderança empreendedora com o comportamento inovador no contexto do setor público. Além disso, avaliar-se-á, se as relações são mediadas, respectivamente, pelo empoderamento psicológico e pelo engajamento.

\section{2}

\section{Objetivos específicos}

Para o atingimento do objetivo geral proposto foram percorridos diversos caminhos, para os quais estão elencados objetivos específicos:

1.2.1 Sumarizar, por meio de revisão sistemática da literatura, as principais tendências na utilização de variáveis mediadoras e moderadoras em estudos sobre liderança, criatividade e comportamento inovador no setor público, com a posterior identificação dos principais contextos organizacionais nos quais os estudos foram realizados.

1.2.2 Investigar as associações entre liderança servidora e comportamento inovador no trabalho, examinando o papel mediador do empoderamento psicológico.

1.2.3 Examinar as associações entre liderança empreendedora e comportamento inovador no trabalho, verificando o papel mediador do engajamento.

1.2.4 Elaborar um mapa de importância-desempenho para aprofundar os entendimentos da importância e do desempenho das variáveis latentes substantivas significativas para o comportamento de inovação. 


\section{3 \\ Delimitação do estudo}

Participaram da pesquisa servidores dos Tribunais de Contas brasileiros situados no âmbito federal, estadual e municipal, distribuídos em Tribunais de Contas de 14 Estados da Federação: Bahia, Espírito Santo, Goiás, Mato Grosso do Sul, Minas Gerais, Paraíba, Paraná, Piauí, Rio de Janeiro, Rio Grande do Sul, Rondônia, Santa Catarina, São Paulo e Distrito Federal.

Os Tribunais de Contas possuem papel constitucional de controle externo da administração pública, aos quais incumbe-se a função de auxiliar o Congresso Nacional na fiscalização contábil, financeira, orçamentária, operacional e patrimonial da União, Estados, Distrito Federal, Municípios e das entidades da administração direta e indireta, no que concerne à legalidade, legitimidade, economicidade, aplicação das subvenções e renúncia de receitas (Brasil, 1988; Souza, 2016).

Além disso, os Tribunais de Contas possuem poder judicante e administrativo, bem como, configuram-se como um órgão técnico, autônomo e protetor dos direitos fundamentais (Castardo, 2007).

Por fim, os participantes são servidores públicos de perfis diversificados. Portanto, a amostra é composta por servidores de diversos cargos e funções, e distintas posições na estrutura hierárquica.

Embora os Tribunais de Contas sejam tipos específicos de organizações públicas, tais características diversificadas, circunscritas à amostra, permitem inferir que os resultados estão relacionados ao que se convenciona denominar como setor público.

\section{4 \\ Relevância e justificativa do estudo}

A relevância do presente estudo envolve abordar a importância relativa dos comportamentos servidor e empreendedor em líderes, o que não foi testado de forma concorrente em um mesmo desenho de pesquisa.

A criatividade e a inovação dos funcionários sofrem diferentes impactos de diversos tipos de liderança (Lee et al., 2020). Deste modo, a inovação como um processo de implementação de ideias pode ser entendida como uma das principais 
ferramentas organizacionais para obtenção de desempenho superior, razão pela qual os líderes parecem ter papel fundamental no incentivo aos comportamentos inovadores dos funcionários (Kremer et al., 2019).

Considerando que o setor público tem características próprias em cada país e que isso impacta na maneira como atitudes inovadoras surgem (Lapuente \& Suzuki, 2020), este estudo é relevante na medida em que descortina os mecanismos envolvidos no fomento do comportamento inovador no Brasil. Além disso, a circunscrição em Tribunais de Contas pode auxiliar no entendimento dos fenômenos da liderança servidora e empreendedora no setor público. Com isso, este trabalho pode contribuir com a literatura e a prática de gestão para inovação no setor público brasileiro.

A liderança servidora foi escolhida como primeiro tipo de liderança a integrar este estudo pelo fato de o setor público ser local privilegiado para valorização desse tipo de líder, caracterizado por agir eticamente e criar valor para comunidade, entre outros atributos. Além disso, embora o comportamento servidor do líder também priorize o desenvolvimento individual dos funcionários, seu ponto crucial é o bem da comunidade (Liden et al., 2008). Diante disso, líderes servidores podem empoderar funcionários públicos para melhorar a coletividade por meio da inovação. De acordo com a teoria da autodeterminação (Deci \& Ryan, 2008), procura-se explicar que a liderança servidora atua como um fator de apoio a funcionários, aumentando o empoderamento psicológico desses, o que pode levar, por sua vez, à expressão de maiores níveis de comportamento inovador no trabalho. Este é o caminho teórico-empírico do dever cívico.

Já o segundo tipo de liderança abordado de forma concorrente neste estudo é a liderança empreendedora, cujas principais marcas são a exploração e o aproveitamento de oportunidades. Essa característica pode levar os funcionários a se engajarem no trabalho, e inovarem mais. Com base na teoria social cognitiva (Bandura, 1986) entende-se que os líderes empreendedores influenciam intencionalmente a organização do trabalho e o cotidiano dos funcionários, estimulando-os e encorajando-os cognitivamente, o que fomenta o engajamento no trabalho. Este seria o caminho teórico-empírico da exploração de oportunidades empreendedoras no setor público.

Nesse sentido, os caminhos teórico-empíricos do dever cívico e da exploração de oportunidades empreendedoras são essenciais para que o setor 
público se mantenha atuante na melhoria do desempenho, e no enfrentamento dos desafios tecnológicos e sociais por meio da criatividade e inovação organizacional.

Este estudo organiza-se em cinco seções. Após esta introdução, o referencial teórico tem início com a inclusão de uma breve revisão sistemática da literatura sobre liderança, criatividade, e inovação no setor público, com vistas a descortinar características próprias desse campo. O referencial teórico aborda os fundamentos teórico-conceituais relacionados à liderança servidora, e empoderamento psicológico, bem como, à liderança empreendedora e engajamento, e suas relações teóricas e empíricas com comportamento inovador no trabalho. Na terceira seção, são discutidos os procedimentos metodológicos. A quarta seção evidencia os resultados dos três modelos deste estudo, seguido, por fim, pelas discussões e considerações finais. 


\section{2 \\ Referencial teórico}

\section{1}

\section{Revisão sistemática da literatura}

Nesta subseção, é apresentada revisão sistemática da literatura sobre comportamento inovador no trabalho, criatividade, inovação, liderança e setor público. Esta breve revisão sistemática busca mapear o estado-da-arte na convergência entre esses temas, e avança em relação àquelas realizadas por Hughes et al. (2018) e Lee et al. (2020) na medida em que circunscreve a análise a estudos aplicados ao setor público, descortinando possíveis mediadores, moderadores, métodos, contextos organizacionais, e tipos de liderança mais investigados.

\subsection{1 \\ Método da revisão sistemática da literatura}

Com vistas a aprofundar o conhecimento acerca do campo de estudos sobre liderança, criatividade e inovação no setor público, foi empreendida revisão da literatura que pode ser considerada sistemática devido ao uso de critérios metodológicos estruturados, transparentes e replicáveis (Hiebl, 2021). A realização deste tipo de levantamento deve-se, em grande medida, ao foco deste trabalho, circunscrito a uma realidade relativamente particular, e foi realizada para permitir uma melhor compreensão sobre o conhecimento na interface entre os temas no setor público.

A revisão foi realizada por meio de levantamento elaborado em fevereiro de 2021, conforme critérios de elegibilidade metodológica presentes na Figura 1.

Foram alocados no campo título as palavras-chave "Innovative Work Behavior", "Innovative Behavior", "IWB”, "Creativity”, "Innovation", "Innovat" separados pelo operador booleano "ou". Em linha adicional, foram inseridas as palavras-chave "Leadership" ou "Leader" em tópico, de modo que as duas linhas estavam separadas pelo operador booleano "e". Por fim, a última string 
de pesquisa envolveu a utilização das palavras-chave "public" ou "government" no campo tópico.

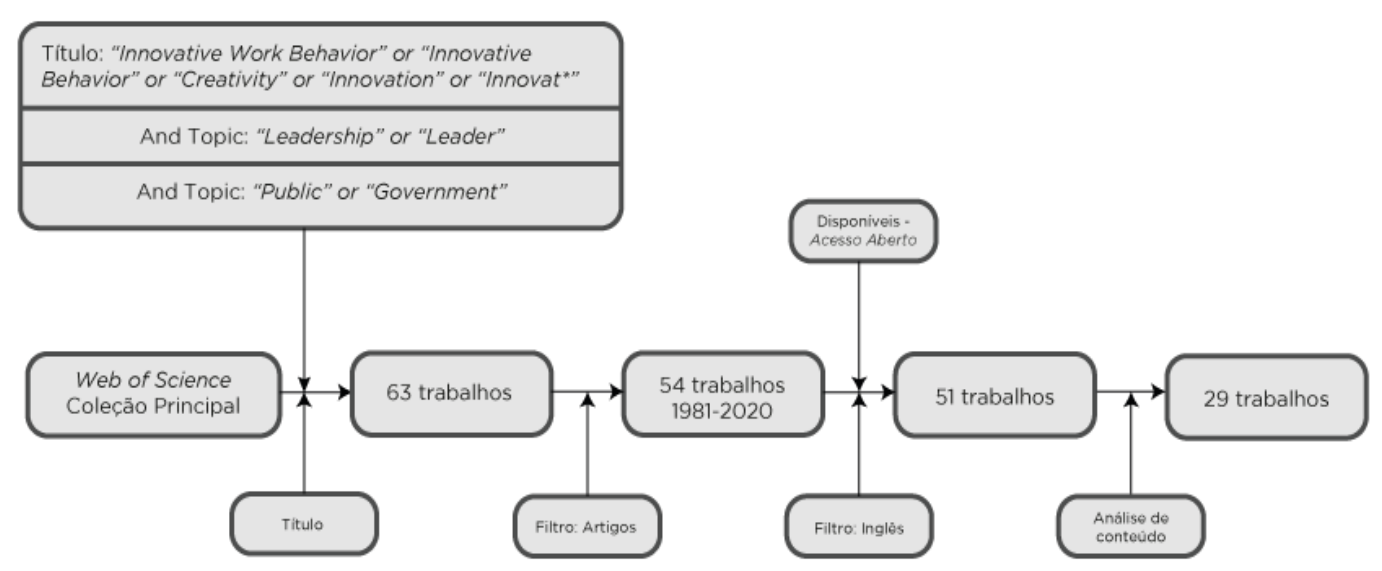

Figura 1 - Método da revisão sistemática da literatura Fonte: Elaborado pela autora.

A busca foi realizada na base de dados Web of Science, e após a exclusão de documentos conforme os critérios de elegibilidade, a amostra foi composta por 29 trabalhos que versavam de forma central sobre liderança, inovação ou criatividade, cuja aplicação tenha ocorrido no setor público.

\subsection{2}

\section{Abordagens nos estudos sobre liderança, criatividade e inovação no setor público}

O Quadro 1 contém os métodos abordados nos estudos sobre liderança e criatividade no setor público. Já estudos que abordaram comportamento inovador no âmbito do setor público seguem dispostos no Quadro 2.

Diante da análise do Quadro 1 fica evidente que, na amostra levantada, os tipos de liderança pesquisados em estudos sobre criatividade no setor público são: transformacional, LMX, empoderadora, autêntica, servidora, ética, carismática e supervisão abusiva. Em termos quantitativos, a liderança transformacional é a que mais concentra estudos transversais e autorrelatados, nos quais os participantes avaliam a si mesmos em relação à criatividade em um momento único no tempo.

A liderança ética é que mais concentra esforços na realização de estudos longitudinais, geralmente por um a três meses, com a utilização de questionários a serem preenchidos pelos líderes. 


\begin{tabular}{|l|c|c|c|}
\hline \multicolumn{1}{|c|}{$\begin{array}{c}\text { Tipos de } \\
\text { Liderança }\end{array}$} & Transversal & \multicolumn{2}{c|}{ Longitudinal } \\
\cline { 2 - 4 } Transformacional & Autoavaliação & Autoavaliação & Avaliação de Superiores \\
\hline Aw Harbi et al. (2019) & - & J. Kim \& Song (2020) \\
\hline EmX & Garg \& Dhar (2017) & - & $\begin{array}{c}\text { Venkataramani et al. } \\
\text { (2014) }\end{array}$ \\
\hline Autêntica & Gkorezis (2016) & - & - \\
\hline Servidora & $\begin{array}{c}\text { Semedo et al. (2016, } \\
\text { 2017) }\end{array}$ & Anwar et al. (2019) & - \\
\hline Ética & - & Wiliams et al. (2017) & - \\
\hline Supervisão abusiva & Ali Chughtai (2016) & - & $\begin{array}{c}\text { Asif et al. (2019, 2020) } \\
\text { Kalyar et al. (2019) }\end{array}$ \\
\hline Carismática & - & Malik et al. (2020) & Khan, Khan, et al. (2020) \\
\hline
\end{tabular}

Quadro 1 - Características metodológicas - criatividade Fonte: Elaborado pela autora.

A liderança servidora, investigada neste estudo, foi abordada de forma autorrelatada em estudo sobre criatividade, separado no tempo, por Williams et al. (2017). Percebeu-se que a maioria dos estudos usa da abordagem de autoavaliação pelos liderados acerca do tipo de liderança e criatividade.

Em relação ao comportamento inovador no trabalho, o Quadro 2 demonstra que dos 29 trabalhos levantados, 12 preocuparam-se com o fenômeno do comportamento inovador no contexto público.

\begin{tabular}{|l|c|c|c|}
\hline \multirow{2}{*}{$\begin{array}{c}\text { Tipos de } \\
\text { Liderança }\end{array}$} & Transversal & Longitudinal \\
\cline { 2 - 4 } & Autoavaliação & $\begin{array}{c}\text { Avaliação de } \\
\text { Superiores } \\
\text { Transformacional }\end{array}$ & $\begin{array}{c}\text { Avaliação de } \\
\text { Superiores }\end{array}$ \\
\hline \multirow{2}{*}{ LMX } & $\begin{array}{c}\text { Al-Shammari \& Khalifa (2019) } \\
\text { Günzel-Jensen et al. (2018) } \\
\text { Gottman et al. (2010) } \\
\text { Kim \& Yoon (2015) }\end{array}$ & $\begin{array}{c}\text { Masood \& Afsar } \\
\text { (2017) } \\
\text { Wipulanusat et al. } \\
(2020)\end{array}$ & $\begin{array}{c}\text { Afsar \& Masood } \\
(2018)\end{array}$ \\
\hline Autêntica & $\begin{array}{c}\text { Nazir et al. (2018) } \\
\text { Park \& Jo (2018) } \\
\text { (Peng, 2020) }\end{array}$ & - & - \\
\hline Empreendedora & Phuong \& Takahashi (2021) & - & Miao et al. (2018) \\
\hline
\end{tabular}

Quadro 2 - Características metodológicas - comportamento inovador Fonte: Elaborado pela autora.

A exemplo do que acontece com o construto criatividade, a liderança transformacional foi a mais estudada em relação ao comportamento inovador no trabalho, por meio de estudo autorrelatado e transversal. Em relação aos questionários ofertados em dois ou mais períodos distintos, com avaliação do supervisor acerca do liderado, a liderança empreendedora também se encontra 
representada, juntamente com a liderança transformacional. Por fim, evidencia-se relativa carência de pesquisas que abordem os tipos de liderança servidora e empreendedora, adotados neste estudo.

\subsection{3}

Moderadores e mediadores

A Figura 2 apresenta as variáveis estudadas em relação aos tipos de liderança, bem como a quantidade de variáveis mediadoras e moderadoras abordadas nos estudos sobre criatividade e comportamento inovador no trabalho no setor público. Os valores dispostos em parênteses representam o número de trabalhos/artigos nos quais as medidas foram utilizadas.

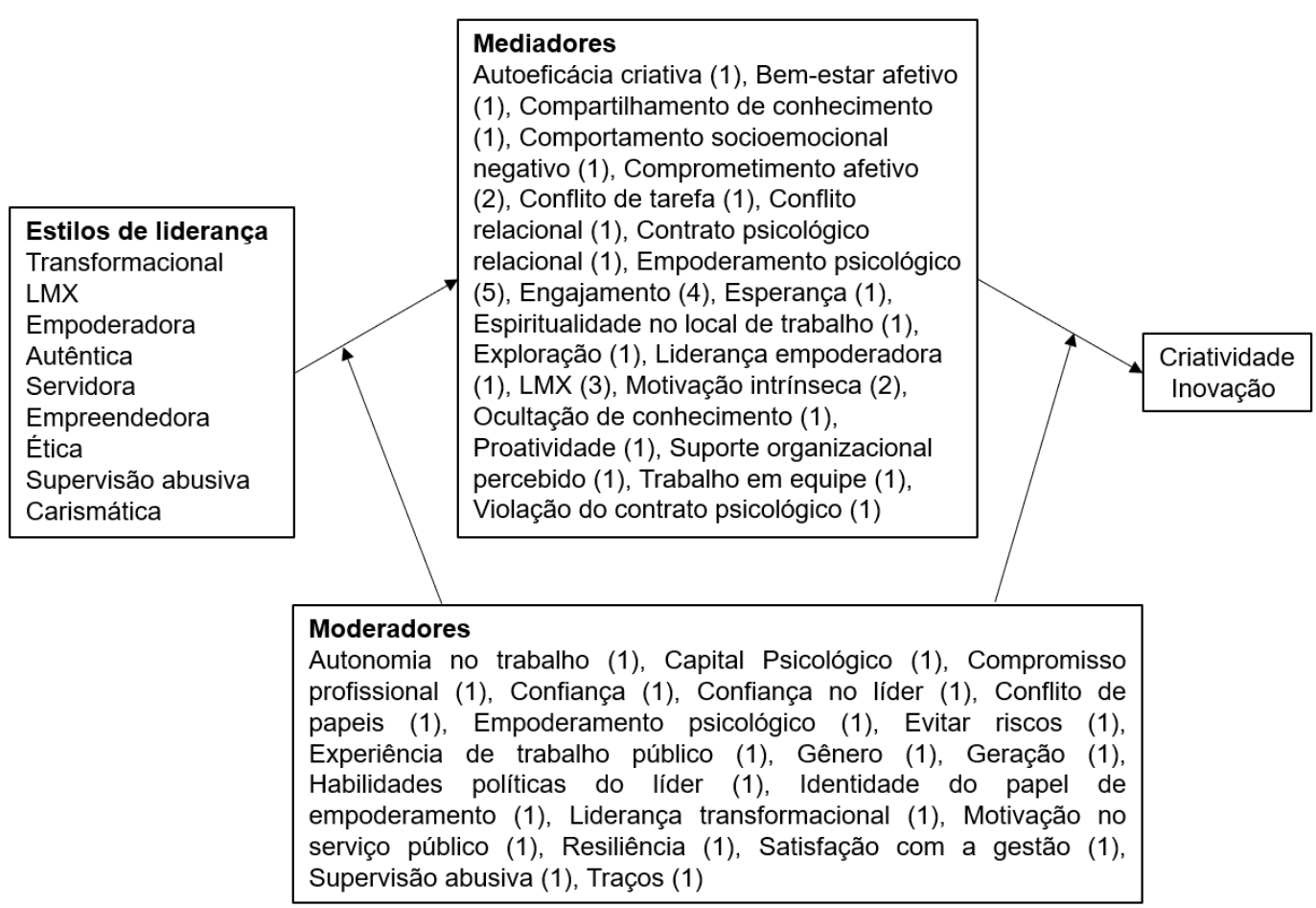

Figura 2 - Rol de variáveis mediadoras e moderadoras Fonte: Elaborado pela autora.

Diante da análise da Figura 2 observa-se que as variáveis comprometimento afetivo foi utilizada como mediadora em dois estudos, seguida por LMX (3 estudos), engajamento (4) e empoderamento psicológico (5). As demais variáveis foram utilizadas em apenas um estudo.

Inúmeros trabalhos empíricos têm identificado dimensões contextuais, individuais, relacionais e do líder, além de diversos tipos de liderança capazes de fomentar a inovação e a criatividade no local de trabalho. 
Em relação às variáveis moderadoras elencadas, destaque especial deve ser dado à variável empoderamento psicológico, que será testada no presente trabalho como variável mediadora, e que aparece em um estudo como variável moderadora, e em cinco estudos como variável mediadora. Além disso, em quatro estudos a variável engajamento, aqui também investigada, aparece como mediadora.

Na seção do referencial teórico destinada a explicitar os 'mecanismos de influência' do modelo (seções 2.3.3 e 2.4.3), serão descritas as lacunas teóricas que sustentam as escolhas de mediadores e moderadores feitas neste estudo.

Por fim, observou-se que os estudos foram aplicados em diversos contextos públicos. Dentre eles, destacam-se hospitais, que foram o lócus de oito pesquisas, seguidos por agências governamentais em geral (8), universidades (3), ministérios (2), setor estatal de tecnologia da informação (2) escolas públicas secundárias (1), bancos públicos (1), institutos de pesquisa e desenvolvimento (1), organização de engenheira pública (1), governo municipal (1) e biblioteca (1).

Conforme demonstrado nessa seção, evidencia-se que são relativamente escassos os estudos sobre criatividade, comportamento inovador, liderança servidora e empreendedora no setor público. Além disso, os contextos institucionais nos quais os estudos foram aplicados mostram a importância de diversificar os locais e realidades organizacionais, com vistas a entender melhor a ocorrência do fenômeno.

A seguir, é apresentado o referencial teórico do estudo.

\section{2}

\section{Comportamento inovador no trabalho}

O crescimento, sucesso e sobrevivência organizacional dependem largamente da capacidade de geração de ideias (criatividade) e da seleção das mais promissoras e sua implantação (inovação) (Lee et al., 2020). Considerando que a liderança molda o ambiente de trabalho (Van Dierendonck et al., 2014), tal ambiente pode ser propício para o fomento do comportamento inovador no trabalho (Bak, 2020; Kundu et al., 2019).

Criatividade e inovação são utilizadas erroneamente como expressões sinônimas, e embora relacionadas entre si, não são idênticas. Mesmo em periódicos de excelência, há confusão entre os dois termos, e amiúde, os autores 
desconsideram que a criatividade (geração de ideias) e a inovação (implementação de ideias) são medidas distintas, oriundas de processos diferentes, cujos resultados também diferem entre si (Hughes et al., 2018). Assim, criatividade relaciona-se à produção de ideias novas, enquanto inovação refere-se à produção e implementação de ideias, de modo que a geração de ideias é apenas uma fase do processo que pode (ou não) culminar na inovação (Hughes et al., 2018; Scott \& Bruce, 1994).

A inovação pode ter início com o reconhecimento do problema, para o qual são geradas ideias. Na próxima etapa, o indivíduo que inova deve procurar patrocínio para que sua ideia seja viabilizada, ou, em outras palavras, deve promover suas ideias. Por fim, a terceira fase envolve a implementação da ideia, ou seja, produtos, processos ou serviços inovadores devem ser adotados, institucionalizados ou difundidos, o que configura o processo de inovação em si (Scott \& Bruce, 1994).

Para evitar imprecisões conceituais comuns à área, neste trabalho utilizouse a definição de Hughes et al. (2018), segundo a qual a criatividade relaciona-se a processos cognitivos e comportamentais envolvidos na tentativa de geração de novas ideias, enquanto a inovação, por sua vez, refere-se aos processos presentes na tentativa de implementar novas ideias. Ainda segundo os autores, a inovação no trabalho caracteriza-se pela combinação de: identificação do problema ou da oportunidade, adoção ou alteração de ideias, promoção de tais ideias e implementação das ideias. Por fim, nem todas as ideias consideradas criativas se tornam inovação, e nem toda inovação exige criatividade, já que a inovação pode advir de outro lugar (Hughes et al., 2018).

O desenvolvimento da criatividade e inovação nas organizações inclui a orientação organizacional para a inovação, por meio especialmente do apoio da alta direção à criatividade e à inovação no âmbito organizacional; em segundo lugar, relaciona-se à disponibilização e viabilização de recursos para inovação, como tempo e treinamento; e por fim, a práticas de gestão, que envolvem a oferta de autonomia, desafios e gerenciamento com vistas à promoção do trabalho inovador (Amabile et al., 1996).

Desse modo, embora grande parte das inovações tenha início com ideias novas, não é verdade que a criatividade só exista como parte de um processo inovador, do mesmo modo que nem todas as ideias criativas passam pelo processo 
de implementação, e nem todos os processos de inovação demandam criatividade (Hughes et al., 2018).

Desafio adicional ao campo de pesquisa de criatividade e inovação no local de trabalho refere-se à escolha da métrica mais adequada para sua mensuração. Nesse sentido, o Quadro 3 evidencia as escalas mais utilizadas nos estudos sobre liderança, criatividade e inovação no trabalho (Hughes et al., 2018) e os motivos pelos quais cada escala não se enquadrou nos objetivos deste estudo.

\begin{tabular}{|c|c|}
\hline Autor e ano & $\begin{array}{l}\text { Limitações das Escalas de Criatividade ou Comportamento Inovador } \\
\text { no Local de Trabalho em relação ao escopo deste estudo }\end{array}$ \\
\hline $\begin{array}{l}\text { Scott \& Bruce } \\
(1994)\end{array}$ & Escala desenvolvida sem esforço empírico completo (Hughes et al., 2018). \\
\hline $\begin{array}{l}\text { Tierney et al. } \\
\text { (1999) }\end{array}$ & $\begin{array}{l}\text { Escala de criatividade. Focada em avaliar apenas processos criativos. Não } \\
\text { alcança a próxima etapa que é a implementação de ideias, ou seja, a } \\
\text { inovação. Além disso, traz implícita a ideia de que a criatividade é algo } \\
\text { extraordinário ou revolucionário no trabalho (Hughes et al., 2018). }\end{array}$ \\
\hline $\begin{array}{l}\text { Oldham \& } \\
\text { Cummings (1996) }\end{array}$ & $\begin{array}{l}\text { Medida unidimensional de três itens que mensura apenas criatividade. } \\
\text { Devido à brevidade da escala, deve ser usada apenas em estudos com } \\
\text { limitação espacial crítica de itens (Hughes et al., 2018). }\end{array}$ \\
\hline $\begin{array}{l}\text { Zhou \& George } \\
(2001)\end{array}$ & $\begin{array}{l}\text { Escala desenvolvida para mensurar apenas criatividade. Medida } \\
\text { unidimensional, porém, a análise minuciosa dos itens revela que são } \\
\text { medidos também comportamentos de inovação relacionados à } \\
\text { implementação de ideias, embora isso não seja relatado pelos autores. }\end{array}$ \\
\hline $\begin{array}{l}\text { De Jong \& Den } \\
\text { Hartog (2010) }\end{array}$ & $\begin{array}{l}\text { Métrica multidimensional, formada por quatro dimensões: exploração, } \\
\text { geração, defesa e implementação de ideias. Esta escala não apresenta } \\
\text { problemas graves, conforme apontam Hughes et al. (2018). Mas, neste } \\
\text { estudo não se optou por ela devido ao fato de ser originalmente criada para } \\
\text { ser respondida pelo líder. }\end{array}$ \\
\hline
\end{tabular}

Quadro 3 - Limitações das escalas de criatividade e inovação Fonte: Elaborado pela autora.

Como buscamos uma medida autoavaliada, e diante das limitações expressas, o construto comportamento inovador no trabalho foi medido neste estudo por meio da escala de Janssen (2000). A escolha pela referida escala deu-se porque tal instrumento de medida possui número razoável de itens (9), divididos em dimensões que embora individualizadas, foram concebidas para se combinarem de forma aditiva na criação de uma escala geral de comportamento inovador no trabalho (Hughes et al., 2018).

Reconhecidas as limitações presentes em todas as escalas, entende-se que a escala de Janssen (2000) atenderá adequadamente aos objetivos do estudo. Embora esta escala contenha geração, implementação e promoção de ideias em um mesmo 
instrumento, este estudo pretende verificar, por meio de análise fatorial exploratória e confirmatória, se a escala contém dois fatores distintos (criatividade e inovação). Isso porque, conforme ensinam (Hughes et al., 2018), é preciso ter cautela ao usar instrumentos sem considerar o que realmente estão a medir, ou seja, criatividade versus inovação.

\section{3}

\section{Liderança servidora}

A expressão liderança servidora foi cunhada por Greenleaf (1970), e a partir desse momento foi amplamente aplicada ao contexto organizacional em mais duas obras seminais do autor (Greenleaf, 1972a, 1972b). Greenleaf (1977) conceituou o líder servidor como aquele que possui o sentimento genuíno e orgânico de servir em primeiro lugar, de modo que, como consequência, os liderados evoluem como pessoas, se tornam mais sábios, autônomos e por conseguinte tendem a se tornar servidores, cujo impacto ocorre não só na organização, mas também na comunidade.

O ponto nodal desta definição é a ideia de que o líder servidor atua naturalmente, superando seus próprios interesses, em prol do atendimento das necessidades dos outros e do crescimento dos liderados, que por sua vez, se tornam o melhor que podem ser (Mittal \& Dorfman, 2012; van Dierendonck, 2011). Em outras palavras, o objetivo do líder servidor é atender às necessidades do outro, sendo essa a motivação mais importante deste tipo de liderança (Russell \& Stone, 2002), que culmina, por sua vez, no desenvolvimento, aprendizado e autodeterminação (J. Zhu et al., 2019) pautados na credibilidade e confiança que os liderados possuem em relação aos seus líderes (Gregory Stone et al., 2004; Sendjaya, Eva, Butar Butar, et al., 2019).

A conceituação de liderança servidora está ligada a atributos positivos como autenticidade, moralidade e espiritualidade, e desse modo, não envolve uma escolha considerada conveniente ou vantajosa, mas sim, refere-se à manifestação voluntária e natural da necessidade de servir, mesmo na ausência de benefícios pessoais (Avolio et al., 2009; Senjaya \& Pekerti, 2010). O trabalho do líder servidor é realizado de 'coração' com vistas ao bem comum, de modo que o foco primordial 
do relacionamento está no desenvolvimento holístico e na autonomia dos seguidores (Gregory Stone et al., 2004; Senjaya \& Pekerti, 2010).

De forma a avançar à conceituação teórica de Greenleaf (1977), o trabalho de Eva et al. (2019) procurou estabelecer uma definição de liderança servidora capaz de fornecer aos pesquisadores uma aplicação empiricamente densa e fundamentada. Para os autores, liderança servidora é uma abordagem com foco primordial no outro, cuja manifestação envolve a priorização de necessidades individuais dos liderados, marcada pelo redirecionamento da preocupação consigo mesmo para a preocupação com os outros e com a comunidade.

Da definição de Eva et al. (2019) emergem três considerações fundamentais, relacionadas ao motivo, modo e mentalidade dos líderes servidores. Para os autores, o motivo do líder servidor não advém de dentro, mas de fora do líder, já que o próprio Greenleaf (1977) descreve o ‘Servo como líder', e não o contrário. Assim, a liderança servidora se diferencia de outros tipos de liderança à medida que o comportamento do líder não se pauta em ambição, mas na necessidade altruísta de servir e ajudar aos outros, afastando-se de seus próprios interesses pessoais (Eva et al., 2019; van Dierendonck \& Patterson, 2015).

Em relação ao modo de agir do líder servidor, Eva et al. (2019) salientam que a priorização de necessidades individuais dos liderados em detrimento das próprias necessidades emerge da consciência que o líder possui a respeito dos anseios, características e limitações de cada um. Diante disso, fica evidente que o relacionamento entre líder e cada liderado pode forjar-se de distintas maneiras entre eles, de maneira que ao contrário de outros tipos de liderança, o modo de agir do líder servidor não tem mero enfoque nos resultados organizacionais, mas no bemestar e no desenvolvimento dos liderados e da comunidade (Chiniara \& Bentein, 2016; van Dierendonck \& Patterson, 2010).

Por fim, em relação à mentalidade dos líderes servidores, Eva et al. (2019) salientam que a preocupação com os liderados e com a comunidade é característica marcante. Dessa maneira, os líderes servidores sentem-se responsáveis pelos seus liderados, a quem devem servir e por quem devem zelar em prol de uma agenda organizacional e social positiva.

Assim, os líderes servidores distinguem-se dos demais devido à motivação fundamental de servir por toda a vida (Parris \& Peachey, 2013). Dessa maneira, a teoria da liderança servidora enfatiza a ideia de que as organizações devem ter como 
escopo fomentar a edificação de pessoas melhores que possam fomentar um desempenho organizacional e social sustentável (Parris \& Peachey, 2013; Saleem et al., 2020).

Todavia, cumpre salientar a existente dificuldade de distinção clara entre liderança servidora e outros tipos de liderança pautadas em valores, em especial a transformacional, ética e autêntica (Eva et al., 2019). Deste modo, a liderança servidora pode ser caracterizada pelo enfoque particular e primordial no atendimento de demandas psicológicas dos liderados, enquanto a liderança transformacional visa primeiramente o alcance dos objetivos organizacionais, de modo que as necessidades psicológicas dos seguidores são observadas de maneira não prioritária (Van Dierendonck et al., 2014). Para os líderes servidores o desenvolvimento multidimensional dos seguidores é fundamental, e é provável que esses líderes definam como prioridade, respectivamente: necessidades e aspirações dos liderados, metas organizacionais e por fim, seus próprios interesses (Sendjaya, 2015; Sendjaya, Eva, Butar Butar, et al., 2019; van Dierendonck, 2011).

Já em relação à liderança ética, o líder servidor é mais flexível, orientador e menos prescritivo em relação a normas éticas (Eisenbeiss, 2012; Eva et al., 2019; Hoch et al., 2018). Por fim, em relação à liderança autêntica, a liderança servidora pauta-se mais na autoconsciência como produto de uma perspectiva espiritual ou altruísta (Hoch et al., 2018; Ling et al., 2017).

A liderança servidora foi descrita inicialmente como um modo de vida, configurando-se como mais do que uma forma de gestão, cujo cerne envolve servir antes de tudo, por meio de compartilhamento da tomada de decisão, trabalho em equipe e fomento ao senso de comunidade (Chiniara \& Bentein, 2018; Greenleaf, 1977). Além disso, outra premissa inequívoca da liderança servidora é a de que os líderes servidores colocam os interesses dos liderados em primeiro lugar (Sendjaya, Eva, Butar Butar, et al., 2019) o que pode levar ao aumento da satisfação das necessidades dos liderados (Chiniara \& Bentein, 2016), incrementando o empoderamento psicológico (Kaur, 2018; Sousa \& van Dierendonck, 2017).

As características mais marcantes da liderança servidora envolvem a habilidade de escutar, ter empatia, realizar a cura, persuasão, consciência, conceituação, previsão, cuidado, comprometimento com o crescimento pessoal e senso de comunidade (Avolio et al., 2009; Nullens, 2019; Russell \& Stone, 2002; Sendjaya, Eva, Butar Butar, et al., 2019; Spears, 2004). Esse rol não é taxativo, já 
que a liderança servidora é um construto multidimensional (Liden et al., 2015), cabendo, dentre outros atributos, a visão, honestidade, confiança, integridade, serviço, pioneirismo, humildade, valorização e empoderamento (Bavik, 2020; Russell \& Stone, 2002; Sun, 2013; van Dierendonck \& Nuijten, 2011).

Os autores Liden et al. (2015) condensam e destacam as sete principais dimensões da liderança servidora, quais sejam, cura emocional, criação de valor para a comunidade, habilidades conceituais, empoderamento, auxílio ao desenvolvimento, colocar os interesses dos liderados em primeiro lugar, e por fim, comportar-se eticamente. A Figura 3 condensa as sete dimensões da liderança servidora.

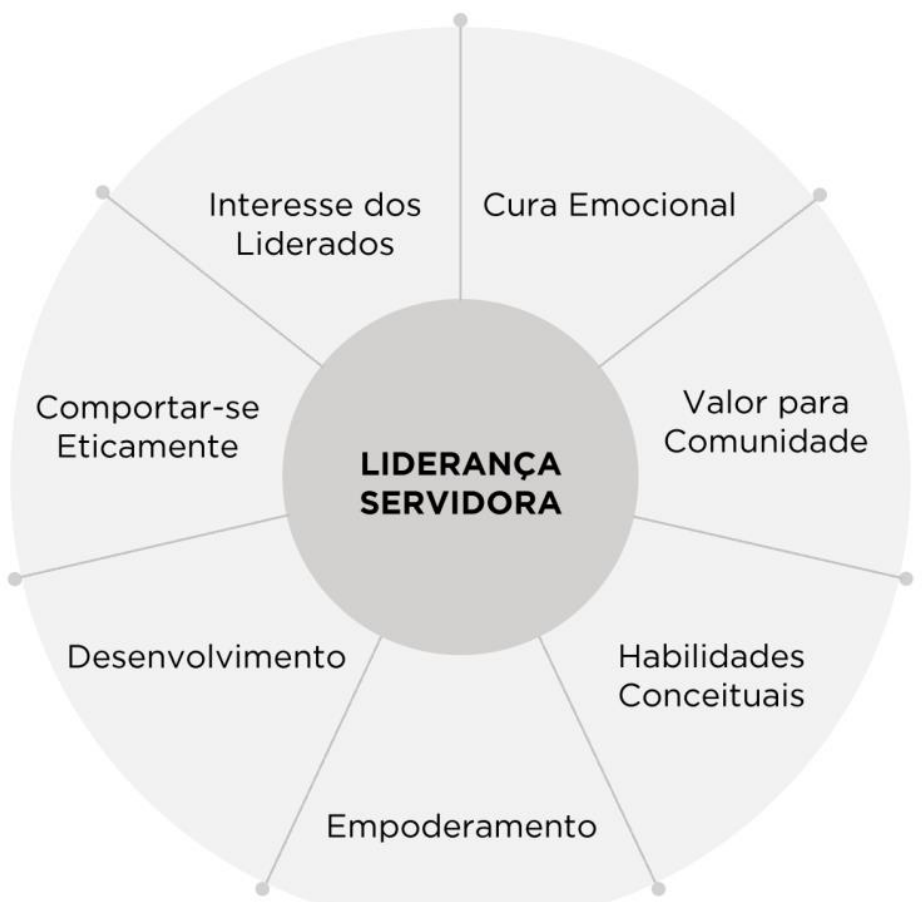

Figura 3 - Dimensões da liderança servidora

Fonte: Elaborado pela autora.

Em relação à cura emocional, o líder servidor tem o papel intrínseco de curar a si, ao mesmo tempo em que cura emocionalmente aos que o rodeiam, ajudando os liderados a estarem emocionalmente saudáveis, e criando senso de coesão, o que é essencial para evitar depressão e exaustão emocional (Paesen et al., 2019; S. Qiu \& Dooley, 2019; van Dierendonck, 2011). A cura emocional envolve a preocupação com o bem-estar e com a solução de problemas pessoais dos 
liderados (Liden et al., 2015), contexto no qual é demandado alto nível de escuta. A escuta favorece a identificação das necessidades do grupo por meio da abertura e reflexão ao que está sendo dito (Spears, 2004; Washington et al., 2006). A partir disso emerge a questão da empatia, de modo que o líder servidor tem como qualidade primordial a aceitação e o reconhecimento estável das diferenças individuais, cujo pressuposto basilar remete à suposição de boas intenções em prol do bem-estar individual e coletivo (Chiniara \& Bentein, 2018; Spears, 2004; Watkins et al., 2019).

Já a criação de valor para a comunidade, outro atributo fundamental dos líderes servidores, é caracterizada pelas ações do líder voltadas à melhoria da sociedade e da comunidade circundante, notadamente por meio de atividades voluntárias capazes de beneficiar a comunidade local, o que é essencial para a construção de significado do trabalho percebido pelo funcionário (Giolito et al., 2020; Liden et al., 2015; Liden, Wayne, et al., 2014).

As habilidades conceituais do líder servidor, por sua vez, referem-se às competências do líder na dissolução de problemas de trabalho, por meio do conhecimento da rotina e das tarefas, auxiliando os liderados, especialmente os imediatos, no desdobramento de ações com vistas ao alcance dos objetivos organizacionais (Liden et al., 2008, 2015; Paesen et al., 2019).

A liderança servidora tem como quarta dimensão fundamental o empoderamento dos liderados. Empoderar significa confiar na autonomia dos liderados para tomada de decisão, atribuindo-lhes responsabilidade, encorajandoos na resolução de problemas em prol da conclusão das tarefas de trabalho, com independência (Franco \& Antunes, 2020; Liden et al., 2008; Sendjaya et al., 2008).

Já o auxílio ao desenvolvimento de liderados para crescer e ter sucesso é marcado pela preocupação genuína dos líderes servidores no que tange ao crescimento, desenvolvimento e atingimento do pleno potencial da carreira dos seguidores, a partir do suporte constante e orientação da liderança (Y. Li et al., 2019; Liden et al., 2008, 2015; van Dierendonck, 2011).

A sexta dimensão elencada por Liden et al. (2015) é colocar os interesses dos liderados em primeiro lugar. De acordo com essa dimensão, a liderança servidora é fortemente marcada pela priorização dos interesses dos subordinados por meio de ações e discursos que evidenciem aos liderados que suas necessidades de trabalho são uma prioridade (Franco \& Antunes, 2020; Liden et al., 2008; Paesen 
et al., 2019). Em termos práticos, líderes que possuem esse atributo são capazes de interromper seu fluxo de trabalho para auxiliar liderados no exercício de suas funções (Liden et al., 2008).

Por fim, a sétima dimensão comum à liderança servidora refere-se ao comportamento ético. Nesse sentido, as ações são guiadas pelo relacionamento aberto e honesto com seguidores, cujo comportamento é centrado no funcionário (Latif \& Marimon, 2019; Liden et al., 2008; van Dierendonck \& Nuijten, 2011). Nesse sentido, o líder servidor com comportamento ético é confiável e serve como um padrão de integridade pessoal e profissional (Liden et al., 2015).

A escala original de 28 itens de liderança servidora desenvolvida por Liden et al. (2008) pode ser usada como construto de ordem superior (Hu \& Liden, 2011), ou em outras palavras, liderança servidora é uma medida global que representa todas as suas dimensões. Isso porque, conforme Figura 4, os resultados da análise fatorial confirmatória, além de outros indicadores, demonstraram cargas fatoriais que deram suporte ao modelo de segunda ordem da escala completa (Hu \& Liden, 2011). Dada a complexidade do modelo, optamos pela versão reduzida desta escala, com sete itens (SL-7), conforme exposto na metodologia.

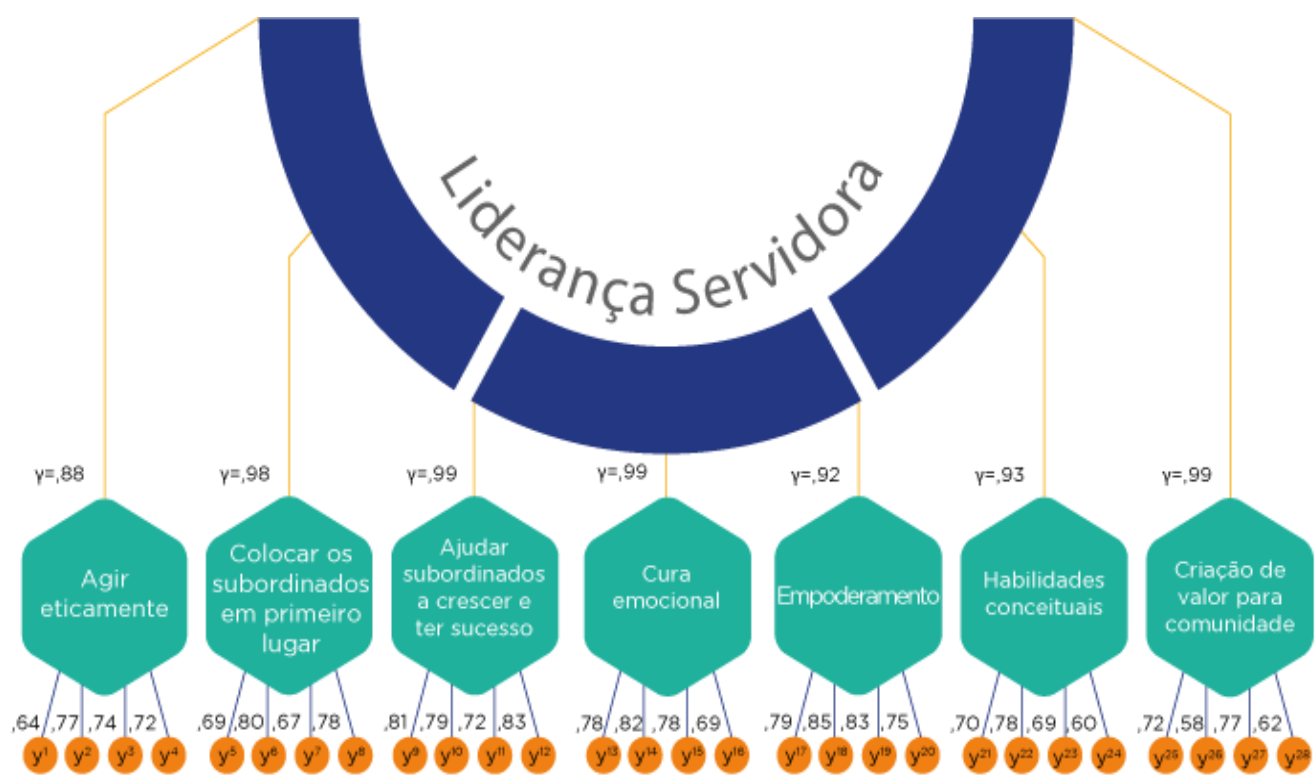

Figura 4 - Análise fatorial confirmatória de segunda ordem Fonte: Adaptado de: Hu \& Liden (2011).

Embora os fatores de primeira ordem (dimensões) sejam distintos, todos estão ajustados dentro do construto de ordem superior, qual seja, da liderança 
servidora. Isso permite que a liderança servidora seja considerada como uma única variável latente (Hu \& Liden, 2011).

A concepção de liderança servidora adotada por este estudo como uma medida global é condizente com a literatura segundo a qual as sete dimensões (quer seja na escala completa/SL-28, ou reduzida/SL-7) carregam um fator que captura integralmente a liderança servidora (Hu \& Liden, 2011; Liden et al., 2008, 2015). Isso traz implicações para esta pesquisa, conforme será demonstrado na seção destinada à metodologia.

Ato contínuo, conforme aponta van Dierendonck (2011) mudanças nos padrões éticos da sociedade demandam líderes centrados nas pessoas, bem como a exigência de inovação individual (Iqbal, Latif, et al., 2020; Liden, Panaccio, et al., 2014) e excelência organizacional (Hernández-Perlines \& Araya-Castillo, 2020; Sendjaya, 2015).

Da mesma forma, a liderança servidora atua no fomento do bem-estar (van Dierendonck \& Nuijten, 2011), bem como da satisfação, engajamento e desempenho (Kaya \& Karatepe, 2020; Sousa \& van Dierendonck, 2017; Sousa \& Van Dierendonck, 2014), o que tornou a liderança servidora uma possibilidade fértil de atendimento de demandas organizacionais de forma positiva. A liderança servidora é, portanto, um contraponto aos líderes egoístas que visam apenas benefícios próprios, ou ainda, apenas o atingimento dos objetivos organizacionais em detrimento do ser humano (Gillet et al., 2011; Peterson et al., 2012).

A liderança servidora é um tipo de liderança capaz de lidar com as incertezas e desafios das organizações modernas ao passo que engendra sentido de pertencimento nos liderados, com positivos impactos no desempenho e crescimento organizacional (Eva et al., 2019; Hernández-Perlines \& Araya-Castillo, 2020; Sendjaya, Eva, Robin, et al., 2019).

Assim, a liderança servidora é uma abordagem integral que abarca os liderados de diversas formas, quais sejam, relacional, emocional, ética e espiritual, cujo intuito é, primeiramente, desenvolver os liderados, e, em segundo lugar, fomentar o bem-estar por meio do altruísmo e da ética, o que, por conseguinte, favorece o engajamento e a eficácia (Eva et al., 2019; Greenleaf, 1977; Sousa \& van Dierendonck, 2017), bem como, a criatividade e o comportamento inovador (Yang et al., 2019). Nesse sentido, atitudes e comportamentos de líderes considerados servidores são capazes de despertar respeito e lealdade, de tal modo 
que a percepção positiva sobre este tipo de líder é a base para relacionamentos de qualidade que podem levar a entregas criativas e inovadoras (Yoshida et al., 2014).

\subsection{1 \\ Teoria da autodeterminação nas relações entre liderança servidora e comportamento inovador no trabalho}

No caminho teórico-empírico do dever cívico, este estudo pauta-se na teoria da autodeterminação, do inglês self-determination theory (Deci \& Ryan, 2008; Gagné \& Deci, 2005; Ryan \& Deci, 2000). Para esta teoria, a motivação humana depende da satisfação de três necessidades psicológicas básicas: de competência, de relacionamento e de autonomia, de modo que a presença desses processos parece facilitar o funcionamento das propensões inatas do ser humano para o crescimento (Ryan \& Deci, 2000).

É evidente que as pessoas podem motivar-se por diferentes razões, como razões extrínsecas (coerção, medo, suborno) e intrínsecas (interesse, compromisso com a excelência) (Ryan \& Deci, 2000). No campo da motivação intrínseca, concebida como a tendência em buscar novidades e procurar por desafios, explorar o novo e aprender, embora haja uma propensão interna, há a necessidade de condições externas de apoio à autonomia (Deci \& Ryan, 2008; Ryan \& Deci, 2000; Vallerand et al., 2008).

Dessa maneira, segundo a teoria da autodeterminação e sua subteoria da avaliação cognitiva, a motivação intrínseca tem expressão viabilizada não apenas pela presença de competência/eficácia, mas também pela presença de fatores sociais e ambientais que facilitam a sua expressão, ou como mencionam Ryan \& Deci (2000, p. 69), a motivação florescerá se as circunstâncias permitirem. Diante disso, o estudo das condições que facilitam a motivação intrínseca é essencial para o entendimento do que favorece o desenvolvimento de aspectos positivos da natureza humana (Ryan \& Deci, 2000; Vallerand et al., 2008).

A Figura 5 mostra o continuum de autodeterminação. No painel esquerdo, está a amotivação, ou seja, a ausência de autodeterminação ou a falta de intenção de agir; no painel central, há diversos graus de autodeterminação dentro da motivação extrínseca; por fim, no painel direito, há a motivação intrínseca, que é totalmente autodeterminada. 


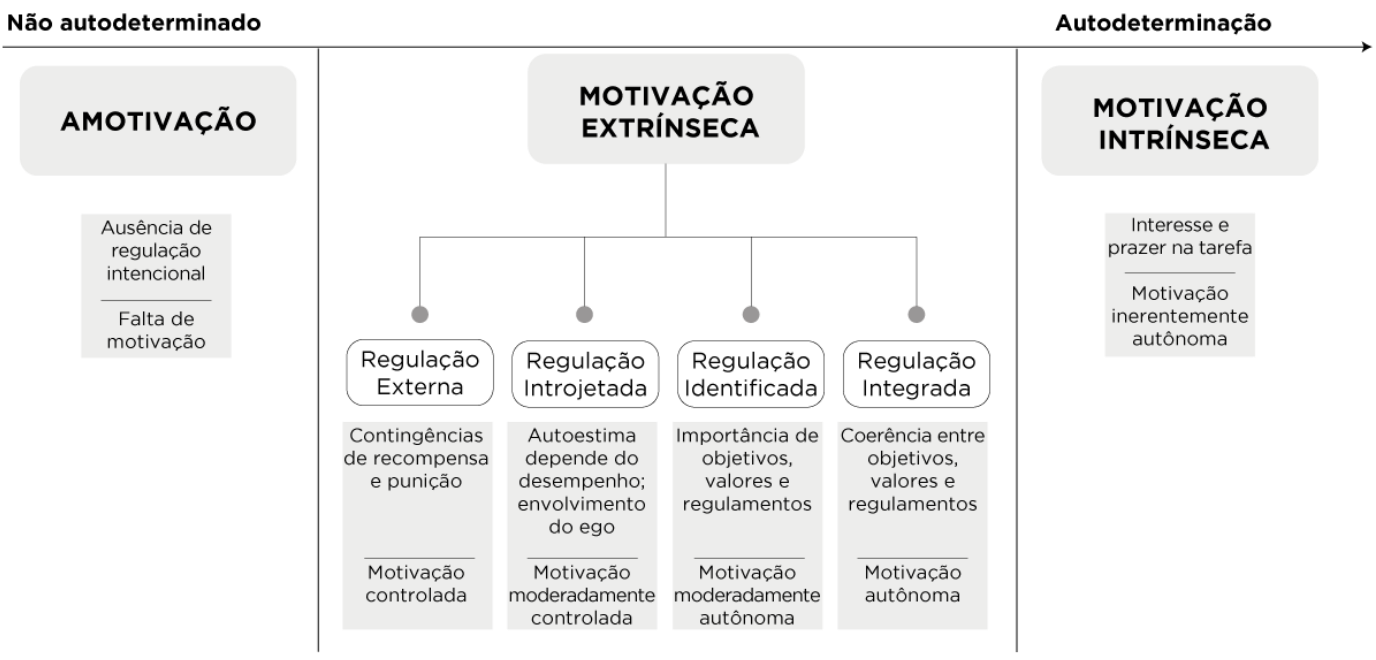

Figura 5 - Continuum de autodeterminação

Fonte: Adaptado de Gagné \& Deci (2005) e Ryan \& Deci (2000).

A amotivação ocorre quando não há a valorização de uma atividade, quando a pessoa não se sente competente para realizá-la, ou ainda, quando não se espera que ela produza o resultado desejado (Ryan \& Deci, 2000). Já a motivação intrínseca refere-se à realização de uma atividade com vistas a satisfações inerentes, de forma autônoma e completamente autodeterminada (Gagné \& Deci, 2005).

Por fim, a motivação extrínseca varia em níveis de acordo com o qual sua regulação é autônoma (Ryan \& Deci, 2000). A regulação externa abrange comportamentos realizados apenas para satisfazer uma demanda externa; já a regulação introjetada relaciona-se à aceitação parcial de um regulamento; a regulação identificada, por sua vez, envolve a aceitação de uma meta externa, que passa a ser considerada importante; por fim, a regulação integrada acontece quando normas externas são totalmente assimiladas, integrando-se aos valores pessoais existentes (Deci \& Ryan, 2008; Ryan \& Deci, 2000).

No presente estudo, a teoria da autodeterminação (Deci \& Ryan, 2008; Gagné \& Deci, 2005; Ryan \& Deci, 2000; Vallerand et al., 2008) é aplicada para explicar como a liderança servidora pode atuar como um fator de apoio para um indivíduo que possui empoderamento psicológico, o que pode levar, por sua vez, a maiores níveis de comportamento inovador no trabalho. Ademais, como uma das dimensões do empoderamento psicológico é a autodeterminação (Spreitzer, 1995), considerou-se que a teoria da autodeterminação pode contribuir para o entendimento do fenômeno. 


\subsection{2}

\section{Liderança servidora e comportamento inovador no trabalho}

O comportamento inovador no trabalho envolve criatividade (geração de ideias) e inovação (promoção e implementação de ideias), e é um tipo de comportamento que exige que os funcionários extrapolem a rotina de trabalho (Khan et al., 2021), quer seja para criar, quanto para implementar ideias originais (Scott \& Bruce, 1994).

O processo de implementação de inovações pode envolver resistência, custos, fracassos e inúmeras tentativas, o que amplia a importância da liderança no estímulo de funcionários em prol da busca pelo comportamento inovador no trabalho (Khan et al., 2021). Desse modo, em concordância com os autores, entende-se que a liderança servidora tem o papel de facilitação na criação e implementação de ideias inovadoras como catalisador e ampliador de emoções positivas, motivações intrínsecas e capacidades cognitivas dos funcionários.

A liderança servidora pode atuar no fomento do comportamento inovador por meio de práticas centradas no funcionário que levam ao seu crescimento e desenvolvimento (Liden et al., 2015). Esse tipo de liderança, por sua vez, aumenta as emoções positivas dos funcionários, que geram maior possibilidade de surgimento de ideias criativas e práticas inovadoras (Yoshida et al., 2014).

Embora a liderança servidora tenha foco no desenvolvimento individual, o seu cerne é o pensamento coletivo dos funcionários, ou, em outras palavras, visa o bem da comunidade (Liden et al., 2008). Diante disso, os funcionários com ideias inovadoras podem melhorar a coletividade social por meio da inovação.

Em relação a estudos empíricos sobre liderança servidora e criatividade e inovação, inúmeros trabalhos encontraram associação positiva em diversos contextos. A associação positiva entre liderança servidora e comportamento inovador de 258 trabalhadores do conhecimento em software foi evidenciada no estudo de Khan et al. (2020), que encontraram ainda, o papel mediador da confiança nessa relação.

Do mesmo modo, Iqbal et al. (2020) conduziram estudo com 347 funcionários de empresas de tecnologia e descobriram que a liderança servidora relaciona-se direta e positivamente com o comportamento inovador dos liderados, 
descortinando os papeis mediadores da segurança psicológica e da prosperidade em tal relacionamento.

Por conseguinte, Zhu \& Zhang (2020), aplicaram três estudos longitudinais com 294 trabalhadores de empresa de tecnologia na China e seus líderes, onde estes últimos avaliaram o comportamento inovador dos liderados. Constatou-se que a liderança servidora melhora o comportamento inovador do funcionário por meio do papel mediador do compartilhamento de conhecimento, com efeitos moderadores da identificação organizacional e da orientação para o objetivo de aprendizagem (Zhu \& Zhang, 2020).

Su et al. (2020), por meio de um estudo longitudinal com 381 funcionários, constataram que a liderança servidora influencia o comportamento inovador dos liderados em um processo mediado pela motivação intrínseca.

Em estudo multinível, os autores Wang et al. (2019), em pesquisa com 199 díades de líderes e liderados em 55 equipes de trabalho, evidenciaram que a liderança servidora afeta o comportamento inovador por meio do sucesso no trabalho. Outro estudo multinível foi aplicado por Yoshida et al. (2014) com 154 equipes, demonstrando que a liderança servidora está positivamente associada à inovação do time e à criatividade do liderado.

Em suma, uma variedade de estudos empíricos evidenciou a existência de associações positivas entre liderança servidora e comportamento inovador no trabalho (Baykal et al., 2018; Cai et al., 2018; Jaiswal \& Dhar, 2017; Karatepe et al., 2020; Krog \& Govender, 2015; Opoku et al., 2019; Panaccio et al., 2015).

A partir desse raciocínio, hipotetiza-se que:

\section{H1 - A liderança servidora está positivamente associada ao comportamento inovador no trabalho.}

Na seção a seguir, são discutidos os mecanismos de influência acerca da relação entre liderança servidora, empoderamento psicológico e comportamento inovador no trabalho. 


\subsection{3 \\ Mecanismos de influência}

Nesta seção, são abordados os mecanismos que influenciam o comportamento inovador no trabalho, partindo das possíveis relações indiretas entre liderança servidora, empoderamento psicológico e comportamento inovador.

\subsection{4 Liderança servidora, empoderamento psicológico e comportamento inovador no trabalho}

A liderança servidora prioriza não apenas a melhoria organizacional, mas também das pessoas e da sociedade como um todo (Christensen et al., 2014). Esse tipo de liderança tem a capacidade de incrementar as motivações dos funcionários, como empoderamento psicológico, abrindo caminho para o comportamento inovador (Yoshida et al., 2014).

Para Spreitzer (1995), o empoderamento psicológico é um construto motivacional intrínseco ativamente orientado para papeis de trabalho, ou seja, o indivíduo se sente responsável, capaz e autodeterminado a moldar sua realidade. Essa sensação de estar no controle do trabalho traz inúmeros efeitos positivos, como melhoria do desempenho (Tripathi et al., 2020), cidadania organizacional (Newman et al., 2017), criatividade (X. Zhang \& Bartol, 2010) e comportamento inovador (Khan et al., 2021).

Cumpre salientar que o empoderamento psicológico não é um traço de personalidade presente em todas as situações, mas, engloba cognições construídas no ambiente de trabalho (Spreitzer, 1995). Além disso, os indivíduos devem ser vistos em graus de empoderamento: as pessoas são menos ou mais capacitadas, em vez de não capacitadas. Por fim, a última premissa do empoderamento psicológico envolve tratar-se de uma medida específica do ambiente de trabalho (Spreitzer, 1995).

Spreitzer (1995) evidencia que o empoderamento psicológico pode ser caracterizado como o aumento da motivação intrínseca manifestada por meio de quatro dimensões: significado, competência (autoeficácia), autodeterminação e impacto. 
A autora define significado como a valorização de uma meta ou tarefa de trabalho, e seu alinhamento com os ideias, crenças, valores e comportamentos (Spreitzer, 1995, 1996). Já a competência ou autoeficácia nada mais é do que a crença pessoal na capacidade de realizar atividades com as habilidades necessárias, ou ainda, a crença de agência ou domínio (Bandura, 1977). A autodeterminação, por sua vez, é a percepção de liberdade de escolha ao iniciar, empreender e regular ações em processos de trabalho (Deci \& Ryan, 2008). Por fim, o impacto é o quanto um funcionário pode influenciar resultados estratégicos, táticos ou operacionais no ambiente de trabalho (Spreitzer, 1995).

Os líderes servidores estão abertos a fornecer autonomia aos funcionários (Liden et al., 2015), aumentando, desse modo, a sua autodeterminação (Ryan \& Deci, 2000). Ainda nessa esteira, esse tipo de liderança amplia a percepção sobre as tarefas e compartilha informações sobre o trabalho (habilidades conceituais) (Liden et al., 2015), melhorando a percepção e significado sobre o trabalho. Em terceiro lugar, o líder servidor coloca os interesses dos liderados em primeiro lugar, ao passo em que prioriza o desenvolvimento da carreira dos funcionários (Liden et al., 2008), o que favorece a dimensão competência do empoderamento psicológico. Por fim, esse tipo de líder, por meio do empoderamento (Liden et al., 2015), amplia o impacto que os funcionários têm na organização.

Em suma, a liderança servidora parece ter o potencial de influenciar positivamente o empoderamento psicológico, bem como o comportamento dos funcionários (Tripathi et al., 2020). Além disso, diversos estudos identificaram que a liderança servidora esteve positivamente associada ao empoderamento psicológico (Khan et al., 2021; Tripathi et al., 2020; Yang et al., 2019), inclusive no setor público (Allen et al., 2018). No contexto das evidências teóricas e empíricas discutidas, hipotetiza-se que:

H2 - A liderança servidora está positivamente associada ao empoderamento psicológico.

Outra premissa de nosso estudo é a de que funcionários competentes, autodeterminados, que veem significado no trabalho e geram impacto na organização, ou, em outras palavras, funcionários que possuem empoderamento psicológico, tendem a direcionar esforços para criar e implementar ideias 
inovadoras no trabalho, mesmo que esse processo seja demorado e custoso. A literatura de empoderamento e de inovação no trabalho descortinam um papel motivacional intrínseco importante do empoderamento psicológico na consecução da inovação no trabalho (Spreitzer, 1995).

Funcionários com altos níveis de empoderamento psicológico acreditam que estão capacitados a realizar tarefas com sucesso em diversos contextos de trabalho, o que é essencial para criar e implementarem ideias inovadoras (Odoardi et al., 2015). Além disso, um trabalho percebido como significativo torna as pessoas mais propensas ao esforço contínuo e dedicação, e um trabalho com impacto e autonomia, por sua vez, permite que inovações sejam implementadas proativamente (Khan et al., 2021; Odoardi et al., 2015).

Além do mais, estudos empíricos relatam que o empoderamento psicológico está positivamente associado ao comportamento inovador no trabalho (Waheed et al., 2018) ou criatividade (Yang et al., 2019). Em outras palavras, altos níveis de empoderamento psicológico, em determinados contextos, podem levar a maiores níveis de comportamento inovador no trabalho, e a partir disso, emerge a hipótese:

H3 - O empoderamento psicológico está positivamente associado ao comportamento inovador no trabalho.

Por fim, recentes estudos documentaram que a liderança servidora pode afetar positivamente o comportamento inovador no trabalho em mecanismos mediados pelo empoderamento psicológico. Isso porque líderes servidores são capacitadores, e ao fazê-lo, empoderam psicologicamente os funcionários, que por sua vez, sentem-se dispostos a inovar no trabalho (Khan et al., 2021; Tripathi et al., 2020; Yang et al., 2019), por meio de uma autodeterminação. Diante disso, hipotetiza-se que:

H4 - O empoderamento psicológico mediará a relação entre liderança servidora e comportamento inovador no trabalho. 


\section{4 Liderança empreendedora}

Em um mundo de mudanças aceleradas, os comportamentos empreendedores de líderes e liderados são importantes em quaisquer contextos, quer seja no setor público (Currie et al., 2008), setor privado (Ruvio et al., 2010), pequenas empresas (Dabić et al., 2021), microempresas (Rusliati et al., 2020), e grandes corporações (Strobl et al., 2020). Tanto em ambientes dinâmicos, ou menos voláteis, é necessário às organizações o aproveitamento de oportunidades de negócios (Shane \& Venkataraman, 2000), e isso envolve a necessidade de adoção de comportamentos empreendedores (Renko, 2017).

O trabalho de Gupta et al. (2004) foi um dos primeiros a introduzir o termo 'liderança empreendedora'. Para os autores, liderança empreendedora é definida como o tipo de liderança no qual são engendrados cenários visionários capazes de congregar e mobilizar atores comprometidos com a exploração e criação de valor estratégico (Gupta et al., 2004), que podem, por sua vez, facilitar a eficiência no setor público (Colares et al., 2020).

Leitch et al. (2013) definem liderança empreendedora como a liderança exercida em contextos empreendedores, ou seja, em negócios pautados pela identificação e exploração sistemática de oportunidades, cuja visão empreendedora procura fomentar a inovação, criar recursos e gerar ideias.

Já para Renko et al. (2015) a liderança empreendedora pode estar presente em quaisquer organizações, independentemente do tipo, tamanho ou maturidade. Esse tipo de liderança caracteriza-se pela influência e direcionamento do desempenho de membros do grupo para o alcance de metas organizacionais por meio da identificação e da exploração de oportunidades empreendedoras (Renko et al., 2015, p. 55), com vistas à inovação (Currie et al., 2008). De fato, liderança empreendedora e a inovação parecem caminhar juntas no campo acadêmico e empírico (Fontana \& Musa, 2017; Huang et al., 2014).

O conceito de liderança empreendedora desenvolvido por Renko et al. (2015) está alinhado a ações empreendidas pelo indivíduo, e por isso, distancia-se em certa medida dos traços de personalidade. Esse tipo de liderança situa-se na intersecção entre empreendedorismo e liderança, de modo que liderança pode ser 
concebida como um processo de influência, enquanto o empreendedorismo referese à conexão entre pessoas e oportunidades (Renko, 2017; Renko et al., 2015).

O empreendedorismo pode ser definido a partir de uma miríade de perspectivas, como busca de concretização dos próprios interesses, arranjo inovador de recursos disponíveis, incerteza e prevenção de riscos, proatividade e viabilização de oportunidades (Gupta et al., 2004; Leitch et al., 2013). Tal elemento, por si só, não explica adequadamente a liderança empreendedora, e para tanto, é preciso analisar o conceito a partir do prisma da mentalidade empreendedora (Gupta et al., 2004).

Ao enfocar o empreendedorismo apenas como uma característica pessoal, ou ainda, como um resultado ao abrir um novo negócio, o conceito de empreendedorismo é uma definição incompleta, pois não considera a qualidade de identificação de oportunidades dos empreendedores (Shane \& Venkataraman, 2000). Assim, para os autores, os estudos sobre empreendedorismo devem considerar as oportunidades, os processos de criação e de exploração de oportunidades.

Em relação à criação de novos empreendimentos, esse argumento seria restrito porque o empreendedorismo pode ocorrer no âmbito de organizações que já existem. O que diferencia um empreendedor é o aproveitamento de oportunidades empreendedoras, essas concebidas como situações nas quais novos procedimentos ou produtos podem ser introduzidos ou vendidos (Shane \& Venkataraman, 2000).

O líder empreendedor é inspirador e direcionador dos funcionários em prol da exploração de oportunidades empreendedoras (Mehmood et al., 2021), cujos papeis envolvem cinco funções principais: enquadramento, absorção de incertezas, preparação do caminho, construção de comprometimento e especificação de limites de modo que as três primeiras funções relacionam-se ao cenário, e os dois últimos, ao elenco (Gupta et al., 2004).

No que tange ao cenário, a função de 'enquadramento' relaciona-se ao papel do líder empreendedor em estruturar desafios e objetivos os quais os funcionários sejam capazes de alcançar, ou em outras palavras, é a combinação de metas ambiciosas somadas à percepção dos limites dos liderados (Gupta et al., 2004; Mehmood et al., 2021). Em segundo lugar, a ‘absorção de incertezas’ é papel do líder empreendedor, que formula a visão de futuro ao mesmo tempo em que 
constrói a confiança dos liderados, que agem como se fosse possível o alcance da visão; o papel de 'preparar o caminho' envolve a negociação e a dissolução de resistências internas e externas, obter apoio e viabilizar recursos (Gupta et al., 2004).

Já em relação ao elenco, a ‘construção de comprometimento' é papel essencial do líder empreendedor à medida que este usa suas habilidades para inspirar e comprometer a equipe; por fim, a 'especificação de limites' envolve a capacidade do líder empreendedor de eliminar crenças limitantes dos funcionários em prol do alcance das metas (Gupta et al., 2004).

Por outro lado, a perspectiva adotada por este trabalho envolve os elementos da liderança empreendedora elaborados por Renko et al. (2015), como visão, criatividade do líder e do seguidor, planejamento, tolerância a riscos, orientação para realizações e oportunidades, persistência, autoconfiança, proatividade, entre outros. Todavia, de forma mais assertiva, a liderança empreendedora diferencia-se de outros tipos de liderança especialmente devido à existência de 'metas empreendedoras' por meio de reconhecimento e exploração de oportunidades, que envolve, por sua vez, a introdução de bens e serviços inovadores (Renko, 2017; Renko et al., 2015).

A liderança empreendedora tem o potencial de transformar a realidade organizacional, e dos liderados (Renko, 2017). Isso porque, a liderança revela um papel de influência em complexos fenômenos sociais e relacionais, e o conceito de empreendedorismo, por sua vez, além de voltar vistas ao empreendedor, foca na intersecção entre o empreendedor e a oportunidade (Renko et al., 2015), conforme representado na Figura 6.

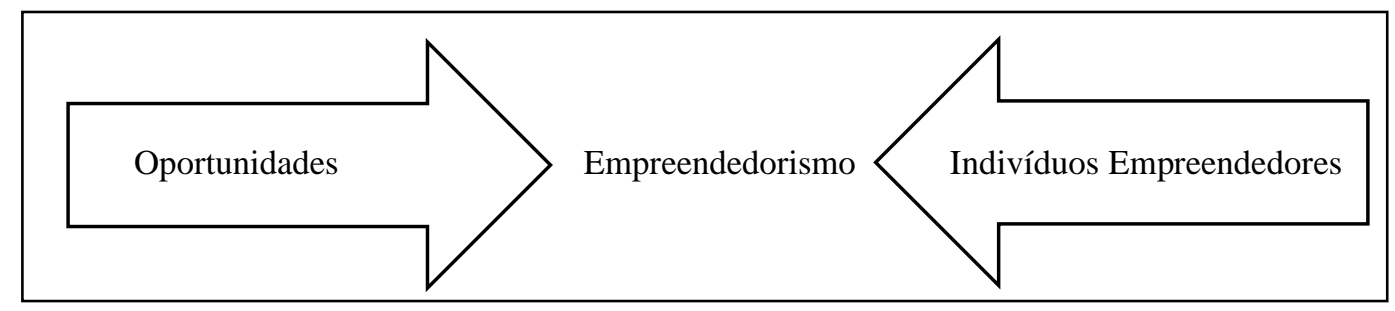

Figura 6 - Fenômeno do empreendedorismo

Fonte: Elaborado pela autora.

Para Shane \& Venkataraman (2000) e Venkataraman (1997), o empreendedorismo emerge da conexão entre dois fenômenos, quais sejam, da 
existência de oportunidades e da presença de pessoas empreendedoras, e portanto, o empreendedorismo não depende apenas de quem é o empreendedor(a) e do que ele(a) faz. É a partir da conexão entre identificação de oportunidades por indivíduos empreendedores em cargos de gestão que emerge a liderança empreendedora.

\subsection{1 \\ Teoria social cognitiva na relação entre liderança empreendedora e comportamento inovador no trabalho}

A teoria social cognitiva tem na autoeficácia percebida um papel central, já que as crenças na eficácia afetam se a pessoa pensa de maneira otimista ou pessimista, se pensam de modo que potencializam ou diminuem a si mesmas, ou ainda, é com base nesta eficácia que as pessoas escolhem os desafios a serem enfrentados bem como, o nível de esforço a ser empregado (Bandura, 1977, 2001).

A teoria social cognitiva se baseia na concepção da agência humana, (Bandura 1997). Ser agente é ter a intenção de influenciar o funcionamento da vida, quer seja por ação do indivíduo (agência pessoal direta), por dependência de outros para agir em seu favor (agência delegada), ou ainda, por meio da ação de um grupo (agência coletiva) (Bandura \& Azzi, 2017). A inovação surge da convergência destes três modos de agência. Em especial, a crença compartilhada das pessoas em seu poder coletivo de produzir os resultados desejados é um ingrediente-chave da ação coletiva (Bandura, 2005).

Portanto, uma das teorias que sustenta o caminho teórico-empírico da exploração de oportunidades empreendedoras neste estudo é a teoria social cognitiva (Bandura, 1986, 2005; Bandura \& Azzi, 2017), a partir da qual sugere-se que a liderança empreendedora fornece condições para a emergência de diversos tipos de agência. A liderança empreendedora, pelo seu perfil ousado, tomador de risco, apaixonado pelo trabalho, idealizador de ideias novas, desafiador de liderados (Renko, 2017) favorece a agência pessoal direta, delegada e coletiva (Bandura \& Azzi, 2017) já que cria uma dinâmica envolvente em torno de metas ousadas e proativas, o que pode ampliar o engajamento, levando, por sua vez, ao comportamento inovador no trabalho, conforme expresso na Figura 7.

Além disso, a partir da perspectiva do agente (Bandura, 2001), entende-se que os líderes empreendedores influenciam intencionalmente os liderados a agir individual e coletivamente, de modo que possuir agência significa empregar auto- 
organização, proatividade, autorregulação e autorreflexão. O liderado, como agente, influencia o cotidiano de trabalho.

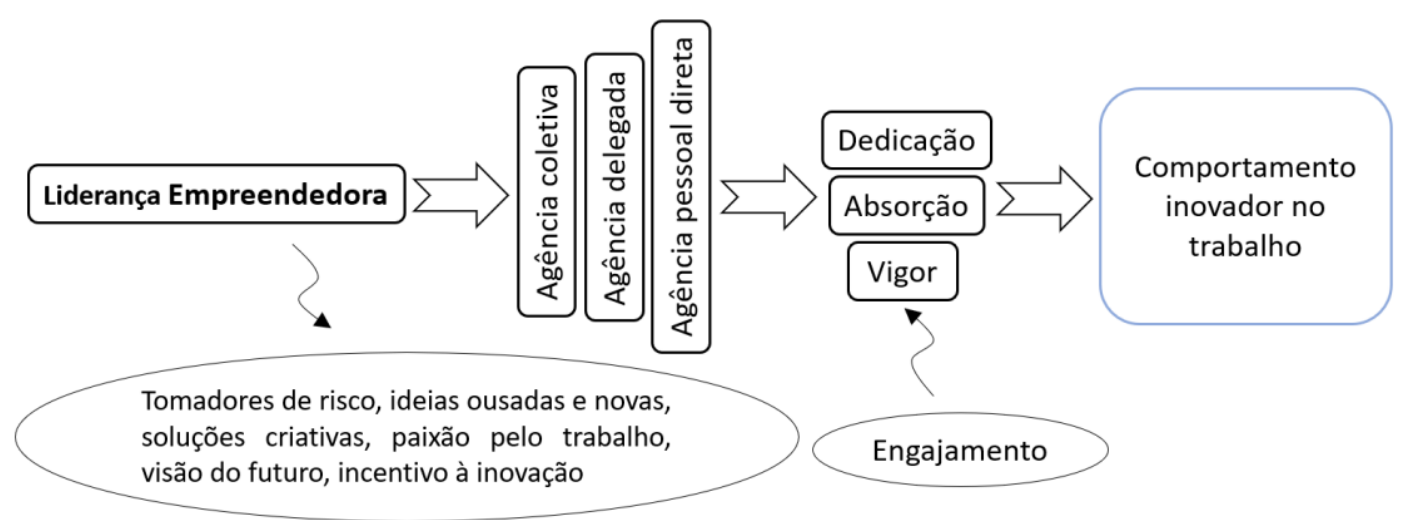

Figura 7 - Teoria social cognitiva

Fonte: Elaborado pela autora.

Desse modo, entende-se que os líderes empreendedores são agentes que estimulam e encorajam os liderados a explorar novas oportunidades, ou seja, a inovar, permitindo que eles mesmos, empreendam e sejam agentes engajados. Em outras palavras, ao fomentar a exploração de oportunidades nos liderados, os líderes empreendedores criam caminho fértil para engendrar maiores níveis de comportamento inovador entre os funcionários, especialmente dentre aqueles mais engajados.

Os empreendedores devem estar dispostos a investir tempo, recursos e esforços em ocasiões de incerteza, o que evidencia a necessidade de existência de altos níveis de eficácia resiliente para perseverar diante de fracassos repetidos (Bandura \& Azzi, 2017). Em suma, a inovação, que advém da geração de ideias criativas (Bandura, 1986) depende de empreendedores que perseverem (Bandura \& Azzi, 2017), e que sua equipe, portanto, esteja engajada no trabalho, apresentando vigor, dedicação e absorção (Schaufeli et al., 2006), já que a inovação é um processo complexo, incerto e demorado.

\subsection{2}

\section{Liderança empreendedora e comportamento inovador no trabalho}

Em relação ao empreendedorismo no nível dos trabalhadores, Ahmetoglu et al. (2015) investigaram o potencial empreendedor dos funcionários como preditor 
da sua realização criativa. Os autores encontraram que o potencial empreendedor aumenta os níveis de realização criativa em funcionários.

O caminho inverso (criatividade levando, por exemplo, a intenções empreendedoras) também foi estudado por pesquisadores. Zampetakis (2008) testou os efeitos da criatividade e da proatividade na intenção empreendedora, e descobriu que a desejabilidade mediou a relação entre criatividade e intenções empreendedoras, evidenciando também que a proatividade está positivamente associada a intenções empreendedoras. De forma semelhante, Khedhaouria et al. (2015) verificaram que a criatividade dos funcionários é preditora do desempenho empresarial, sendo essa relação totalmente mediada pela orientação empreendedora.

Diversos estudos demonstraram que a liderança empreendedora é capaz de fomentar o comportamento inovador no trabalho (Bagheri, Akbari, et al., 2020; Bagheri \& Akbari, 2018; Iqbal, Nazir, et al., 2020; C. Li et al., 2020; Miao et al., 2018), a criatividade dos funcionários (Lingo, 2020; Mehmood, Jian, \& Akram, 2020; Ximenes et al., 2019), a inovação a nível organizacional em termos de produtos e serviços (Dabić et al., 2021; Mokhber et al., 2015), e ainda, fomenta a criatividade com foco na criação de um novo empreendimento de pequena e média empresa (He et al., 2017; Sklaveniti, 2017).

Já Bagheri et al. (2013), em estudo qualitativo, exploraram as competências pessoais dos líderes empreendedores, identificando que as principais competências envolvem proatividade, inovação, amor pelos desafios e versatilidade. Diante disso, considerando que a própria inovação é uma competência pessoal desse tipo de liderança, é de se esperar que tais líderes fomentem o comportamento inovador nos seus liderados. He et al. (2017), em outro estudo qualitativo, mapeou as principais características dos líderes empreendedores, que envolvem, por sua vez, a capacidade de serem visionários, elevada motivação e ética.

Cai et al. (2019) evidenciaram que a liderança empreendedora se relaciona com a criatividade dos funcionários, quer seja a nível individual quanto a nível de esquipes, o que sugere que os funcionários e equipes gerenciadas por líderes empreendedores têm maior chance de alcançar resultados criativos.

Em estudo recente, Mehmood, Jian, \& Gilal (2020) encontraram associações diretas positivas entre liderança empreendedora e comportamento inovador dos liderados, ocasião na qual foram testados efeitos mediadores da 
autoeficácia criativa. Já Newman et al. (2018) analisaram as relações entre autoeficácia criativa dos liderados e comportamento inovador, onde a liderança empreendedora atuou positivamente como moderadora da relação, demonstrando que líderes empreendedores direcionam os funcionários para a exploração de oportunidades o que fomenta a inovação no trabalho.

O líder empreendedor tem capacidade de visão, planejamento, criatividade, tolera riscos, explora oportunidades, é orientado à realização, tem persistência, autoconfiança, e proatividade (Renko et al., 2015), o que pode favorecer o surgimento do comportamento de inovação dos funcionários por meio do poder coletivo de produzir resultados (Bandura, 2005).

Considerando que o líder empreendedor possui capacidade de exploração de oportunidades (Renko, 2017), e que ainda, esse comportamento abre diversas possibilidades ou frentes de ação proativa pelos funcionários, como geração de ideias ou início de novos projetos, processos, produtos ou serviços, hipotetiza-se que:

H5 - A liderança empreendedora está positivamente associada ao comportamento inovador no trabalho.

\subsection{3}

Mecanismos de influência

Nesta seção, são abordados os possíveis caminhos que influenciam o comportamento inovador no trabalho, partindo das relações entre liderança empreendedora, engajamento e comportamento inovador no trabalho.

\subsection{4}

Liderança empreendedora, engajamento e comportamento inovador no trabalho

O engajamento pode ser entendido como um estado atual de espírito positivo, duradouro, de cunho gratificante em relação ao trabalho, cujas dimensões distintivas são vigor, dedicação e absorção (Salanova \& Schaufeli, 2008; Schaufeli et al., 2002, 2006). Mesmo existindo diferentes conceituações sobre 
engajamento no trabalho, a visão majoritária é a de que funcionários engajados expressam energia e se identificam com o trabalho (Bakker et al., 2008).

Vigor caracteriza-se pela resiliência mental no exercício do trabalho, ou ainda, energia, vontade e disposição para aplicar esforço e persistência mesmo diante de dificuldades (Schaufeli et al., 2006). A dedicação, por sua vez, reflete entusiasmo, inspiração, orgulho, resolução de desafios e senso de significado, sendo marcada por um envolvimento que vai além da identificação em níveis normais com a organização, pois inclui a dimensão afetiva (Bakker et al., 2008; Schaufeli \& Bakker, 2004). Por fim, a absorção é definida como um estado concentrado no trabalho, no qual o tempo passa rápido, e o funcionário tem dificuldade em se desconectar do trabalho. A absorção envolve atenção concentrada sem esforço, clareza de pensamento e prazer intrínseco (Schaufeli et al., 2009).

O engajamento, nas suas duas dimensões principais de vigor e dedicação, é o oposto conceitual das duas dimensões que compõem burnout / esgotamento, conhecidas como exaustão e cinismo (González-Romá et al., 2006; Schaufeli et al., 2002). Especificamente, vigor é o oposto de exaustão emocional, e dedicação é o oposto de cinismo (Langelaan et al., 2006).

Em outras palavras, o engajamento é um estado afetivo-cognitivo penetrante que transcende um estado momentâneo e não está relacionado a um objeto, evento ou pessoa em particular, mas antes de tudo, deve-se a uma identificação psicológica (Schaufeli et al., 2002, 2006).

É importante salientar que a criatividade e a inovação são processos para os quais não há certeza de resultados, e que, por isso, exigem altos níveis de engajamento (Gilson \& Shalley, 2004).

O engajamento, de cunho cognitivo, é um processo psicológico marcado por ativação, persistência e foco (Salanova \& Schaufeli, 2008). Especificamente, em relação à dimensão vigor, ao refletir energia e concentração em uma meta, pode ser concebido como um conceito motivacional, tanto intrínseca quanto extrinsecamente. Já a segunda dimensão do engajamento, relacionada à dedicação, retrata um conceito genuinamente intrínseco, à medida que ao trabalhar, o indivíduo visa alcançar satisfação pessoal (Salanova \& Schaufeli, 2008).

O aumento de recursos de trabalho disponíveis (apoio social, autonomia, oportunidades de aprender, e feedback) podem aumentar o nível de engajamento, o que por sua vez, diminui a intenção de rotatividade e ausências por doença 
(Schaufeli et al., 2009; Schaufeli \& Bakker, 2004), aumentando o desempenho no trabalho (Bakker et al., 2008).

Os comportamentos de líderes empreendedores são capazes de reduzir o burnout e a intenção rotatividade, ao passo que aumentam o engajamento dos liderados no trabalho (Steffens et al., 2018). Ademais, funcionários com altos níveis de engajamento possuem elevada energia, o que por sua vez, favorece a capacidade de lidar com demandas diversificadas de trabalho (Schaufeli et al., 2002).

Em relação ao papel da liderança, os autores Papalexandris \& Galanaki (2009) identificaram que maiores níveis de liderança empreendedora, marcada por características como orientação para o futuro (ser um líder decisivo, visionário e inspirador) levam a maior engajamento dos funcionários. No mesmo sentido, Laguna \& Razmus (2019) identificaram que características dos empreendedores, como orientação positiva, influenciam no engajamento, além de favorecer o sucesso organizacional.

Pesquisas anteriores evidenciam que o engajamento depende de climas favoráveis como metas compartilhadas, resolução participativa de problemas (Gilson \& Shalley, 2004), bem como de tipos de liderança positivos, como liderança empreendedora (Papalexandris \& Galanaki, 2009), liderança empoderadora (X. Zhang \& Bartol, 2010), liderança servidora (Sousa \& van Dierendonck, 2017), liderança transformacional (Van Dierendonck et al., 2014), liderança ética (Naeem et al., 2020), troca líder-membro-LMX (Matta et al., 2015), entre outros. Diante disso, hipotetiza-se que:

H6 - A liderança empreendedora está positivamente associada ao engajamento.

Os autores De Spiegelaere et al. (2014) identificaram que o engajamento está positivamente relacionado à inovação, à medida que o engajamento exerce papel mediador da relação entre autonomia e comportamento inovador no trabalho. Da mesma forma, Bhatnagar (2012) evidenciou que o engajamento leva à inovação, diminuindo a intenção de rotatividade. Outro caso de engajamento como mediador para inovação no local de trabalho está presente em W. Kim \& Park (2017).

Diversos tipos de liderança estão relacionados ao engajamento, criatividade e inovação no trabalho. Asif et al. (2019) encontrou relações positivas entre liderança ética e criatividade, com papel mediador total do engajamento. Ademais, 
inúmeros estudos identificaram efeitos positivos diretos do engajamento no comportamento inovador no trabalho (Agarwal, 2014; De Spiegelaere et al., 2016) e criatividade (Chaudhary \& Akhouri, 2018; Rodríguez-Sánchez et al., 2017; W. Zhang et al., 2017).

Em suma, funcionários com alto engajamento no trabalho possuem flexibilidade, perseverança, tendem a desejar trabalhos mais desafiadores, e buscam resolver problemas ou gerar novas ideias com entusiasmo (X. Zhang \& Bartol, 2010), o que por sua vez, é capazes de impulsionar a busca pela inovação (Wu \& Wu, 2019). Diante do exposto, com base na teoria social cognitiva, hipotetiza-se que:

H7 - O engajamento está positivamente associado ao comportamento inovador.

Com base na teoria social cognitiva (Bandura, 2005), este estudo propõe que o comportamento empreendedor do líder, ao ensejar altos níveis de engajamento dos funcionários, leva um indivíduo autodeterminado a realizar ações positivas por meio da agência coletiva, delegada e pessoal direta, mesmo diante de dificuldades.

Em outras palavras, o líder empreendedor ao arriscar, persistir, ser proativo, ter visão do futuro, e autoconfiança (Renko et al., 2015) estimula o engajamento no trabalho por meio do aumento do vigor, da dedicação e da absorção dos liderados (Schaufeli et al., 2006), o que por sua vez, pode culminar na maior possibilidade da expressão de comportamento de inovação no trabalho.

Em trabalhos empíricos, o engajamento no trabalho, devido sua característica positiva, estabeleceu papel mediador positivo entre diversos tipos de liderança e o comportamento inovador no trabalho (Tong et al., 2019; Wu \& Wu, 2019).

Assim, entende-se que trabalhos desafiadores, agradáveis e orientados por um líder empreendedor são capazes de fomentar o engajamento, o que leva a maiores níveis de inovação. Portanto, com base na teoria social cognitiva (Bandura, 1986, 2005), apregoa-se que engajamento atua como mecanismo cognitivo por meio do qual a liderança empreendedora impulsiona os comportamentos inovadores dos liderados. Diante disso, hipotetiza-se que: 
H8 - O engajamento mediará a relação entre liderança empreendedora $e$ comportamento inovador no trabalho.

\section{5}

\section{Modelo conceitual e hipóteses}

A Figura 8 evidencia o modelo conceitual do estudo, incluindo as variáveis latentes substantivas e as variáveis de controle. O Quadro 4 arrola e sumariza as hipóteses previamente apresentadas.

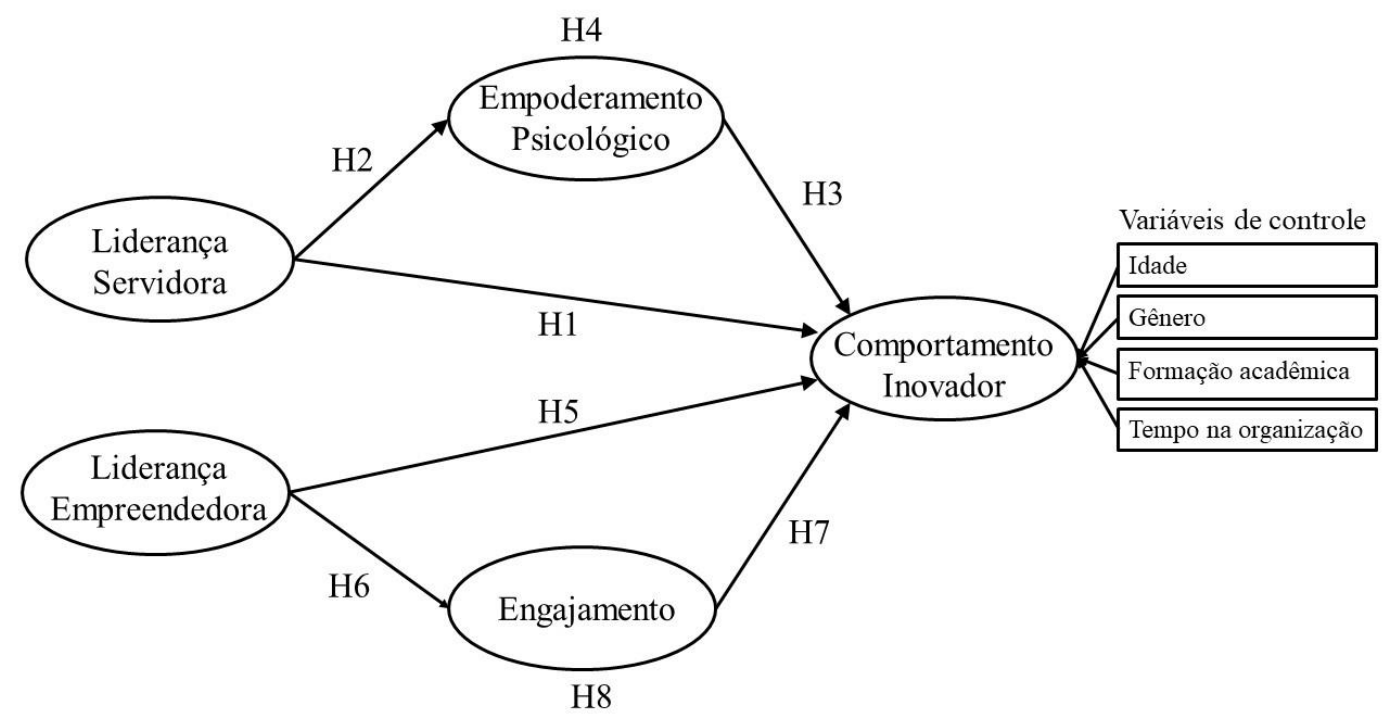

Figura 8 - Modelo conceitual do estudo

Fonte: Elaborado pela autora.

\begin{tabular}{ll}
\hline Hipótese & \multicolumn{1}{c}{ Descrição } \\
\hline H1 & $\begin{array}{l}\text { A liderança servidora está positivamente associada ao comportamento inovador no } \\
\text { trabalho. }\end{array}$ \\
\hline H2 & A liderança servidora está positivamente associada ao empoderamento psicológico. \\
\hline H3 & $\begin{array}{l}\text { O empoderamento psicológico está positivamente associado ao comportamento } \\
\text { inovador no trabalho. }\end{array}$ \\
\hline H4 & $\begin{array}{l}\text { O empoderamento psicológico mediará a relação entre liderança servidora e } \\
\text { comportamento inovador no trabalho. }\end{array}$ \\
\hline H5 & $\begin{array}{l}\text { A liderança empreendedora está positivamente associada ao comportamento } \\
\text { inovador no trabalho. }\end{array}$
\end{tabular}

H6 A liderança empreendedora está positivamente associada ao engajamento. 
H7 O engajamento está positivamente associado ao comportamento inovador.

$\mathrm{H} 8$

O engajamento mediará a relação entre liderança empreendedora e comportamento inovador no trabalho.

Quadro 4 - Sumarização das hipóteses

Fonte: Elaborado pela autora. 


\section{3 \\ Método}

\section{1}

\section{Desenho da pesquisa e participantes}

Para testar as hipóteses, este trabalho utilizou método quantitativo, por meio da estratégia de pesquisa de levantamento (survey). O questionário foi aplicado em Tribunais de Contas brasileiros com uso do software de pesquisa on-line Qualtrics ${ }^{\mathrm{xm}}$.

Após aprovação do projeto de pesquisa pela Câmara de Ética em Pesquisa da PUC-Rio, por meio do Parecer n. 099/2020 - Protocolo 123/2020, o instrumento de levantamento foi compartilhado via e-mail institucional de servidores públicos de Tribunais de Contas.

O instrumento continha a exigência de que o respondente possuísse tempo de relacionamento presencial mínimo com o líder de ao menos seis meses, ou ainda, que o líder fosse aquele relacionado à gestão anterior, até dezembro de 2020, caso houvesse ocorrido troca de cargos de gestão.

Essa necessidade de convívio presencial é importante porque os dados deste trabalho foram coletados durante a pandemia do novo coronavírus (abril de 2021), ocasião na qual houve significativa mudança na rotina de trabalho, em especial nas organizações estudadas, que passou a funcionar prioritariamente em um regime de teletrabalho. Some-se a isso que houve mudanças importantes em termos de troca de cargos de liderança de diversos tribunais em janeiro de 2021. Com isso, assegurou-se que o líder tenha tido relacionamentos pessoais e presenciais significativos com os liderados, haja vista que os cargos são nomeados a cada dois anos, e, portanto, tais líderes foram nomeados para o interstício 2019-2020.

A coleta de dados envolveu questionário específico, conforme Anexo. O referido questionário foi compartilhado via e-mails institucionais dos funcionários e redes oficiais de comunicação entre servidores dos tribunais de contas brasileiros. Além disso, contatos telefônicos foram estabelecidos entre a pesquisadora e servidores, com vistas a fomentar a participação na coleta de dados. 
Além das escalas para mensurar os construtos aportados no estudo (descritas em detalhes na próxima seção), foram levantados dados demográficos como idade, estado civil, gênero do respondente e da liderança, formação, tempo de trabalho na organização, tempo de trabalho com a liderança, vínculo organizacional, Estado da Federação, grau de conforto durante o teletrabalho e probabilidade de desejar permanecer em teletrabalho. O questionário ficou aberto para coleta de dados de 03/05/21 a 21/05/21, com participação de servidores públicos de diversos Tribunais de Contas Brasileiros.

O tamanho da amostra mínima necessário de acordo com o número de preditores foi calculado com o uso do software G-power 3.1.9.7 (Faul et al., 2009), conforme Tabela 1.

Tabela 1 - Cálculo da amostra mínima da pesquisa

Regressão linear múltipla: modelo fixo, coeficiente de regressão simples

\begin{tabular}{lllll}
\hline \multicolumn{2}{c}{ Entradas } & \multicolumn{4}{c}{ Saídas } \\
\hline Tamanho do efeito $\mathrm{f}^{2}$ & $=0,15$ & Parâmetro de não centralidade $\lambda=$ & 2,539650 \\
$\alpha$ err prob & $=0,05$ & F crítico & $=$ & 3,1381419 \\
Poder $(1-\beta$ err prob) & $=0,80$ & Graus de liberdade & $=$ & 38 \\
$\mathrm{~N}^{\circ}$ de preditores & $=4$ & Tamanho total amostra & $=$ & 43 \\
& & Poder atual & $=$ & 0,8021127 \\
\hline
\end{tabular}

Fonte: Dados da pesquisa com aplicação do G-Power 3.1.9.7 (Faul et al., 2009).

O cálculo considera a variável latente que recebe maior número de preditores (no caso em tela, a variável "comportamento inovador no trabalho" recebe quatro preditores). Os critérios utilizados no G-power consideraram o tamanho de efeito $f^{2}$ de 0,15 , com poder de efeito de 0,80 e $\alpha=0,05$ propostos por Ringle et al. (2014), o que resultou na necessidade de 43 respostas por preditor, conforme a métrica 'tamanho total da amostra' presente na Tabela 1.

Conforme ensinam Ringle et al. (2014), o próximo passo para o cálculo da amostra envolve multiplicar o valor total do tamanho da amostra obtido no G-Power por duas a três vezes. De modo a assegurar a acurácia dos cálculos e dada a relativa complexidade do modelo, optou-se pelo número mínimo de 129 respondentes, conforme segundo cenário da Tabela 2. Logo, o número mínimo da nossa amostra deveria contemplar pelo menos 129 respostas válidas. 
Tabela 2 - Possibilidades de respondentes

\begin{tabular}{cc}
\hline Cenários & Cálculos \\
\hline 1 & $43 \times 2=86$ respondentes \\
2 & $43 \times 3=129$ respondentes \\
\hline
\end{tabular}

Fonte: Dados da pesquisa.

Esse requisito foi alcançado já que foram coletadas 139 respostas. Após a remoção de um outlier identificado pelo método de cálculo Cooks Distance, e de dados omissos, a quantidade de observações válidas foi de 135.

Primeiramente, foi identificada a presença de um possível outlier nos dados residuais ao realizar-se os testes de análise de regressão linear no SAS Enterprise Guide. A Figura 9 evidenciou a presença de um possível outlier entre as observações 100 e 138 dos dados.

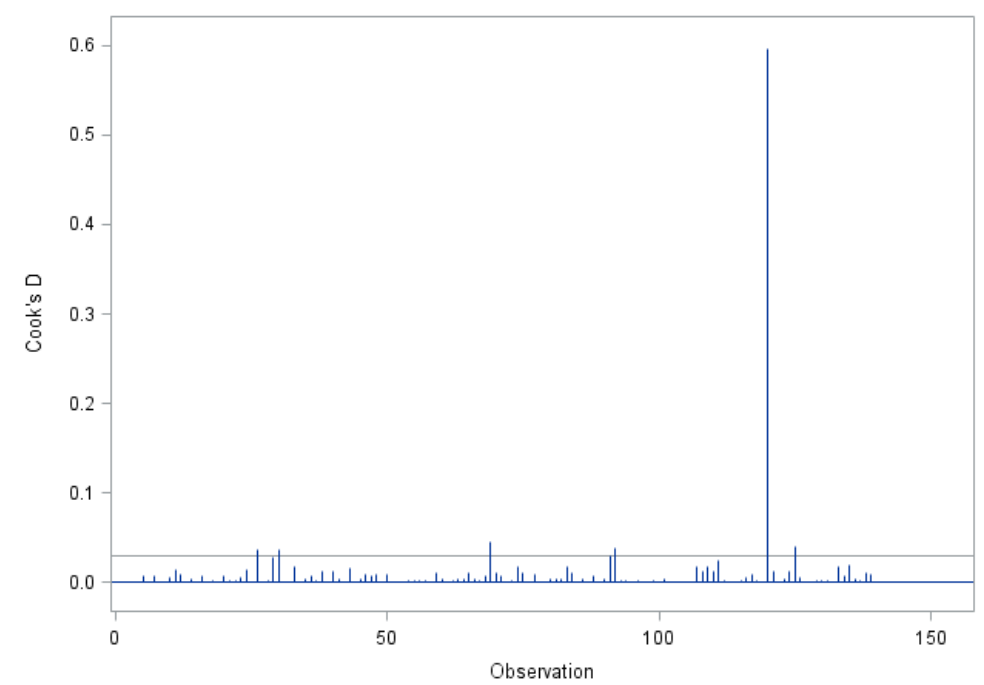

Figura 9 - Detecção de potenciais outliers

Fonte: Elaborado pela autora com software SAS.

Diante dessa possibilidade, identificou-se qual observação da planilha de dados era o outlier por meio do cálculo de Cook's Distance usando o SPSS. Para este cálculo "comportamento inovador" foi inserida como variável dependente, e como variáveis independentes foram inseridas todas as outras do modelo: liderança servidora, liderança empreendedora, empoderamento psicológico e engajamento.

O maior valor de Cook's distance encontrado foi de 0,6118. O segundo maior valor foi de 0,0769, quase oito vezes menor do que o primeiro. Em adição a isso, foi gerado um Gráfico de Dispersão / Scatter Plot, com rotulagem, que permitiu a identificação do outlier, conforme Figura 10. 


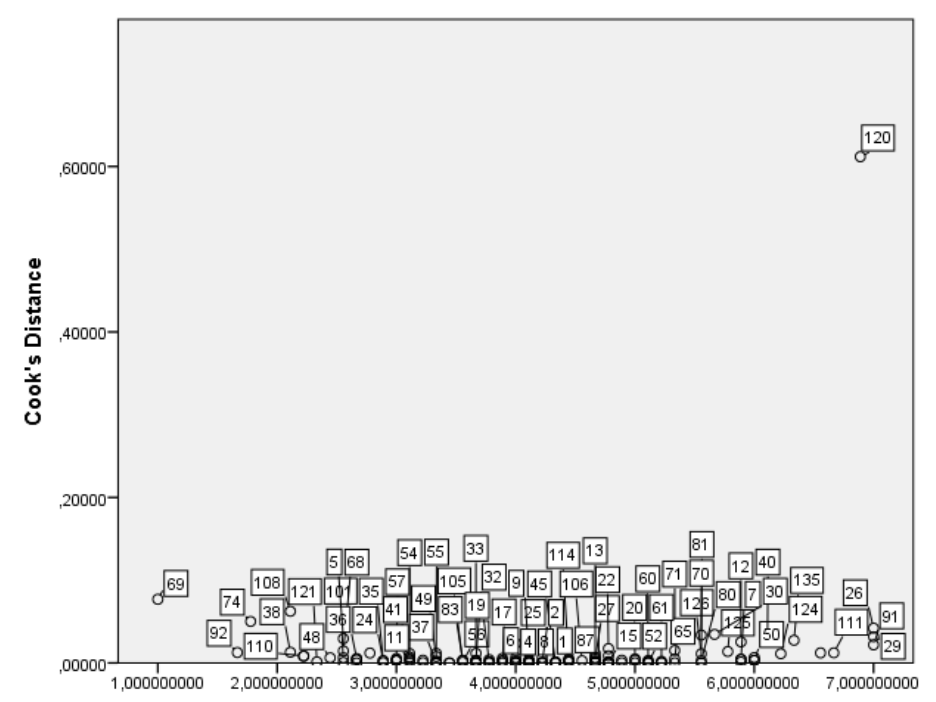

Figura 10 - Detecção de potenciais outliers

Fonte: Elaborado pela autora com software SPSS.

Conforme é possível verificar na Figura 10, o outlier do banco de dados é a observação de número 120. A partir do elevado valor obtido pelo cálculo Cook's Distance, o referido caso foi removido da amostra. Posteriormente, foram identificados dados omissos, e o número final de observações válidas foi de 135.

\section{2 \\ Escalas}

As escalas empregadas neste estudo estão sumarizadas no Quadro 5, e seguem dispostas no anexo deste documento (p. 105).

\begin{tabular}{|l|c|c|c|l|}
\hline \multicolumn{1}{|c|}{ Variável latente } & $\begin{array}{c}\mathbf{N}^{\mathbf{0}} \text { de } \\
\text { itens }\end{array}$ & Âncora & $\begin{array}{c}\mathbf{N}^{\mathbf{0}} \text { de } \\
\text { fatores }\end{array}$ & \multicolumn{1}{|c|}{ Fonte } \\
\hline Liderança Servidora & 7 & $\begin{array}{c}\text { Discordo a concordo } \\
\text { totalmente: 7 pontos }\end{array}$ & 1 & Liden et al. (2015) \\
\hline Liderança Empreendedora & 8 & $\begin{array}{c}\text { Discordo a concordo } \\
\text { totalmente: 7 pontos }\end{array}$ & 1 & $\begin{array}{l}\text { Renko et al. (2015); } \\
\text { Renko (2017) }\end{array}$ \\
\hline Engajamento & 9 & $\begin{array}{c}\text { Nunca a sempre: 7 } \\
\text { pontos }\end{array}$ & 1 & Schaufeli et al. (2006) \\
\hline $\begin{array}{l}\text { Empoderamento } \\
\text { Psicológico }\end{array}$ & 12 & $\begin{array}{c}\text { Discordo a concordo } \\
\text { totalmente: 7 pontos }\end{array}$ & 4 & Spreitzer (1995) \\
\hline $\begin{array}{l}\text { Comportamento Inovador } \\
\text { no trabalho }\end{array}$ & 9 & $\begin{array}{c}\text { Nunca a sempre: 7 } \\
\text { pontos }\end{array}$ & 2 & Janssen (2000) \\
\hline
\end{tabular}

Quadro 5 - Fontes dos questionários e métricas Fonte: Elaborado pela autora.

Na realização desta pesquisa, todas as variáveis foram medidas por meio de respostas dos respondentes às perguntas por meio de escalas do tipo Likert, que 
variaram entre concordo totalmente e discordo totalmente, com sete pontos, bem como, de sempre a nunca. As escalas seguem explicitadas nas subseções seguintes.

\subsection{1}

\section{Liderança servidora}

A percepção dos liderados acerca da existência da liderança servidora em seus líderes imediatos foi levantada por meio da versão reduzida da escala Servant Leadership-28 (Liden et al., 2008) contendo apenas sete itens. A versão curta da escala, chamada de SL-7 (Servant Leadership - 7) foi desenvolvida e validada por Liden et al. (2015).

A escala SL-7 possui integridade psicométrica e menor número de itens. Os itens envolvem, por exemplo, "Meu (minha) líder enfatiza a importância de retribuir à comunidade", ou ainda, "Meu (minha) líder dá mais prioridade aos meus interesses do que aos seus próprios". Seguindo o disposto por Liden et al. (2015) foi empregada escala tipo Likert de sete pontos, variando entre discordância total e concordância total.

A liderança servidora está dividida em sete dimensões: 1) cura emocional; 2) criação de valor para a comunidade; 3) habilidades conceituais; 4) capacitar; 5) ajudar os subordinados a crescer e ter sucesso; 6) colocar os subordinados em primeiro lugar, e 7) comportar-se de forma ética. A análise de cada dimensão só é possível quando a escala completa SL-28 é utilizada, já que o SL-7 não serve como substituta da SL-28 em pesquisas nas quais as dimensões são analisadas separadamente (Liden et al., 2015, p. 267). Assim, a essência da liderança servidora é analisada de maneira não individualizada em dimensões por meio da SL-7.

\subsection{2}

\section{Liderança empreendedora}

A percepção de liderança empreendedora dos liderados sobre os líderes foi coletada por meio da escala de oito itens presente nos trabalhos de Renko (2017) e Renko et al. (2015). Os itens compõem-se, por exemplo, por: "Tem soluções criativas para problemas" e "Desafia-me e incentiva-me a agir de forma mais inovadora". Conforme indicado por Renko et al. (2015), foi utilizada escala tipo Likert de sete pontos, com variação entre discordância total e concordância total. 


\subsection{3 \\ Empoderamento psicológico}

A fim de verificar o grau de empoderamento psicológico dos liderados diante do trabalho foi aplicada a escala de Spreitzer (1995). A escala é dividida em quatro dimensões, quais sejam, significado, competência, autodeterminação e impacto.

A dimensão Significado refere-se ao valor de uma meta de trabalho face aos ideais de um indivíduo, e foi medida, por exemplo, como: "O trabalho que realizo é muito importante para mim". A dimensão Competência, também conhecida como autoeficácia, avalia a crença pessoal na capacidade de realização das atividades laborais, cuja mensuração se deu por itens como: "Confio nas minhas habilidades para desempenhar o meu trabalho". Já a dimensão Autodeterminação relaciona-se à autonomia em iniciar e terminar processos de trabalho, de modo que sua mensuração foi avaliada por meio de itens como: "Posso decidir por conta própria como realizar o meu trabalho". Por fim, a dimensão Impacto pode ser definida como o grau em que as atividades do indivíduo são capazes de influenciar resultados estratégicos, e sua mensuração se deu por meio de itens como, por exemplo: "O impacto do meu trabalho no que ocorre no meu departamento é alto". Foi empregada escala do tipo Likert de sete pontos, com variação entre discordo totalmente e concordo totalmente.

\subsection{4 \\ Engajamento}

O engajamento foi mensurado por meio da versão curta da escala de engajamento denominada UWES-9 (Schaufeli et al., 2006), contendo três itens para cada dimensão: vigor, dedicação e absorção. A dimensão vigor foi mensurada por meio de perguntas como: "No trabalho, sinto-me forte e com vigor."; já a dedicação foi medida por itens como: "Estou entusiasmado com meu trabalho."; por fim, a absorção foi mensura por meio de questões como, por exemplo: "Sinto-me feliz quando trabalho intensamente.”. foi utilizada escala Likert de sete pontos, variando entre nunca e sempre. 


\subsection{5}

\section{Comportamento inovador no trabalho}

O comportamento inovador do liderado no local de trabalho foi mensurado de forma autorrelatada. Foi utilizada a escala de Janssen (2000), originalmente dividida em três dimensões: Geração de ideias, Promoção de ideias e Realização de ideias. As perguntas sobre essa medida foram intercaladas em três blocos distintos e separados no questionário de levantamento. A dimensão Geração de ideias continha assertivas como: "Gero soluções originais para problemas"; a dimensão Promoção de ideias foi medida por itens como: "Mobilizo apoio para ideias inovadoras"; por fim, a dimensão Realização de ideias foi representada por itens como: "Introduzo ideias inovadoras no ambiente de trabalho de forma sistemática". Foi empregada escala do tipo Likert de sete pontos, variando entre nunca e sempre.

\subsection{6}

\section{Variáveis demográficas e de controle}

Diversos estudos demonstraram que características demográficas e socioeconômicas influenciam comportamentos em relação à inovação no trabalho, como gênero (Menter, 2020; van Acker et al., 2018), grau de escolaridade (Oldham \& Cummings, 1996), estabilidade organizacional/tempo de organização (Woods et al., 2018), e idade (Khan, Mubarak, et al., 2020). Por isso, variáveis demográficas e de controle foram coletadas para serem aplicadas como variáveis de controle na análise, conforme Quadro 6.

\begin{tabular}{|l|c|}
\hline Variável & Tipo \\
\hline Idade & Numérica \\
\hline Gênero & Categórica/dummy \\
\hline Formação & Categórica \\
\hline Tempo na organização & Numérica \\
\hline
\end{tabular}

Quadro 6 - Variáveis demográficas e de controle Fonte: Elaborado pela autora.

As variáveis de controle como idade e tempo na organização foram medidas como variáveis numéricas contínuas. Já a variável gênero assume o valor de 1 se o gênero for masculino, e 0 se o gênero for feminino. 
Por fim, a variável sobre o nível de formação também foi inserida como variável de controle, em uma escala ordinal de níveis acadêmicos, variando entre ensino médio à pós-graduação stricto sensu. O uso de variáveis de controle obedeceu ao proposto por Atinc et al. (2012), que sugerem o uso parcimonioso dessas variáveis.

\section{3 Procedimentos para análise de dados da pesquisa}

Para a análise dos dados foram utilizados três softwares. O primeiro deles denomina-se SAS Enterprise Guide 7.1, e foi usado para a identificação de outliers e testes de normalidade. O software Statistical Package for the Social Sciences SPSS 23.0 foi utilizado para inversão de variáveis, criação de variáveis dummy, e também para corroborar a identificação de outliers e testes de normalidade.

O software SmartPLS 3.3.3 foi escolhido para a análise dos dados a partir da abordagem de Modelagem de Equações Estruturais (MEE) de Mínimos Quadrados Parciais (MQP), do inglês Partial Least Squares - Structural Equation Modeling (PLS-SEM). A avaliação do modelo de mensuração foi calculada no SmartPLS 3.3.3 por meio do comando PLS Algoritmo, com esquemas de ponderação de caminho, número máximo de iterações $=300$ e critério de parada $=$ 7. Já a avaliação do modelo estrutural ocorreu por meio do bootstrapping com 5000 repetições, através de processamento paralelo, com exigência de bootstrapping completo, viés corrigido e acelerado, e teste bicaudal. Por fim, a criação do mapa de importância-desempenho também foi realizada no SmartPLS 3.3.3, com o construto-alvo denominado 'comportamento inovador' e todos os predecessores selecionados. 


\section{Resultados}

\section{1}

\section{Análise descritiva dos dados demográficos da amostra}

Nesta seção é apresentada a análise descritiva dos dados demográficos da amostra. A coleta de dados culminou em 140 respostas. Após limpeza dos dados e remoção de respostas inválidas, restaram 135 respostas. A amostra foi composta, assim, por 135 participantes, dentre os quais, 46,7\% são do sexo masculino, 51,5\% do sexo feminino, e 2,2\% preferem não dizer, conforme Figura 11.

A Figura 11 também aborda o gênero da liderança. Em relação ao sexo dos líderes, percebe-se uma majoração na quantidade de líderes homens (82 líderes homens, ou 60,7\%) em relação às líderes mulheres (51, ou 37,8\%), e, por fim, 1,5\% preferem não responder.

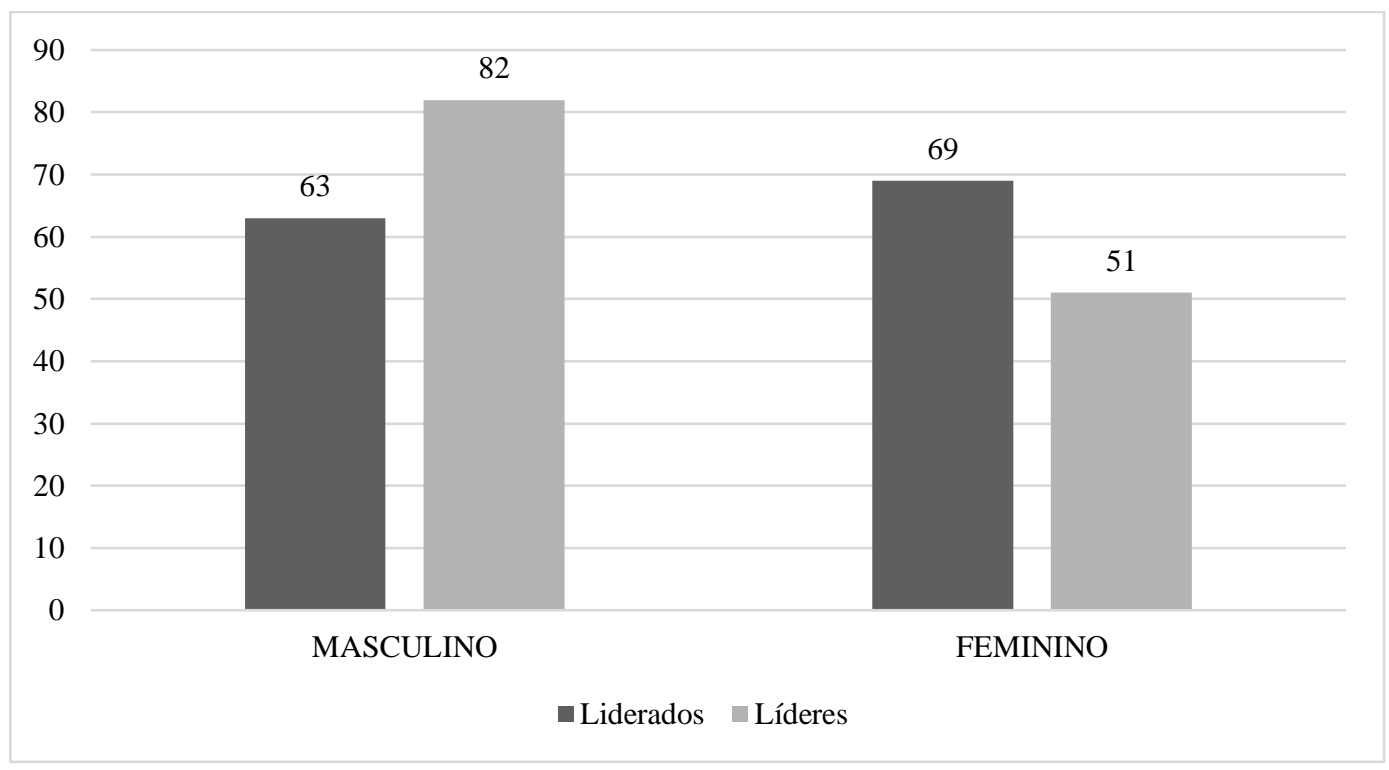

Figura 11 - Distribuição de gêneros, em números absolutos Fonte: Elaborado pela autora.

A idade dos participantes está compreendida entre 20 e 64 anos, com média de 41 anos. Aproximadamente 59\% são casados ou em união estável, e $41 \%$ são solteiros(as), separados(as) ou viúvos(as). Já em relação à formação escolar ou 
acadêmica, 56,3\% (ou 76 pessoas) possuem especialização, já 14,1\% possuem algum nível de pós-graduação stricto sensu, dentre os quais situam-se mestrado, doutorado ou pós-doutorado, conforme Figura 12.

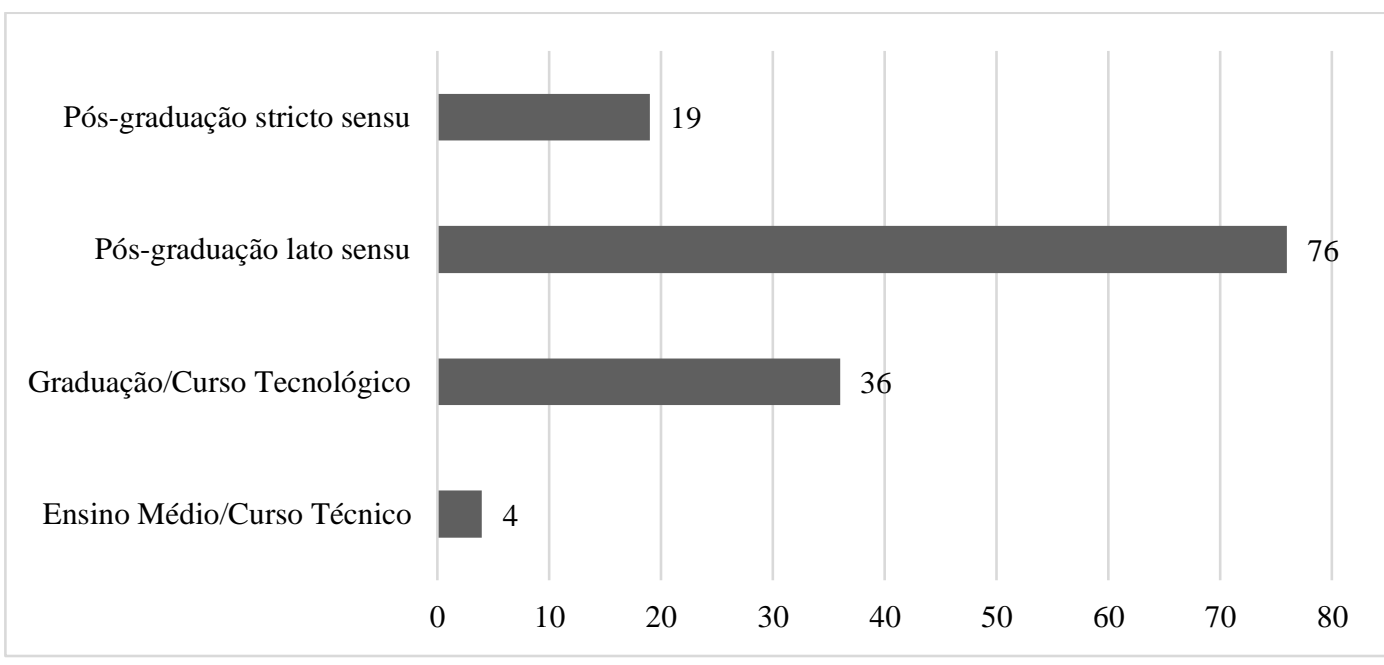

Figura 12 - Formação acadêmica, em números absolutos Fonte: Elaborado pela autora.

Conforme a Figura 13, em relação ao tempo de trabalho na organização atual, 25,9\% (35 servidores) estão há pelo menos quatro anos na organização, já 28,9\% (39 servidores) estão há pelo menos nove anos na organização, concentrando a maior parte dos respondentes. O tempo de permanência na organização varia entre 1 e 37 anos completos, com média de 11 anos de trabalho.

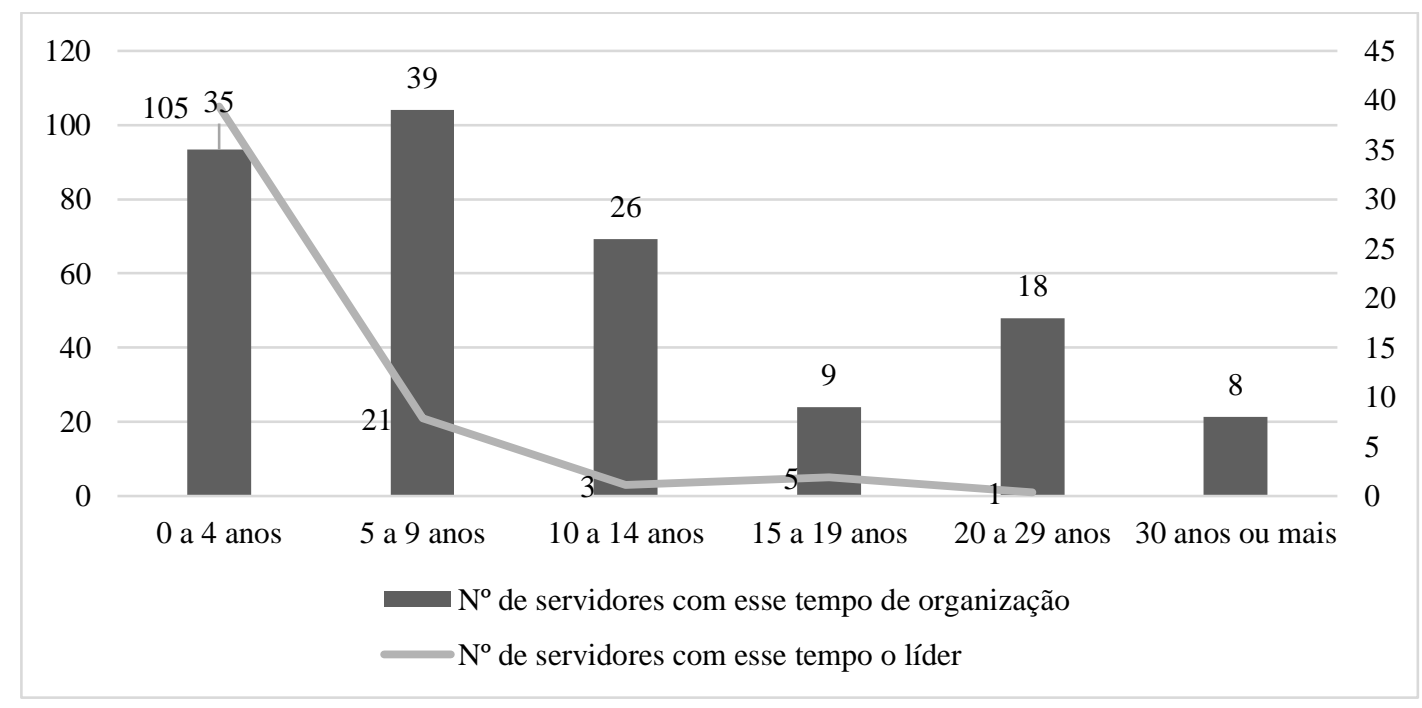

Figura 13 - Tempo de trabalho na organização e com o líder Fonte: Elaborado pela autora. 
O tempo com o líder varia entre 1 e 27 anos completos, com média geral de três anos com o mesmo líder. Por fim, oito servidores trabalham há 30 anos ou mais na organização, tendo apenas um servidor experenciado 27 anos ou mais com o mesmo líder.

No que concerne à participação dos Tribunais de Contas Brasileiros, a Figura 14 evidencia a distribuição de respondentes por Estado da Federação. Integraram a pesquisa servidores de catorze estados (sendo um deles o Distrito Federal), dentre os quais destacam-se Bahia, Espírito Santo, Goiás, Mato Grosso do Sul, Minas Gerais, Paraíba, Paraná, Piauí, Rio de Janeiro, Rio Grande do Sul, Rondônia, Santa Catarina e São Paulo.

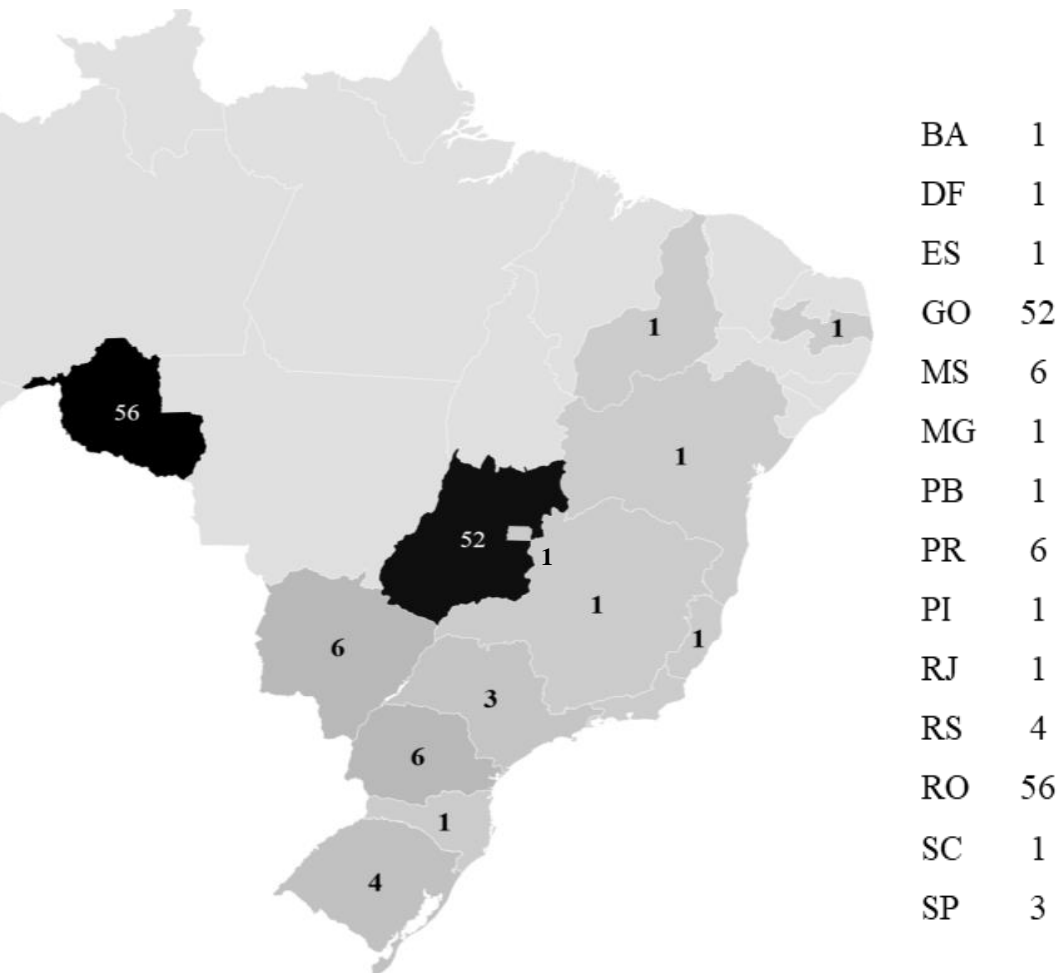

Figura 14 - Distribuição de respondentes por Estado brasileiro Fonte: Elaborado pela autora.

Cerca de 38,5\% dos participantes são de Goiás, e aproximadamente 41,5\% são de Rondônia. Os demais respondentes estão distribuídos pelos demais tribunais do Brasil. Além disso, catorze estados brasileiros estão representados com pelo menos um respondente na amostra.

Em relação ao teletrabalho na pandemia por Covid-19, os participantes foram questionados a respeito do bem-estar sentido durante esse processo, e sobre 
a intenção futura em permanecer no teletrabalho, caso possível, após o fim da pandemia. Os resultados seguem dispostos na Figura 15.

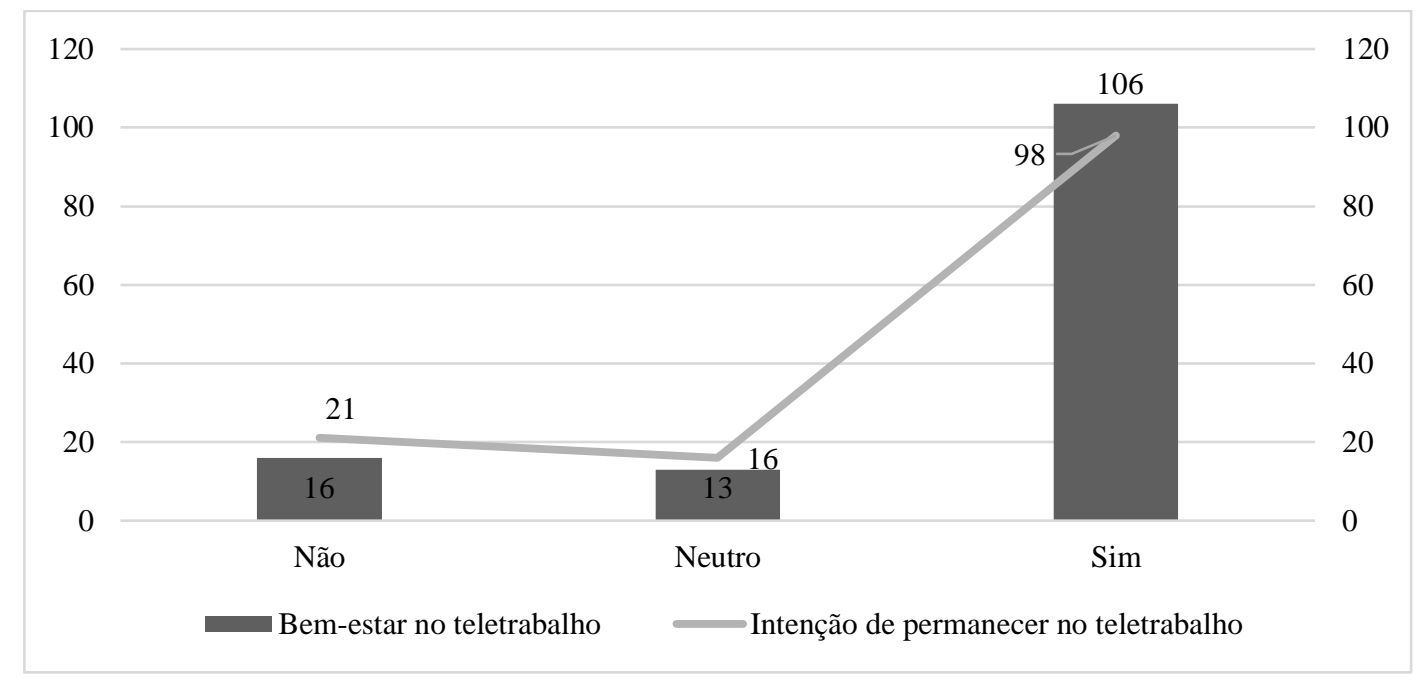

Figura 15 - Bem-estar e intenção de permanecer no teletrabalho Fonte: Elaborado pela autora.

Evidencia-se que a maioria dos respondentes se sentiu confortável e com bem-estar no teletrabalho, cerca de 106 participantes (78,5\% da amostra). Além disso, 98 respondentes $(72,6 \%)$ expressaram que têm intenção em permanecer no teletrabalho após o término da pandemia, caso isso seja possível.

\section{2}

\section{Testes de normalidade}

Os testes de normalidade da variável dependente, realizados por meio do software SAS Enterprise Guide evidenciam que a variável dependente 'comportamento inovador no trabalho' possui distribuição normal, conforme testes estatísticos da Tabela 3.

De acordo com os testes Shapiro-Wilk, Kolmogorov-Smirnov, Cramer-von Mises e Anderson-Darling, evidencia-se que a hipótese nula (H0) refere-se à distribuição ser normal. Dessa maneira, para falhar na rejeição da hipótese nula, espera-se que os $\mathrm{p}$-valores sejam maiores do que $\alpha=0,05$. Diante dos $\mathrm{p}$-valores maiores do que $5 \%$, não é possível rejeitar a hipótese nula, e, portanto, a distribuição da variável dependente é normal. Embora o método de mínimos quadrados parciais não contenha a exigência de normalidade dos dados (Hair et al., 2017), cumpri-la não deixa de ser benéfico. 
Tabela 3 - Testes de normalidade dos resíduos

\begin{tabular}{lcc}
\hline Teste & Estatística de teste & p-valor \\
\hline Shapiro-Wilk & 0,99 & 0,89 \\
Kolmogorov-Smirnov & 0,049 & $>0,1500$ \\
Cramer-von Mises & 0,03 & $>0,2500$ \\
Anderson-Darling & 0,17 & $>0,2500$ \\
\hline
\end{tabular}

Fonte: Elaborado pela autora.

Outra maneira de checar a normalidade dos resíduos da variável dependente é a análise do gráfico QQ-Plot, disposto na Figura 16, e o gráfico de distribuição, presente na Figura 17.

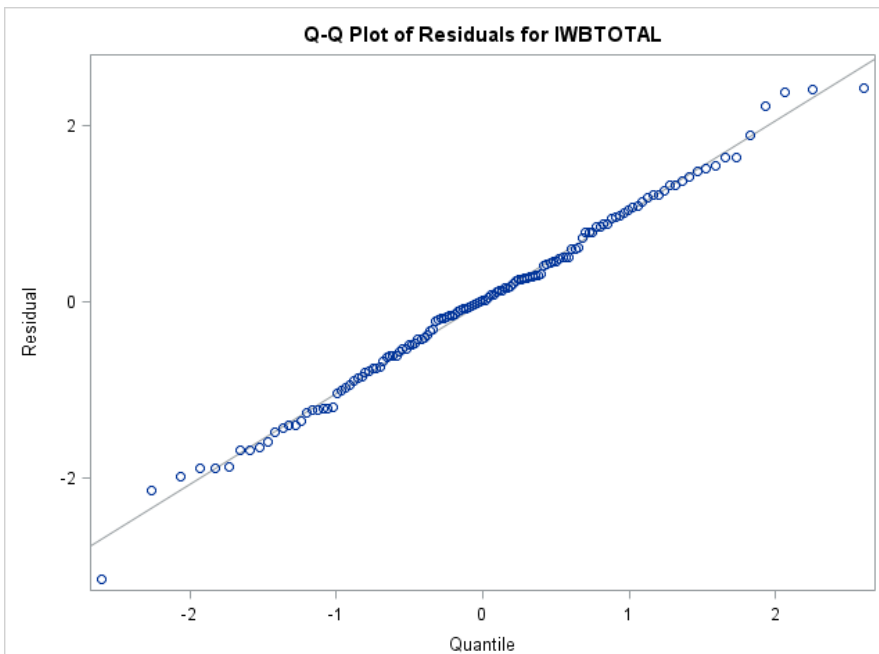

Figura 16 - Gráfico QQ-Plot para análise de normalidade Fonte: Elaborado pela autora no software SAS Enterprise Guide.

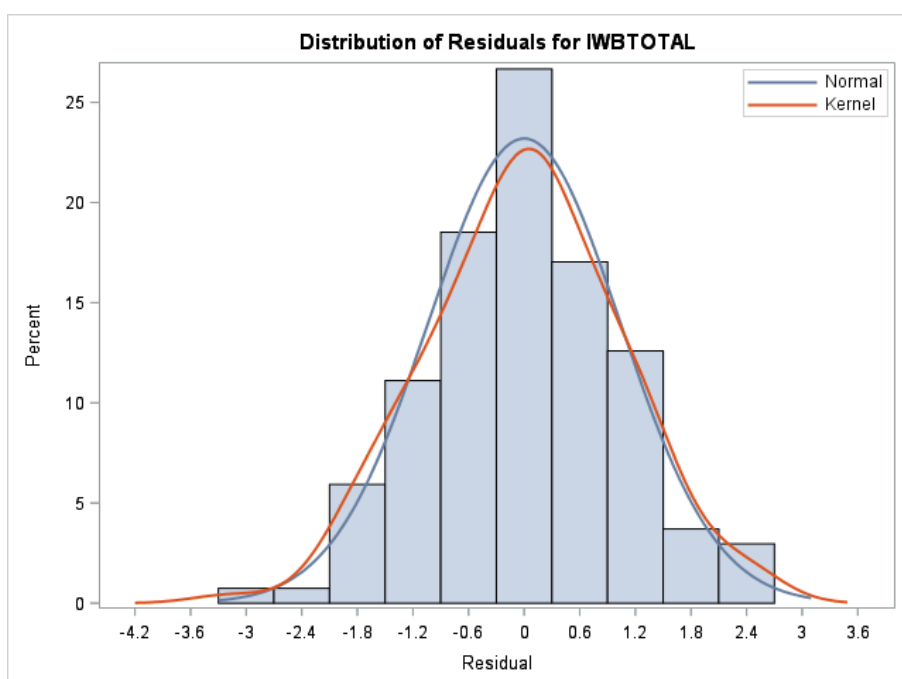

Figura 17 - Gráfico de distribuição para análise de normalidade Fonte: Elaborado pela autora no software SAS Enterprise Guide. 
Os dois gráficos não apresentam desalinhamentos, informando que existe a normalidade dos resíduos da variável dependente (Black, 2010).

\section{3}

\section{Análise Fatorial Exploratória}

Com vistas a verificar as escalas de mensuração aplicadas, foi realizada a análise fatorial exploratória das variáveis do estudo. Duas das variáveis se mostraram adequadas para a realização da análise fatorial exploratória: comportamento inovador no trabalho e empoderamento psicológico, conforme disposto a seguir.

\subsection{1}

\section{Comportamento inovador no trabalho}

Foi aplicado o teste de Kaiser - Meyer - Olkin (KMO) e o teste de esfericidade de Bartlett para analisar a possibilidade da aplicação de análise fatorial à escala de comportamento inovador no trabalho (Qiu \& Dooley, 2019), conforme disposto na Tabela 4.

Tabela 4 - Teste KMO e de Barlett

\begin{tabular}{lc}
\hline Descrição & Valor \\
\hline Medida Kaiser-Meyer-Olkin de adequação de amostragem (KMO) & 0,865 \\
Teste de esfericidade de Bartlett & \\
Aprox. Qui-quadrado $(\chi 2)$ & 1081,87 \\
Graus de liberdade $(\mathrm{gl})$ & 36 \\
Sig. & 0,000 \\
\hline
\end{tabular}

Fonte: Elaborado pela autora.

Os resultados mostram que o $\chi 2$ aproximado relativo ao teste de esfericidade de Bartlett foi significativo $(\chi 2=1081,87, \mathrm{gl}=36, \mathrm{p}<0,000)$. Já a estatística de teste de adequação da amostragem KMO é 0,865 , o que é maior do que o limite mínimo de 0,5 , e evidencia que os dados são adequados para análise fatorial (S. Qiu \& Dooley, 2019).

Ainda na escala de escala de comportamento inovador no trabalho foi aplicada a rotação Oblimin com normalização de Kaiser para extrair fatores, com base em autovalores acima de 1 , exclusão de valores menores do que 0,4 , o que resultou em uma estrutura de dois fatores, com rotação convergida em 4 iterações, conforme Tabela 5. 
Tabela 5 - Matriz padrão

\begin{tabular}{lcc}
\hline Itens & \multicolumn{2}{c}{ Componentes } \\
\hline Com que frequência você se sente à vontade para: & 1 & \multicolumn{1}{c}{2} \\
\hline 1 Criar novas ideias para questões difíceis & $-0,95$ \\
2 Pesquisar novos métodos de trabalho, técnicas ou instrumentos & $-0,95$ \\
3 Gerar soluções originais para problemas & $-0,91$ \\
4 Mobilizar apoio para ideias inovadoras & 0,71 \\
5 Obter aprovação para ideias inovadoras & 0,79 \\
6 Fazer com que membros importantes da organização fiquem entusiasmados & 0,77 \\
com ideias inovadoras & 0,91 \\
7 Transforma ideias inovadoras em aplicações úteis & 0,92 \\
8 Introduz ideias inovadoras no ambiente de trabalho de forma sistemática & 0,74 \\
9 Avalia a utilidade de ideias inovadoras & \\
\hline
\end{tabular}

Fonte: Elaborado pela autora.

Neste trabalho, foram observadas duas dimensões: criatividade (geração de ideias - 3 itens), e inovação (promoção e implementação de ideias - 6 itens). $\mathrm{O}$ alfa de Cronbach da criatividade foi 0,950 (3 itens), e o de inovação foi de 0,909 (6 itens).

Cumpre salientar que a análise fatorial exploratória permitiu tornar o modelo mais parcimonioso. Isso porque a variável latente 'comportamento inovador', ao invés de compreender nove indicadores, foi composta por apenas dois indicadores (criatividade e inovação). O indicador criatividade foi calculado a partir da média dos três itens do componente 2 da Tabela 5. Já o indicador inovação, foi calculado pela média dos seis indicadores do componente 1 da matriz padrão extraída na análise fatorial exploratória.

Do ponto de vista teórico, pesquisadores concordam que o comportamento de trabalho inovador pode ser caracterizado pela dimensão dupla de: geração (criatividade) e implementação de ideias (inovação em si) (De Spiegelaere et al., 2014; Volery \& Tarabashkina, 2021). Do mesmo modo, Hughes et al. (2018) sugerem diferenciar criatividade e inovação, dimensões muitas vezes imbricadas nos próprios instrumentos de mensuração.

\subsection{2 \\ Empoderamento psicológico}

A escala de empoderamento psicológico também se mostrou adequada para a realização da análise fatorial exploratória. Para tanto, utilizou-se o teste de Kaiser - Meyer - Olkin (KMO) e o teste de esfericidade de Bartlett, conforme Tabela 6. 
Tabela 6 - Teste KMO e de Barlett

\begin{tabular}{lc}
\hline Descrição & Valor \\
\hline Medida Kaiser-Meyer-Olkin de adequação de amostragem (KMO) & 0,820 \\
Teste de esfericidade de Bartlett & \\
Aprox. Qui-quadrado $(\chi 2)$ & 983,872 \\
Graus de liberdade $(\mathrm{gl})$ & 66 \\
Sig. & 0,000 \\
\hline
\end{tabular}

Fonte: Elaborado pela autora.

Os resultados evidenciam que o $\chi 2$ aproximado do teste de esfericidade de Barlett é significativo, de modo que o $\chi^{2}=983,872, \mathrm{gl}=66, \mathrm{p}<0,000$, somado ao fato de que a estatística de adequação da amostragem KMO é 0,820, valor bastante superior mínimo de 0,50, tornando possível a análise fatorial (S. Qiu \& Dooley, 2019).

Com utilização da rotação Oblimin e normalização de Kaiser por meio de autovalores acima de 1 , exclusão de valores menores do que 0,4 , identificou-se uma estrutura de quatro fatores na escala de empoderamento psicológico, com rotação convergida em 8 iterações, conforme Tabela 7.

Tabela 7 - Matriz padrão

\begin{tabular}{|c|c|c|c|c|}
\hline \multirow{2}{*}{ Itens } & \multicolumn{4}{|c|}{ Componentes } \\
\hline & 1 & 2 & 3 & 4 \\
\hline 7 Tenho autonomia para determinar como faço o meu trabalho. & 0,94 & & & \\
\hline 8 Posso decidir por conta própria como realizar o meu trabalho. & 0,95 & & & \\
\hline $\begin{array}{l}9 \text { Tenho considerável independência e liberdade para realizar meu } \\
\text { trabalho. }\end{array}$ & 0,92 & & & \\
\hline $1 \mathrm{O}$ trabalho que realizo é muito importante para mim. & & 0,93 & & \\
\hline $\begin{array}{l}2 \text { As atividades que executo em meu trabalho me proporcionam } \\
\text { autorrealização. }\end{array}$ & & 0,78 & & \\
\hline 3 Sou capaz de perceber o propósito do trabalho que desempenho. & & 0,82 & & \\
\hline 4 Confio nas minhas habilidades para desempenhar o meu trabalho. & & & 0,76 & \\
\hline $\begin{array}{l}5 \text { Tenho autoconsciência das minhas competências para } \\
\text { desempenhar as atividades do meu trabalho. }\end{array}$ & & & 0,84 & \\
\hline $\begin{array}{l}6 \text { Domino totalmente as competências necessárias para desempenhar } \\
\text { o meu trabalho. }\end{array}$ & & & 0,84 & \\
\hline $\begin{array}{l}10 \mathrm{O} \text { impacto do meu trabalho no que ocorre no meu departamento } \\
\text { é alto. }\end{array}$ & & & & 0,66 \\
\hline $\begin{array}{l}11 \text { Tenho capacidade de controlar o que ocorre no meu } \\
\text { departamento. }\end{array}$ & & & & 0,87 \\
\hline $\begin{array}{l}12 \text { Tenho significativa influência no que ocorre no meu } \\
\text { departamento. }\end{array}$ & & & & 0,88 \\
\hline
\end{tabular}

Fonte: Elaborado pela autora.

O resultado de quatro fatores identificado por meio da análise fatorial exploratória está em concordância à literatura tradicional de empoderamento 
psicológico, segundo a qual, o empoderamento psicológico divide-se nas dimensões autodeterminação, significado, competência e impacto (Spreitzer, 1995).

A análise fatorial exploratória permitiu, assim como na escala de comportamento inovador, tornar o modelo mais parcimonioso. Assim, a variável latente 'empoderamento psicológico', ao invés de compreender doze indicadores, foi composta por apenas quatro indicadores (autodeterminação, significado, competência e impacto).

O indicador 'autodeterminação' foi calculado a partir da média dos três itens do componente 1 da Tabela 7. Já o indicador 'significado', foi calculado a partir da média dos três indicadores do componente 2 da mesma tabela. $\mathrm{O}$ indicador 'competência', por sua vez, foi calculado extraindo-se a média dos itens situados no componente 3. E por fim, o indicador 'impacto' refere-se à média dos itens do quarto componente fatorial. Desse modo, cada fator contou com três itens, de acordo com a Tabela 8.

Tabela 8 - Alfa de Cronbach - empoderamento psicológico

\begin{tabular}{lcc}
\hline Dimensões & Número de itens & Alfa de Cronbach \\
\hline Significado & 3 & 0,863 \\
Competência & 3 & 0,805 \\
Autodeterminação & 3 & 0,929 \\
Impacto & 3 & 0,787 \\
\hline
\end{tabular}

Fonte: Elaborado pela autora.

$\mathrm{O}$ alfa de Cronbach foi acima do exigido de 0,7 para todas as dimensões, e as correlações entre as dimensões foi moderada, indicando que a estrutura de quatro fatores é adequada.

\section{4}

\section{Avaliação do modelo de mensuração}

Nesta seção é abordada a avaliação do modelo de mensuração por meio do Alpha de Cronbach, confiabilidade composta, validade convergente, e validade discriminante. Tais dados foram obtidos por meio de PLS Algoritmo, conforme disposto na página 59.

Segundo Hair et al. (2017, p. 121) a avaliação do modelo de mensuração reflexivos deve ser realizada por meio de diversas análises, conforme Quadro 7. 


\begin{tabular}{|l|l|}
\hline \multirow{2}{*}{ Consistência interna } & Alpha de Cronbach \\
\cline { 2 - 2 } & Confiabilidade Composta \\
\hline \multirow{2}{*}{ Validade convergente } & Variância Média Extraída-AVE \\
\cline { 2 - 2 } & Confiabilidade/significância do indicador \\
\hline \multirow{2}{*}{ Validade discriminante } & Critério de Fornell e Lacker \\
\cline { 2 - 2 } & Cargas fatoriais cruzadas \\
\hline
\end{tabular}

Quadro 7 - Avaliação do modelo de mensuração

Fonte: Elaborado pela autora.

A validade convergente do modelo foi mensurada por meio da variância média extraída (average variance extracted - AVE) e pela confiabilidade do indicador. A validade discriminante foi medida por meio do critério de Fornell e Larcker (Fornell \& Larcker, 1981) e cargas fatoriais cruzadas. Além disso, o modelo foi avaliado por meio de significância, bem como, por meio do coeficiente de determinação $\mathrm{R}^{2}$.

$\mathrm{Na}$ Tabela 9 são apresentados os resultados as análises de validade discriminante pelo critério de Fornell e Larcker, confiabilidade composta e validade convergente no nível das Variáveis Latentes - VL.

Tabela 9 - Validade discriminante, convergente e confiabilidade

\begin{tabular}{lccccc}
\hline & $\begin{array}{c}\text { Empoderamento } \\
\text { Psicológico }\end{array}$ & Engajamento & $\begin{array}{c}\text { Comportamento } \\
\text { Inovador }\end{array}$ & $\begin{array}{c}\text { Liderança } \\
\text { Empreendedora }\end{array}$ & $\begin{array}{c}\text { Liderança } \\
\text { Servidora }\end{array}$ \\
\hline $\begin{array}{l}\text { Empoderamento } \\
\text { Psicológico }\end{array}$ & $\mathbf{0 , 7 3 8}$ & & & & \\
Engajamento & 0,667 & $\mathbf{0 , 8 5 3}$ & & & \\
$\begin{array}{l}\text { Comportamento } \\
\text { Inovador }\end{array}$ & 0,574 & 0,527 & $\mathbf{0 , 8 9 1}$ & & \\
$\begin{array}{l}\text { Liderança } \\
\text { Empreendedora }\end{array}$ & 0,334 & 0,329 & 0,507 & $\mathbf{0 , 8 0 5}$ & \\
$\begin{array}{l}\text { Liderança } \\
\text { Servidora }\end{array}$ & 0,456 & 0,409 & 0,532 & 0,670 & $\mathbf{0 , 7 2 2}$ \\
\hline $\begin{array}{l}\text { Confiabilidade } \\
\text { Composta }>>0,7)\end{array}$ & 0,826 & 0,960 & 0,885 & 0,936 & 0,883 \\
$\begin{array}{l}\text { Variância Média } \\
\text { Extraída (>0,5) }\end{array}$ & 0,545 & 0,727 & 0,793 & 0,648 & 0,521 \\
$\begin{array}{l}\text { Alpha de } \\
\text { Cronbach (>0,70) }\end{array}$ & 0,727 & 0,953 & 0,740 & 0,923 & 0,848 \\
\hline
\end{tabular}

Fonte: Elaborado pelos autora. 
Segundo Chin (1998), em estudos que aplicam modelagem de equações estruturais recomenda-se que a confiabilidade do construto seja avaliada não só por meio do Alfa de Cronbach, que deve ser maior do que 0,70, mas também, por meio da confiabilidade composta, de mesmo valor. Desse modo, a partir dos valores de confiabilidade composta e de Alfa de Cronbach da Tabela 9, verifica-se que os valores relacionados a todos os construtos do estudo estão acima dos valores mínimos exigidos de 0,7 , e há, portanto, confiabilidade na mensuração dos construtos.

Além disso, em termos de validade convergente evidencia-se que os valores da variância média extraída dos construtos estão acima valor mínimo exigido de 0,50, o que demonstra a presença de validade convergente do modelo.

A análise discriminante foi avaliada por dois critérios: critério de Fornell e Larcker e cargas cruzadas. O critério de Fornell e Larcker (1981) compara a raiz quadrada dos valores de Variância Média Extraída - AVE de cada construto, com as correlações de outras variáveis latentes, de modo que a validade discriminante é confirmada quando a raiz quadrada do construto é mais elevada do que as correlações de quaisquer outros construtos (Fornell \& Larcker, 1981; Hair et al., 2017).

Desse modo, valores na diagonal (hachurados) da Tabela 9 representam a raiz quadrada da variância média extraída, e considerando que são maiores do que as correlações entre as variáveis latentes (valores fora da diagonal), é possível depreender que o modelo apresenta validade discriminante pelo critério de Fornell e Larcker (1981). As cargas fatoriais cruzadas também foram investigadas, e seguem apresentadas na Tabela 10. As cargas fatoriais são significativas em $\alpha=$ 0,001\% o que atua como evidência de validade convergente (Bido et al., 2011).

Para verificar a validade discriminante no nível dos indicadores, a carga de um indicador dentro do construto deve ser mais alta do que as cargas em outros construtos (Chin, 1998). Neste estudo, as cargas cruzadas dos itens (hachuradas) apresentaram valores maiores dentro de suas respectivas variáveis latentes do que em outras. 
Tabela 10 - Cargas cruzadas

\begin{tabular}{|c|c|c|c|c|c|c|}
\hline Itens & $\begin{array}{l}\text { Empoderamento } \\
\text { Psicológico }\end{array}$ & Engajamento & $\begin{array}{c}\text { Comportamento } \\
\text { Inovador }\end{array}$ & $\begin{array}{c}\text { Liderança } \\
\text { Empreendedora }\end{array}$ & $\begin{array}{l}\text { Liderança } \\
\text { Servidora }\end{array}$ & Marcador \\
\hline EPS1 & 0,747 & 0,740 & 0,492 & 0,297 & 0,333 & 0,238 \\
\hline EPS2 & 0,640 & 0,352 & 0,254 & 0,093 & 0,098 & 0,310 \\
\hline EPS3 & 0,806 & 0,438 & 0,459 & 0,313 & 0,501 & 0,223 \\
\hline EPS4 & 0,750 & 0,392 & 0,435 & 0,215 & 0,303 & 0,086 \\
\hline ENG1 & 0,617 & 0,873 & 0,442 & 0,234 & 0,390 & 0,175 \\
\hline ENG2 & 0,552 & $\mathbf{0 , 8 8 4}$ & 0,422 & 0,210 & 0,300 & 0,154 \\
\hline ENG3 & 0,597 & 0,907 & 0,456 & 0,376 & 0,412 & 0,170 \\
\hline ENG4 & 0,579 & $\mathbf{0 , 8 8 8}$ & 0,514 & 0,326 & 0,350 & 0,196 \\
\hline ENG5 & 0,506 & $\mathbf{0 , 8 2 7}$ & 0,415 & 0,280 & 0,355 & 0,146 \\
\hline ENG6 & 0,524 & 0,766 & 0,405 & 0,276 & 0,373 & 0,165 \\
\hline ENG7 & 0,615 & 0,870 & 0,490 & 0,242 & 0,311 & 0,187 \\
\hline ENG8 & 0,527 & 0,768 & 0,419 & 0,227 & 0,283 & 0,065 \\
\hline ENG9 & 0,592 & 0,878 & 0,463 & 0,320 & 0,356 & 0,250 \\
\hline CIN1 & 0,548 & 0,509 & 0,904 & 0,473 & 0,549 & 0,016 \\
\hline CIN2 & 0,472 & 0,425 & 0,877 & 0,429 & 0,390 & $-0,024$ \\
\hline LEM1 & 0,116 & 0,113 & 0,334 & 0,758 & 0,396 & 0,024 \\
\hline LEM2 & 0,130 & 0,139 & 0,370 & 0,738 & 0,421 & $-0,006$ \\
\hline LEM3 & 0,193 & 0,190 & 0,370 & $\mathbf{0 , 7 7 7}$ & 0,507 & 0,022 \\
\hline LEM4 & 0,261 & 0,280 & 0,371 & $\mathbf{0 , 8 3 4}$ & 0,607 & 0,088 \\
\hline LEM5 & 0,363 & 0,356 & 0,475 & 0,796 & 0,624 & 0,094 \\
\hline LEM6 & 0,321 & 0,328 & 0,363 & $\mathbf{0 , 8 2 5}$ & 0,571 & 0,041 \\
\hline LEM7 & 0,376 & 0,354 & 0,494 & 0,863 & 0,572 & 0,105 \\
\hline LEM8 & 0,269 & 0,242 & 0,432 & 0,840 & 0,543 & 0,017 \\
\hline LSE1 & 0,176 & 0,209 & 0,304 & 0,479 & 0,606 & $-0,010$ \\
\hline LSE2 & 0,344 & 0,297 & 0,403 & 0,642 & 0,799 & 0,100 \\
\hline LSE3 & 0,280 & 0,292 & 0,380 & 0,474 & 0,756 & $-0,068$ \\
\hline LSE4 & 0,264 & 0,355 & 0,379 & 0,553 & 0,707 & 0,111 \\
\hline LSE5 & 0,342 & 0,266 & 0,374 & 0,391 & 0,729 & $-0,031$ \\
\hline LSE6 & 0,529 & 0,361 & 0,507 & 0,461 & 0,786 & 0,083 \\
\hline LSE7 & 0,215 & 0,249 & 0,251 & 0,414 & 0,649 & $-0,050$ \\
\hline MAR1 & 0,127 & 0,069 & $-0,013$ & $-0,063$ & $-0,100$ & 0,448 \\
\hline MAR2 & 0,027 & 0,083 & $-0,075$ & $-0,124$ & $-0,081$ & 0,306 \\
\hline MAR3 & 0,112 & 0,094 & $-0,052$ & $-0,090$ & 0,000 & 0,534 \\
\hline MAR4 & 0,099 & 0,054 & $-0,149$ & $-0,078$ & $-0,095$ & 0,565 \\
\hline MAR5 & 0,196 & 0,113 & $-0,002$ & 0,037 & $-0,002$ & 0,724 \\
\hline MAR6 & 0,263 & 0,159 & 0,043 & 0,159 & 0,141 & 0,739 \\
\hline MAR7 & 0,086 & 0,163 & 0,030 & 0,055 & 0,020 & 0,511 \\
\hline MAR8 & $-0,021$ & $-0,006$ & $-0,060$ & $-0,087$ & 0,064 & 0,272 \\
\hline
\end{tabular}

Nota: EPS: Empoderamento Psicológico; ENG: Engajamento; CIN: Comportamento Inovador; LEM: Liderança Empreendedora; LSE: Liderança Servidora; MAR: variável marcadora.

Fonte: Elaborado pela autora. 


\section{5 Teste de correlação}

A Tabela 11 apresenta o teste de correlação entre as variáveis. Diante dela, depreende-se que o comportamento inovador está positivamente correlacionado com empoderamento psicológico, engajamento, liderança empreendedora, e liderança servidora. Em contrapartida, comportamento inovador está negativamente correlacionado ao tempo de organização, o que significa dizer que quanto menor a estabilidade na organização, maiores os níveis de comportamento inovador no trabalho.

Importante salientar que liderança empreendedora e liderança servidora apresentam uma correlação que pode ser considerada elevada $(0,669)$, o que instiga a realização de estudos com vistas a analisar o grau de diferenciação desses tipos de liderança no setor público.

A liderança servidora está negativamente correlacionada à formação acadêmica, tempo na organização e idade dos liderados, ou seja, quanto mais velho, estável ou instruído é o liderado, mais rigoroso ele foi no julgamento sobre o comportamento servidor do seu líder.

A idade está positivamente relacionada à formação acadêmica e empoderamento psicológico. Em outras palavras, quanto maior a idade, maior o nível de escolaridade e maior o empoderamento psicológico relatado.

A correlação negativa entre liderança servidora e tempo na organização parece fazer sentido do ponto de vista da dinâmica do setor público na medida em que, quanto maior o tempo que os funcionários permanecem na organização, maior a percepção de que seu líder é servidor, ou seja, mais preocupado com o bem dos indivíduos e da coletividade, característica distintiva de funcionários públicos (Shim \& Park, 2019).

Os resultados das correlações sugerem que as variáveis latentes do estudo estão todas correlacionadas entre si, e apresentam, além disso, correlações com as variáveis de controle, com exceção da variável gênero dos respondentes, que não se correlacionou com nenhuma outra presente neste estudo. 
Tabela 11 - Correlação de Pearson entre as variáveis latentes

\begin{tabular}{|c|c|c|c|c|c|c|c|c|c|}
\hline Variáveis & $\begin{array}{l}\text { Empoderamento } \\
\text { Psicológico }\end{array}$ & Engajamento & $\begin{array}{l}\text { Comportamento } \\
\text { Inovador }\end{array}$ & $\begin{array}{c}\text { Liderança } \\
\text { Empreendedora }\end{array}$ & $\begin{array}{l}\text { Liderança } \\
\text { Servidora }\end{array}$ & Formação & Idade & Gênero & $\begin{array}{c}\text { Tempo na } \\
\text { organização }\end{array}$ \\
\hline 1 Empoderamento Psicológico & 1 & & & & & & & & \\
\hline 2 Engajamento & $0,67 * * *$ & 1 & & & & & & & \\
\hline 3 Comportamento Inovador & $0,57 * * *$ & $0,53 * * *$ & 1 & & & & & & \\
\hline 4 Liderança Empreendedora & $0,33 * * *$ & $0,33 * * *$ & $0,51 * * *$ & 1 & & & & & \\
\hline 5 Liderança Servidora & $0,46 * * *$ & $0,41 * * *$ & $0,53 * * *$ & $0,67 * * *$ & 1 & & & & \\
\hline 6 Formação & 0,13 & $-0,06$ & $-0,04$ & $-0,11$ & $-0,17 * *$ & 1 & & & \\
\hline 7 Idade & $0,14 *$ & 0,10 & 0,01 & $-0,01$ & $-0,14^{*}$ & $0,36 * * *$ & 1 & & \\
\hline 8 Gênero & 0,01 & $-0,02$ & $-0,03$ & $-0,10$ & $-0,04$ & 0,04 & $-0,06$ & 1 & \\
\hline 9 Tempo na organização & 0,03 & $-0,07$ & $-0,14 *$ & $-0,09$ & $-0,18^{* *}$ & 0,34 & $0,67 * * *$ & 0,02 & 1 \\
\hline Média & 5,19 & 5,47 & 4,94 & 4,92 & 2,81 & 40,58 & 0,47 & 10,77 & 4,12 \\
\hline Desvio-padrão & 0,97 & 1,16 & 1,18 & 1,23 & 1,14 & 0,70 & 10,79 & 0,50 & 9,05 \\
\hline
\end{tabular}

Nota: $* \mathrm{p}<0.05, * * \mathrm{p}<0.01, * * * \mathrm{p}<0.001$.

Fonte: Elaborado pela autora. 


\section{6}

\section{Avaliação do viés do método comum}

O viés do método comum é conhecido no campo de estudos internacional como "common method bias" ou ainda, como "common method variance" (Williams et al., 2010). O referido viés relaciona-se à ocorrência de uma correlação espúria entre indicadores ou construtos atribuída à forma comum de coleta de dados (Podsakoff et al., 2003).

Considerando que a variância do método comum, entendida como a variância atribuível ao método de mensuração e não aos construtos que as medidas por si representam, é causa de problemas para a pesquisa comportamental, procurou-se mitigar e controlar tais efeitos com o uso de variáveis marcadoras, conforme lecionado por Williams et al. (2010). As variáveis marcadoras são variáveis que não estão relacionadas teoricamente a variáveis substantivas, e diante disso, espera-se que sua correlação com variáveis substantivas seja nula (Williams et al., 2010).

Nesse sentido, foi aplicada a técnica de variável marcadora (Williams et al., 2010) com vistas a controlar os efeitos do viés do método comum, nos permitindo extrair, em última instância, coeficientes estruturais não enviesados pelo método.

\section{7}

\section{Avaliação do modelo estrutural}

O modelo estrutural será avaliado por meio de três modelos distintos, conforme Quadro 8. Cumpre salientar que o terceiro modelo representa o modelo final a ser repercutido neste estudo.

\begin{tabular}{ll}
\hline Etapas & Preditores \\
\hline Modelo 1 & $\begin{array}{l}\text { Inclusão de variáveis sociodemográficas e variável dependente comportamento } \\
\text { inovador no trabalho }\end{array}$ \\
Modelo 2 & $\begin{array}{l}\text { Inclusão de variáveis sociodemográficas e todas as variáveis substantivas do } \\
\text { estudo }\end{array}$ \\
Modelo 3 & $\begin{array}{l}\text { Inclusão de variáveis sociodemográficas, variáveis substantivas do estudo e } \\
\text { variáveis marcadoras para controle e remoção do viés do método comum }\end{array}$
\end{tabular}

Quadro 8 - Modelos do estudo

Fonte: Elaborado pela autora. 
A apresentação dos dados por meio desses três modelos permitirá observar a mudança dos betas e p-valores antes e após a inclusão das variáveis marcadoras.

A avaliação do modelo estrutural foi calculada por meio do bootstrapping, conforme relatado na página 59. Com isso, evidenciaram-se os coeficientes de determinação $\mathrm{R}^{2}$, significâncias das relações diretas, e indiretas entre as variáveis latentes e de controle, conforme Tabela 12, e Figuras 18 e 19.

Em primeiro lugar, foram examinados problemas de colinearidade no modelo estrutural. Tal análise deve revelar se os valores dos fatores de inflação de variância, do inglês variance inflation fator (VIF) dos conjuntos de construtos preditores no modelo estrutural possuem valor menor do que o limite de 5, para, desse modo, não haver problemas de colinearidade (Hair et al., 2017).

O segundo passo na análise foi avaliar a significância das relações hipotetizadas por meio de p-valores dos coeficientes de caminho/betas das regressões. Some-se a isso, que além de efeitos diretos de um construto sobre outro, foram avaliados efeitos indiretos (mediação) (Hair et al., 2017).

O terceiro passo envolveu a análise do coeficiente de determinação $\mathrm{R}^{2}$, variando de 0 a 1 , que representa "os efeitos combinados das variáveis latentes exógenas na variável latente endógena" (Hair et al., 2017, p. 174), ou, em outras palavras, o $\mathrm{R}^{2}$ revela a quantidade de variância da variável 'dependente' explicada pelas variáveis 'independentes' ligadas a ela. O coeficiente de determinação, em especial nas ciências sociais, tem a seguinte configuração: $\mathrm{R}^{2}$ pequeno $=2 \% \mathrm{ou}$ 0,$02 ; \mathrm{R}^{2}$ médio $=13 \%$ ou 0,$13 ; \mathrm{R}^{2}$ grande $=26 \%$ ou 0,26 (Cohen, 1988$)$.

Nas sessões a seguir, com base nas informações presentes na Tabela 12, avalia-se o modelo estrutural de cada estudo. 
Tabela 12 - Modelos estruturais preditores do comportamento inovador

\begin{tabular}{|c|c|c|c|c|c|c|c|}
\hline & \multicolumn{2}{|c|}{ Modelo 1} & \multicolumn{2}{|c|}{ Modelo 2} & \multicolumn{2}{|c|}{ Modelo 3} & \multirow{2}{*}{$\begin{array}{c}\text { Dif. } \\
\beta 2-\beta 3\end{array}$} \\
\hline & $\beta$ & p-valor & $\beta$ & p-valor & $\beta$ & p-valor & \\
\hline \multicolumn{8}{|l|}{ Efeitos Diretos } \\
\hline Formação & $-0,01$ & 0,946 & 0,01 & 0,909 & 0,00 & 0,980 & $-0,01$ \\
\hline Gênero & $-0,05$ & 0,739 & 0,01 & 0,902 & $-0,01$ & 0,920 & $-0,02$ \\
\hline Idade & 0,18 & 0,211 & 0,05 & 0,590 & 0,06 & 0,551 & 0,01 \\
\hline Tempo na organização & $-0,30 * *$ & 0,011 & $-0,13$ & 0,199 & $-0,12$ & 0,228 & 0,01 \\
\hline Empoderamento Psicológico -> Comportamento Inovador & & & $0,32 * * *$ & 0,001 & $0,36^{* * *}$ & 0,000 & 0,04 \\
\hline Engajamento -> Comportamento Inovador & & & $0,17^{\dagger}$ & 0,097 & $0,17^{\dagger}$ & 0,076 & 0,00 \\
\hline Liderança Empreendedora -> Engajamento & & & $0,33 * * *$ & 0,000 & $0,32 * * *$ & 0,000 & $-0,01$ \\
\hline Liderança Empreendedora -> Comportamento Inovador & & & $0,24 * *$ & 0,002 & $0,25 * *$ & 0,002 & 0,01 \\
\hline Liderança Servidora -> Empoderamento Psicológico & & & $0,46^{* * *}$ & 0,000 & $0,45^{* * *}$ & 0,000 & $-0,01$ \\
\hline Liderança Servidora -> Comportamento Inovador & & & 0,14 & 0,154 & 0,13 & 0,222 & $-0,01$ \\
\hline Marcador -> Empoderamento Psicológico & & & & & $0,26^{\dagger}$ & 0,094 & \\
\hline Marcador ->Engajamento & & & & & 0,18 & 0,161 & \\
\hline Marcador -> Comportamento Inovador & & & & & $-0,15^{\dagger}$ & 0,078 & \\
\hline Marcador $->$ Liderança Empreendedora & & & & & 0,07 & 0,769 & \\
\hline Marcador -> Liderança Servidora & & & & & 0,04 & 0,843 & \\
\hline \multicolumn{8}{|l|}{ Efeitos Indiretos } \\
\hline Liderança Empreendedora -> Engajamento -> Comp. Inovador & & & 0,054 & 0,122 & $0,055^{\dagger}$ & 0,099 & 0,003 \\
\hline Liderança Servidora->Empoderamento Psicológico-> Comp. Inovador & & & $0,147 * *$ & 0,005 & $0,160 * *$ & 0,003 & 0,018 \\
\hline $\mathrm{R}^{2}$ & \multicolumn{2}{|c|}{0,06} & \multicolumn{2}{|c|}{$0,487 * * *$} & \multicolumn{2}{|c|}{$0,506^{* * *}$} & \\
\hline $\mathrm{R}^{2}$ ajustado & \multicolumn{2}{|c|}{0,03} & \multicolumn{2}{|c|}{$0,454 * * *$} & \multicolumn{2}{|c|}{$0,471 * * *$} & \\
\hline
\end{tabular}

Nota: $\uparrow \mathrm{p}<0,1, * \mathrm{p}<0,05, * * \mathrm{p}<0,01, * * * \mathrm{p}<0,001$. Dif $\beta 2$ - $\beta 3$ : diferença nos coeficientes estruturais entre os modelos 2 e 3 atribuída ao viés do método comum.

Fonte: Elaborado pela autora 


\subsection{1}

\section{Avaliação do Modelo 1}

Em relação aos resultados dos modelos estruturais relacionados ao comportamento inovador no trabalho, o Modelo 1 traz as variáveis de controle de cunho demográfico, dentre as quais, apenas a variável 'Tempo na organização' mostrou significância estatística $(\beta=-0,30 p<0,05)$.

\subsection{2}

\section{Avaliação do Modelo 2}

O Modelo 2, além de conter as variáveis de controle da etapa anterior, apresenta a inclusão de todos os preditores relacionados às variáveis latentes substantivas. Em outras palavras, o referido modelo representa o modelo conceitual do estudo, sem a presença das variáveis marcadoras para controle do viés do método comum, pois estas ingressarão apenas no Modelo 3.

Todos os valores de VIF encontram-se situados abaixo do limite máximo de 5, o que significa que não há problemas de colinearidade (Hair et al., 2017). A Figura 18 contém os valores dos coeficientes de caminho $(\beta)$ e os p-valores a eles associados.

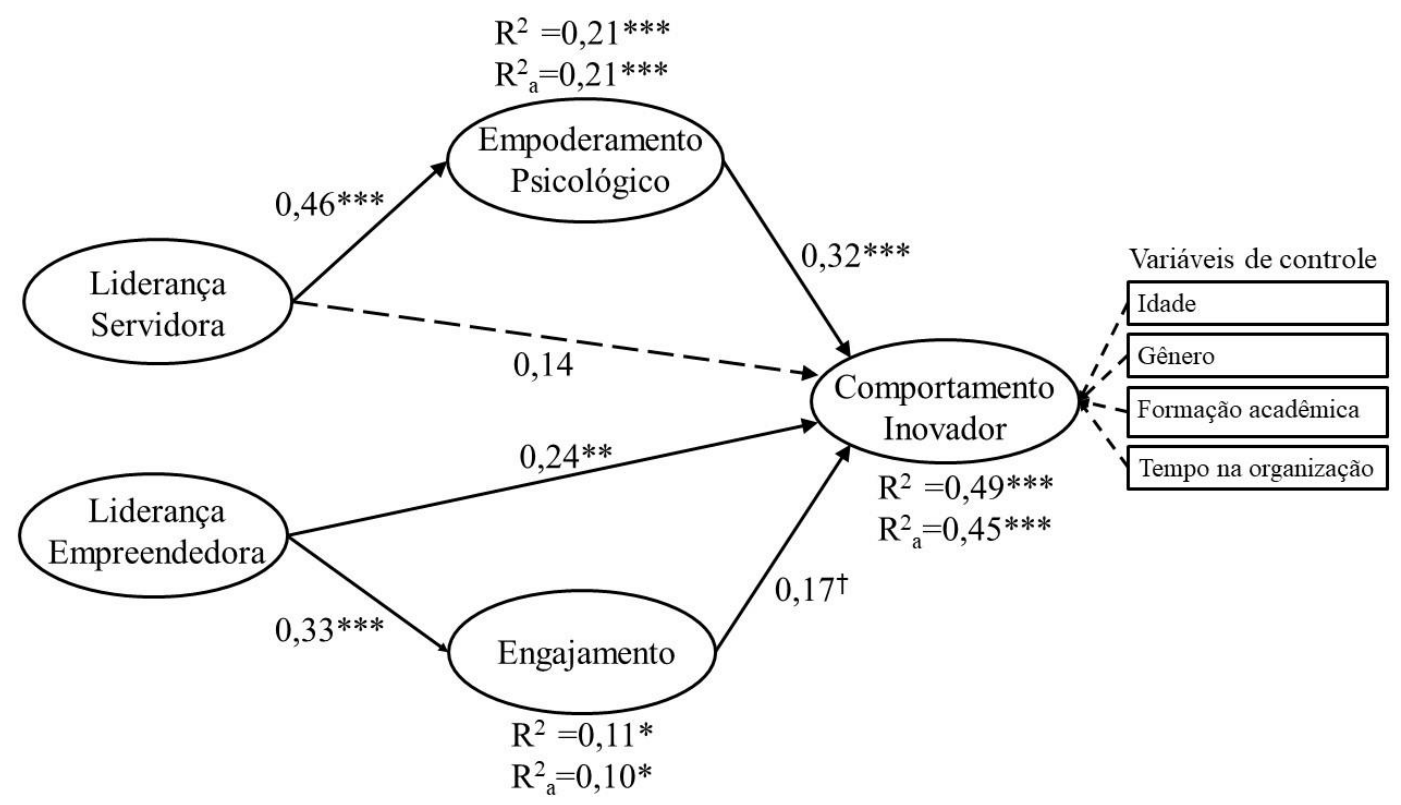

Figura 18 - Resultados estruturais do Modelo 2

Fonte: Elaborado pelos autora. 
Somado a isso, o exame das significâncias do Modelo 2 presentes na Tabela 12 mostra que a relação entre liderança servidora e comportamento inovador no trabalho $(\beta=0,14, p>0,05$ não possui significância estatística nesta associação, e, portanto, a hipótese $\mathrm{H} 1$ não foi suportada, conforme sumário das hipóteses do Modelo 2 presente no Quadro 9. Em outras palavras, neste modelo, não há efeito direto da liderança servidora no comportamento inovador no trabalho, mas há um efeito indireto, mediado pelo empoderamento psicológico que será discutido adiante.

Já a avaliação das relações entre liderança servidora e empoderamento psicológico revela que a liderança servidora está positivamente associada ao empoderamento psicológico $(\beta=0,46, \mathrm{p}<0,001)$, e desse modo, a hipótese $\mathrm{H} 2$ foi suportada.

Da mesma maneira, a hipótese H3 foi suportada, já que o empoderamento psicológico está positivamente associado ao comportamento inovador no trabalho $(\beta=0,32, \mathrm{p}<0,001)$.

Em relação à hipótese $\mathrm{H} 4$, evidencia-se que o empoderamento psicológico estabelece papel mediador entre liderança servidora e o comportamento inovador no trabalho $\left(\beta_{\text {LID_SERV, EMP_PSIC }} * \beta_{\text {EMP_PSIC, COMP_INOV }}=0,147, \mathrm{p}<0,01\right)$, o que que torna essa hipótese aceita. Além disso, pode-se dizer que há mediação total da relação entre liderança servidora e comportamento inovador no trabalho via empoderamento psicológico, haja vista que a relação direta entre liderança servidora e comportamento inovador no trabalho não foi significativa, conforme constatado na $\mathrm{H} 1$.

A hipótese H5, que postula que a liderança empreendedora está positivamente associada ao comportamento inovador no trabalho foi aceita, e constatou-se um efeito direto significativo entre essas variáveis $(\beta=0,24, p<0,01)$.

No que concerne à hipótese H6, constata-se que há efeito positivo da liderança empreendedora no engajamento $(\beta=0,33, \mathrm{p}<0,001)$, e assim, esta hipótese foi suportada.

Além disso, foram encontradas evidências de que o engajamento está positivamente associado ao comportamento inovador no trabalho $(\beta=0,17, \mathrm{p}<$ 0,1), e, portanto, a hipótese $\mathrm{H} 7$ foi aceita. Cumpre salientar que nesse caso, considerou-se $\alpha=0,1$. 
Por fim, a hipótese H8 que versa sobre a mediação do engajamento na relação entre liderança empreendedora e comportamento inovador no trabalho não foi suportada ( $\left.\beta_{\text {LID_EMPR, ENGAJ }} * \beta_{\text {ENGAJ, COMP_INOV }}=0,054, p>0,05\right)$.

No Modelo 2, a variável de controle 'tempo na organização' perdeu poder de explicação e não apresentou significância estatística.

\begin{tabular}{|c|c|c|}
\hline Hipótese & Descrição & Situação \\
\hline $\mathrm{H} 1$ & $\begin{array}{l}\text { A liderança servidora está positivamente associada ao } \\
\text { comportamento inovador no trabalho. }\end{array}$ & Não suportada \\
\hline $\mathrm{H} 2$ & $\begin{array}{l}\text { A liderança servidora está positivamente associada ao } \\
\text { empoderamento psicológico. }\end{array}$ & Suportada \\
\hline H3 & $\begin{array}{l}\text { O empoderamento psicológico está positivamente associado ao } \\
\text { comportamento inovador no trabalho. }\end{array}$ & Suportada \\
\hline $\mathrm{H} 4$ & $\begin{array}{l}\text { O empoderamento psicológico mediará a relação entre liderança } \\
\text { servidora e comportamento inovador no trabalho. }\end{array}$ & Suportada \\
\hline H5 & $\begin{array}{l}\text { A liderança empreendedora está positivamente associada ao } \\
\text { comportamento inovador no trabalho. }\end{array}$ & Suportada \\
\hline H6 & $\begin{array}{l}\text { A liderança empreendedora está positivamente associada ao } \\
\text { engajamento. }\end{array}$ & Suportada \\
\hline $\mathrm{H} 7$ & $\begin{array}{l}\text { O engajamento está positivamente associado ao comportamento } \\
\text { inovador. }\end{array}$ & Suportada \\
\hline $\mathrm{H} 8$ & $\begin{array}{l}\text { O engajamento mediará a relação entre liderança empreendedora e } \\
\text { comportamento inovador no trabalho. }\end{array}$ & Não suportada \\
\hline
\end{tabular}

Quadro 9 - Sumarização das hipóteses - Modelo 2

Fonte: Elaborado pela autora.

O terceiro passo da análise do Modelo 2 envolve o exame do coeficiente de determinação $\mathrm{R}^{2}$. Nesse sentido, o modelo proposto foi capaz de explicar parcela importante da variável endógena 'comportamento inovador no trabalho' $\left(R^{2}=0,49\right.$, $\mathrm{p}<0,001)$. $\mathrm{O}$ valor de $\mathrm{R}^{2}=0,49$ indica que o modelo tem um grande poder de explicação, já que está acima de 0,26 conforme ensina Cohen (1988).

$\mathrm{O}$ valor $\mathrm{R}^{2}$ dos mediadores (empoderamento psicológico e engajamento) presentes na Figura 18 foram significativos em $\alpha=0,05$. Especificamente em relação ao mediador empoderamento psicológico, o coeficiente de determinação tem um poder médio de explicação $\left(\mathrm{R}^{2}=0,21, \mathrm{p}<0,001\right)$. Já no que concerne ao 
mediador engajamento, o coeficiente de determinação tem um poder pequeno de explicação $\left(\mathrm{R}^{2}=0,11, \mathrm{p}<0,05\right)$.

De modo geral, todos os coeficientes de caminho significativos estão acima de 0,25 , e apenas um está abaixo de 0,20. Os resultados, em conjunto, sugerem que o desempenho geral de previsão do modelo é adequado, embora apenas 6 hipóteses tenham sido confirmadas, dentre as 8 hipóteses propostas.

\subsection{3}

\section{Avaliação do Modelo 3}

Embora os resultados do Modelo 2 sejam sugestivos de um modelo adequado, considerando os efeitos problemáticos do viés do método comum nas ciências comportamentais (Podsakoff et al., 2003), optou-se pela inclusão de variáveis marcadoras com o intuito de estimar e remover o efeito da variação devido ao método. Para tanto, foi aplicada a técnica de variável marcadora proposta por Williams et al. (2010). Diante disso, foram obtidos os coeficientes estruturais padronizados livres do viés do método comum, conforme Figura 19.

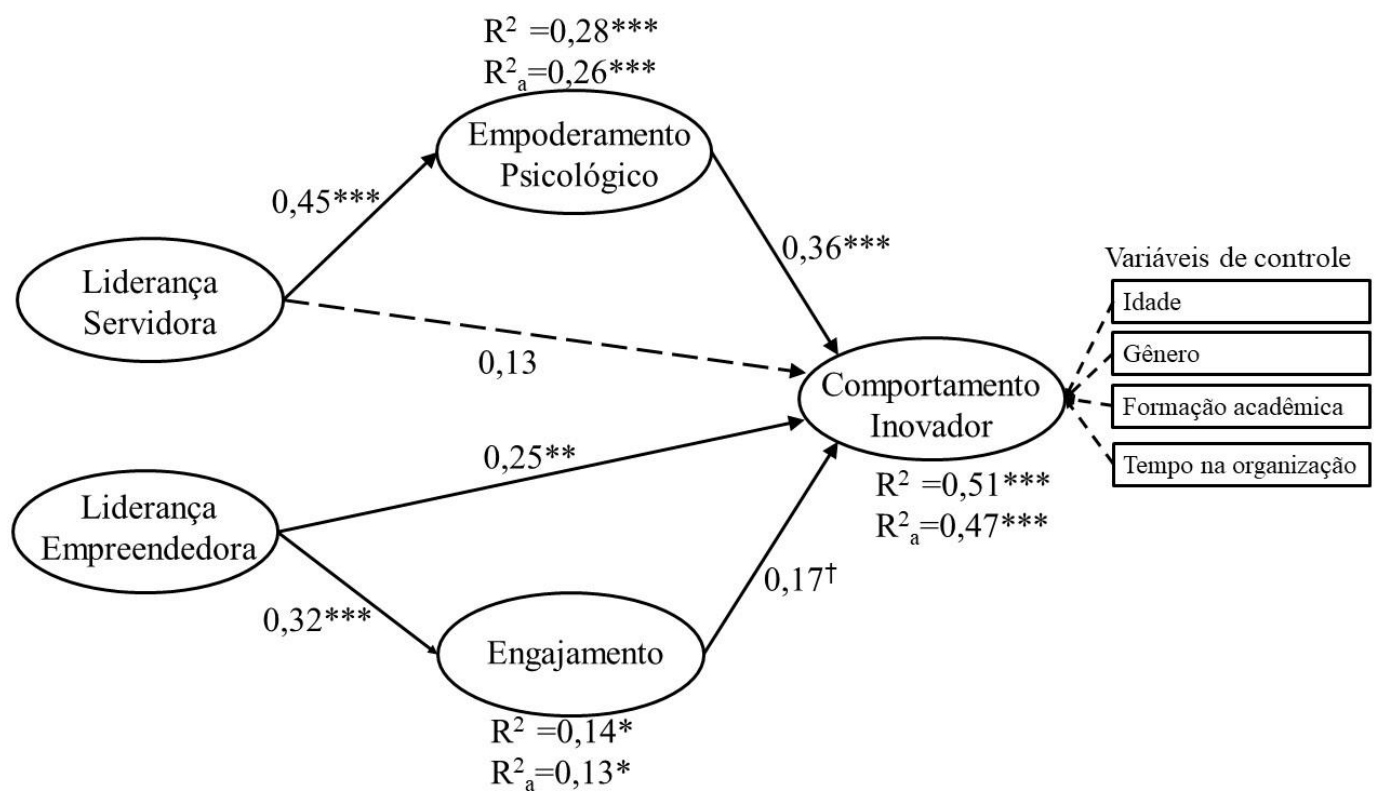

Figura 19 - Resultados estruturais do Modelo 3

Fonte: Elaborado pela autora.

Primeiramente, é possível perceber que a inclusão das variáveis marcadoras melhorou os valores dos coeficientes de caminho $(\beta)$, valores de $\mathrm{R}^{2}$, e $\mathrm{p}$-valores. Com isso, foi possível aceitar um total de 7 hipóteses, dentre as 8 hipóteses 
elencadas. A inclusão das variáveis marcadoras foi capaz de remover efeitos indesejáveis relacionados ao viés do método comum que estavam presentes no Modelo 2.

Os valores de VIF das variáveis substantivas e marcadoras presentes no Modelo 3 estão bastante abaixo do limite máximo de 5, e portanto, não há colinearidade (Hair et al., 2017).

No que concerne ao exame das significâncias das relações, conforme dados da Tabela 12, não há associação significativa direta entre liderança servidora e comportamento inovador no trabalho $(\beta=0,13, \mathrm{p}>0,05)$, e assim, a hipótese H1 permanece não aceita. Todavia, há uma relação indireta entre as variáveis a ser discutida na hipótese 4 .

A associação entre liderança servidora e empoderamento psicológico permanece significativa no modelo atual, $(\beta=0,45, \mathrm{p}<0,001)$, e dessa maneira, a hipótese $\mathrm{H} 2$ é suportada.

O mesmo acontece com a hipótese $\mathrm{H} 3$, segundo a qual o empoderamento psicológico está positivamente associado ao comportamento inovador no trabalho $(\beta=0,36, p<0,001)$. Em relação ao modelo anterior, no Modelo 3 houve incremento importante neste coeficiente estrutural, cujo $\beta$ passou de 0,32 para 0,36.

A hipótese $\mathrm{H} 4$, que trata da mediação do empoderamento psicológico no relacionamento entre liderança servidora e comportamento inovador no trabalho também permanece suportada no modelo atual ( $\beta_{\text {LID_SERV, EMP_PSIC }} * \beta_{\text {EMP_PSIC, }}$ COMP_INOV $=0,160, p<0,01)$, com melhoria dos valores de $\beta$ e de $p$-valor em relação ao modelo 2. Vale ressaltar que o empoderamento psicológico medeia totalmente a relação entre liderança servidora e comportamento inovador no trabalho, haja vista a inexistência de relação direta entre liderança servidora e comportamento inovador.

No que se refere à hipótese H5, segundo a qual a liderança empreendedora está positivamente associada ao comportamento inovador no trabalho, o relacionamento é significativo $(\beta=0,25, \mathrm{p}<0,01)$. O valor de $\beta$ mudou pouco entre os dois modelos, e o p-valor permaneceu o mesmo.

Já sobre a hipótese H6, evidencia-se relacionamento positivo entre liderança empreendedora e engajamento $(\beta=0,32, \mathrm{p}<0,001)$, e, portanto, a referida hipótese continua aceita. Houve ligeira diminuição deste $\beta$ em relação ao modelo anterior. 
Além do mais, o engajamento parece levar a um maior comportamento inovador no trabalho $(\beta=0,17, \mathrm{p}<0,10)$. Houve melhoria importante no $\mathrm{p}$-valor deste efeito, que passou de 0,97 para 0,076. Dessa maneira, a hipótese 7 permanece aceita, se $\alpha=0,1$.

Por fim, a hipótese H8, segundo a qual o engajamento mediará a relação entre liderança empreendedora e comportamento inovador no trabalho, antes não aceita no modelo 2, passa a apresentar significância estatística em $\alpha=10 \%$ e é suportada no Modelo 3 ( $\beta_{\text {LID_EMPR, ENGAJ }} * \beta_{\text {ENGAJ, COMP_INOv }}=0,055, \mathrm{p}<0,10$ ). O p-valor do efeito indireto desta relação passou de 0,122 no Modelo 2 para 0,099 no Modelo 3. Assim, o engajamento medeia parcialmente a relação entre liderança empreendedora e comportamento inovador no trabalho em $\alpha=10 \%$.

Em geral, um dos ganhos mais importantes da inclusão das variáveis marcadoras no Modelo 3 foi a mudança de p-valor associado ao efeito de mediação do engajamento na relação entre liderança empreendedora e comportamento inovador no trabalho. Com isso, a hipótese H8 que foi rejeitada no Modelo 2, passa a ser aceita no Modelo 3, provavelmente, pela remoção do viés do método comum.

A última coluna da Tabela 12, (Coluna Diferença de $\beta 2$ - $\beta 3$ ), relaciona-se à diferença dos coeficientes estruturais atribuída ao viés do método comum, na qual foram subtraídos os betas da regressão entre os modelos 2 e 3 . Desse modo, uma mudança significativa entre os modelos 2 e 3 foi o aumento do coeficiente de caminho entre 'empoderamento psicológico e comportamento inovador no trabalho', cujo $\beta$ passou de 0,32 para $0,36(\beta 2-\beta 3=0,04)$. A análise das diferenças revela que em geral houve mudança em termos de betas entre os modelos.

No Modelo 3 as variáveis de controle não apresentaram significância estatística. O Quadro 10 sumariza as hipóteses deste modelo.

A etapa subsequente de análise do Modelo 3 refere-se ao exame do coeficiente de determinação $\mathrm{R}^{2}$. O Modelo 3 apresenta $\mathrm{R}^{2}$ de comportamento inovador no trabalho mais elevado em relação ao modelo anterior, que passou de 0,49 para 0,51. Assim, o modelo final proposto, com mediadores, variáveis de controle e variáveis marcadoras foi capaz de explicar fração considerável da variável dependente 'comportamento inovador no trabalho' $\left(\mathrm{R}^{2}=0,51, \mathrm{p}<0,001\right)$, o que é entendido como um grande poder de explicação nas ciências sociais (Cohen, 1988). 


\begin{tabular}{|c|c|c|}
\hline Hipótese & Descrição & Situação \\
\hline $\mathrm{H} 1$ & $\begin{array}{l}\text { A liderança servidora está positivamente associada ao } \\
\text { comportamento inovador no trabalho. }\end{array}$ & Não suportada \\
\hline $\mathrm{H} 2$ & $\begin{array}{l}\text { A liderança servidora está positivamente associada ao } \\
\text { empoderamento psicológico. }\end{array}$ & Suportada \\
\hline $\mathrm{H} 3$ & $\begin{array}{l}\text { O empoderamento psicológico está positivamente associado ao } \\
\text { comportamento inovador no trabalho. }\end{array}$ & Suportada \\
\hline $\mathrm{H} 4$ & $\begin{array}{l}\text { O empoderamento psicológico mediará a relação entre liderança } \\
\text { servidora e comportamento inovador no trabalho. }\end{array}$ & Suportada \\
\hline H5 & $\begin{array}{l}\text { A liderança empreendedora está positivamente associada ao } \\
\text { comportamento inovador no trabalho. }\end{array}$ & Suportada \\
\hline H6 & $\begin{array}{l}\text { A liderança empreendedora está positivamente associada ao } \\
\text { engajamento. }\end{array}$ & Suportada \\
\hline $\mathrm{H} 7$ & $\begin{array}{l}\text { O engajamento está positivamente associado ao comportamento } \\
\text { inovador. }\end{array}$ & Suportada \\
\hline H8 & $\begin{array}{l}\text { O engajamento mediará a relação entre liderança empreendedora e } \\
\text { comportamento inovador no trabalho. }\end{array}$ & Suportada \\
\hline
\end{tabular}

Quadro 10 - Sumarização das hipóteses - Modelo 3

Fonte: Elaborado pela autora.

Os coeficientes de determinação $\mathrm{R}^{2}$ das variáveis mediadoras (empoderamento psicológico e engajamento) aumentaram consideravelmente em relação ao modelo 2, o que demonstra a importância do uso de variáveis marcadoras no controle do viés do método comum (Williams et al., 2010). Desse modo, o coeficiente de determinação do empoderamento psicológico passou de 0,21 para $\mathbf{R}^{2}$ $=0,28(\mathrm{p}<0,001)$, e o de engajamento subiu de 0,11 para $R^{2}=0,14(p<0,05)$.

Nessa esteira, as alterações dos coeficientes de determinação dos dois mediadores os levaram a integrar um novo patamar de efeito, e passaram a apresentar um poder maior de explicação. Em outras palavras, o $R^{2}$ de empoderamento psicológico passou de um efeito médio para um efeito grande, e o de engajamento foi alterado de um efeito pequeno, para um efeito médio.

De maneira geral, o Modelo 3 mostra-se adequado e mais bem ajustado do que o modelo anterior, apresentando elevado poder de explicação do fenômeno do comportamento inovador no setor público. Além disso, o atual modelo suportou a maioria das hipóteses do estudo, alinhando-se à teoria subjacente a este estudo. 


\section{8 \\ Mapa de importância-desempenho}

O mapa de importância-desempenho (importance-performance map analysis / IPMA) é uma análise capaz de enriquecer os resultados da modelagem de equações estruturais à medida que propicia a interpretação gráfica da importância/efeito total do modelo estrutural (soma dos efeitos diretos e indiretos) em um construto-alvo, com as pontuações médias das variáveis latentes explicativas/desempenho das variáveis (Hair et al., 2018, 2019). A Figura 20 evidencia o mapa de importância-desempenho das variáveis deste estudo.

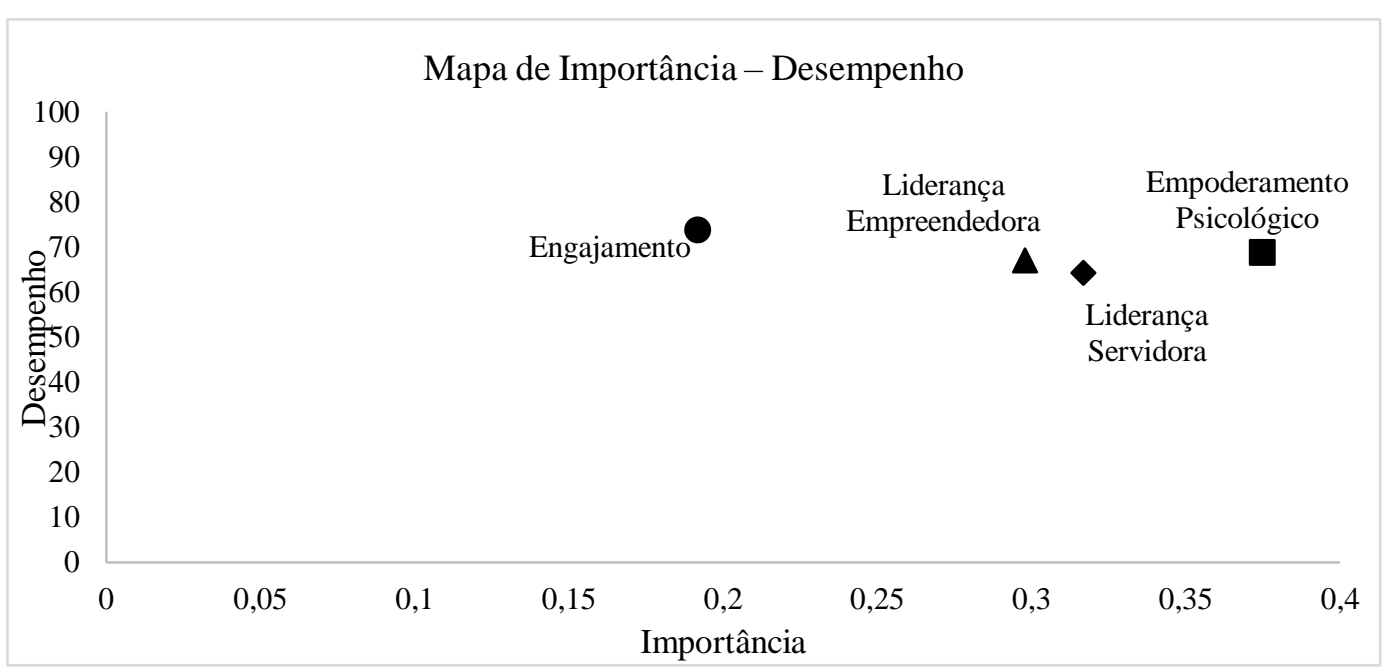

Figura 20 - Mapa de importância-desempenho

Fonte: Elaborado pela autora.

O foco do mapa é identificar variáveis exógenas com alta importância para o construto-alvo (comportamento inovador no trabalho), mas com desempenho relativamente baixo, já que o aperfeiçoamento do desempenho da variável pode engendrar oportunidades de melhoria para a gestão (Hair et al., 2018).

Assim, especialmente do ponto de vista prático, o mapa de importânciadesempenho traz interessantes insights na identificação das áreas mais importantes para a tomada das decisões gerenciais (Ringle \& Sarstedt, 2016). Desse modo, quanto mais baixo é o desempenho, mais substancial é o espaço para melhoria, em especial do ponto de vista gerencial, conforme ensinam Ringle \& Sarstedt (2016).

Em relação à Figura 20, o empoderamento psicológico é particularmente o construto mais importante para fomentar o comportamento inovador no setor público, cuja importância é de 0,37. Especificamente, o aumento de uma unidade 
no desempenho da variável empoderamento psicológico (eixo y: 68,76) aumenta o desempenho do comportamento inovador no trabalho pelo valor do efeito total do empoderamento psicológico (eixo x: 0,37).

A Tabela 13 pormenoriza os valores de importância e desempenho presentes na Figura 20.

Tabela 13 - Valores de importância e desempenho

\begin{tabular}{lcc}
\hline Variáveis exógenas & $\begin{array}{c}\text { Importância } \\
\text { Eixo x }\end{array}$ & $\begin{array}{c}\text { Desempenho } \\
\text { Eixo y }\end{array}$ \\
\hline Empoderamento Psicológico & 0,37 & 68,76 \\
Engajamento & 0,19 & 73,66 \\
Liderança Empreendedora & 0,30 & 67,04 \\
Liderança Servidora & 0,32 & 64,37 \\
\hline Nota: Importância: efeitos totais em relação ao comportamento inovador no trabalho. Desempenho: escores das \\
variáveis latentes.
\end{tabular}

Além disso, a liderança servidora também parece ser uma variável importante para a inovação no setor público. Dado que a liderança servidora tem o menor dos quatro desempenhos, com valor de 64,37, e importância relativamente alta $(0,32)$, este tipo de liderança pode ser priorizado pela gestão para incremento dos níveis de comportamento inovador dos funcionários.

Na seção a seguir, são apresentadas as considerações finais. 


\section{5 \\ Discussão e conclusão}

\section{1 Discussão}

O objetivo do presente estudo foi investigar as associações entre liderança servidora e liderança empreendedora com o comportamento inovador no contexto do serviço público. Além disso, foi avaliado se as relações foram respectivamente mediadas pelo empoderamento psicológico e pelo engajamento.

O modelo de pesquisa foi testado por modelagem de equações estruturais e a maioria das hipóteses foram suportadas.

Em primeiro lugar, os resultados indicam que a liderança servidora está associada a maiores níveis de empoderamento psicológico. Em outros termos, dada a existência do tipo de liderança servidora em maior grau no contexto do serviço público, mais elevado é o nível de empoderamento psicológico.

Destaca-se também que o aumento do empoderamento psicológico nesta amostra está associado a um incremento do comportamento inovador dos funcionários. Dado que o efeito direto entre liderança servidora e comportamento inovador no trabalho não é significativo, a maneira pela qual a liderança servidora gera inovação no contexto do setor público, neste estudo, se dá através da mediação estabelecida pelo empoderamento psicológico. Isso é digno de nota, pois destaca a importância do empoderamento psicológico como fator que leva à maior inovação neste ambiente.

Em outras palavras, a organização dotada de líderes servidores e que favorece o desenvolvimento do empoderamento psicológico dos liderados abre caminho para a criatividade e inovação no trabalho. Como o efeito indireto entre liderança servidora e comportamento inovador é significativo, conclui-se que a liderança servidora promove a inovação por meio do empoderamento psicológico, e assim, todo o efeito se dá através desse mecanismo, nesta amostra. Isso revela a necessidade de fomentar o encontro dos fatores: líder servidor e empoderamento 
psicológico dos funcionários para incremento do comportamento inovador no âmbito do serviço público.

A constatação do efeito indireto entre liderança servidora e comportamento inovador no setor público está em consonância com estudos empíricos realizados em diversos contextos (Karatepe et al., 2020; Khan et al., 2021; Khan, Mubarak, et al., 2020; Su et al., 2020). A literatura não tem investigado sistematicamente essas relações no contexto específico do setor público, e por isso, este estudo traz um novo olhar sobre como o líder servidor pode fomentar a inovação no âmbito do setor público.

Já em relação ao caminho teórico-empírico da exploração de oportunidades empreendedoras, o presente estudo demonstra que os subordinados de indivíduos que são percebidos como líderes empreendedores relatam maior nível de inovação no trabalho. Além disso, evidencia-se que o engajamento pode ser um dos caminhos pelos quais os líderes empreendedores tendem a fomentar o comportamento inovador no setor público. Esses achados encontram assento na literatura corrente, que encontrou efeitos diretos e indiretos (com distintos mediadores) da liderança empreendedora no comportamento inovador em diversos contextos (Bagheri, Newman, et al., 2020; Iqbal, Nazir, et al., 2020; C. Li et al., 2020; S. Malik et al., 2020), inclusive no setor público (Miao et al., 2018).

Essas descobertas não apenas contribuem para a literatura de liderança, mas também lançam luz sobre o que os gestores com comportamentos empreendedores e servidores podem fazer para viabilizar a inovação. Por exemplo, em momentos de mudança organizacional ou de necessidade de criação e de implantação de novas rotinas, processos, produtos ou serviços, os gestores devem estar atentos em como empoderar psicologicamente e engajar os funcionários para que a inovação aconteça. Embora os gestores possam sentir o desejo de criar e implementar ideias por conta própria, um caminho bastante profícuo para a criatividade e a inovação é o envolvimento e empoderamento dos funcionários.

Já em relação ao mapa de importância-desempenho, este evidencia que, do ponto de vista gerencial, parece ser profícuo investir no desenvolvimento do empoderamento psicológico dos funcionários e da liderança servidora para fomento da inovação no setor público, à medida que essas duas variáveis apresentaram maior importância e menor desempenho. 
O mapa de importância-desempenho revela que a liderança servidora é relativamente mais importante para o comportamento inovador no setor público do que a liderança empreendedora. Esse achado contrasta com o encontrado por metaanálise recente (Lee et al., 2020), na qual constata-se que, dentre 13 diferentes tipos de liderança, a liderança empreendedora é um dos preditores mais fortes de comportamento inovador no trabalho. Tal resultado pode dever-se ao fato da presença de características próprias do setor público, na amostra.

Nesse sentido, do ponto de vista de implicações práticas, o desenvolvimento do empoderamento psicológico pode ser alcançado por meio do fomento às suas dimensões conceituais: 1. Autodeterminação: estímulo à autonomia dos funcionários via gestão mais participativa na tomada de decisão, 2. Competência: oferta de cursos de formação (educação formal, como cursos de especialização, mestrado e doutorado) e capacitação (cursos de curta duração e treinamento), programas de mentoria e acompanhamento com foco no desenvolvimento de competências técnicas, transversais e gerenciais; 3 . Significado: a autorrealização e o propósito do trabalho envolvem a oferta de tarefas que encontrem aderência às competências, e para tanto, a política de recursos humanos e a gestão por competências tem papel fundamental; 4. Impacto: a percepção de que o trabalho impacta na organização depende, em grande medida, da autonomia / agência do trabalhador, e por isso, processos de trabalho devem ser dotados de participação.

Além disso, este estudo contribui para a prática de gestão à medida que analisa a influência da liderança servidora e empreendedora no comportamento inovador em ambiente do setor público moderno. Isso é importante porque em um contexto dinâmico e complexo, são requeridos cada vez mais comportamentos organizacionais positivos dos funcionários. Assim, este estuda auxilia na descoberta de mecanismos positivos que endossam e favorecem a inovação.

Do ponto de vista teórico, este estudo contribui com a pesquisa à medida que atende a diversos apelos de Hughes et al. (2018). Em primeiro lugar, este estudo atende ao chamado dos autores, de identificação da criatividade e inovação, no instrumento de levantamento. Isso foi possível porque a aplicação da escala de comportamento inovador foi separada em diferentes seções do questionário, e assim, os itens que estavam relacionados à criatividade (Geração de ideias - 3 itens), foram desagregados daqueles possivelmente vinculados à inovação: Promoção de ideias (3 itens) e Implementação de ideias (3 itens). Tal procedimento pode ter 
propiciado o sucesso do achado da análise fatorial exploratória, que encontrou dois fatores na escala de comportamento inovador no trabalho, aos quais foram denominados como criatividade (geração de ideias) e inovação (promoção e implementação de ideias) e que juntos formam o comportamento inovador no trabalho. Assim, este estudo inova ao construir um modelo parcimonioso com a variável latente 'comportamento inovador' sendo composta pelas duas dimensões encontradas na análise fatorial, já que a variável de interesse não é criatividade ou inovação isoladamente, mas sim, o comportamento inovador como um todo.

Além disso, Hughes et al. (2018), em seu chamado para pesquisas futuras de $\mathrm{n}^{\circ} 20$, salientam a necessidade de mais pesquisas sobre liderança, criatividade e inovação que explorem caminhos de mediação concorrentes (motivacionais versus cognitivos). Logo, do ponto de vista teórico, este estudo avança ao atender ao pedido dos autores, à medida que foram utilizados caminhos de mediação concorrentes: empoderamento psicológico (motivacional) e engajamento (cognitivo).

\section{2 \\ Limitações do estudo e agenda de pesquisa}

Embora este estudo possua uma série de contribuições, também possui limitações. Em primeiro lugar, o viés do método comum, embora controlado, estimado e removido, pode se fazer presente devido ao levantamento de dados por meio de autorrelato, coletado em estudo transversal.

Disso emerge uma agenda de pesquisa relacionada à realização de estudos capazes de avaliar a inovação por métricas objetivas ou via avaliação de superiores, de forma longitudinal. Além disso, permanece a necessidade de inclusão de variáveis psicossociais que sejam capazes de descortinar diferenças individuais capazes de afetar os resultados.

A correlação encontrada entre os dois tipos de liderança (liderança servidora e liderança empreendedora), na ordem de 0,669, pode configurar uma limitação deste estudo, ao acenar para a dificuldade de particularização dos dois tipos de liderança pelos respondentes. Assim, estudos futuros podem analisar o grau de diferenciação desses tipos de liderança no setor público. 
Por fim, estudos futuros podem investigar se a liderança servidora favorece diretamente a inovação no contexto de outras organizações públicas nacionais e internacionais, já que, como constatam Liu et al. (2015), a liderança servidora embora parta de um conceito universalmente ético, varia entre diferentes contextos culturais. 


\section{Referências}

Afsar, B., \& Masood, M. (2018). Transformational Leadership, Creative SelfEfficacy, Trust in Supervisor, Uncertainty Avoidance, and Innovative Work Behavior of Nurses*. Journal of Applied Behavioral Science, 54(1), 36-61.

Agarwal, U. A. (2014). Linking justice, trust and innovative work behaviour to work engagement. Personnel Review, 43(1), 41-73.

Agarwal, U. A., Datta, S., Blake-Beard, S., \& Bhargava, S. (2012). Linking LMX, innovative work behaviour and turnover intentions: The mediating role of work engagement. Career Development International, 17(3), 208-230.

Ahmetoglu, G., Harding, X., Akhtar, R., \& Chamorro-Premuzic, T. (2015). Predictors of Creative Achievement: Assessing the Impact of Entrepreneurial Potential, Perfectionism, and Employee Engagement. Creativity Research Journal, 27(2), 198-205.

Al-Shammari, M. M., \& Khalifa, N. Y. (2019). Transformational leadership and innovative work behavior in an IT department of a public organization in the Kingdom of Bahrain*. International Journal of Human Capital and Information Technology Professionals, 10(3), 20-32.

Al Harbi, J. A., Alarifi, S., \& Mosbah, A. (2019). Transformation leadership and creativity: Effects of employees pyschological empowerment and intrinsic motivation*. Personnel Review, 48(5), 1082-1099.

Ali Chughtai, A. (2016). Can ethical leaders enhance their followers' creativity?*. Leadership, 12(2), 230-249.

Allen, S., Winston, B. E., Tatone, G. R., \& Crowson, H. M. (2018). Exploring a model of servant leadership, empowerment, and commitment in nonprofit organizations. Nonprofit Management and Leadership, 29(1), 123-140.

Amabile, T. M., Conti, R., Coon, H., Lazenby, J., \& Herron, M. (1996). Assessing the work environment for creativity. Academy of Management Journal, 39(5), 1154-1184.

Antonakis, J., \& Day, D. V. (2018). The nature of leadership (Third Edit). SAGE Publications.

Antonakis, J., \& House, R. J. (2014). Instrumental leadership: Measurement and extension of transformational-transactional leadership theory. Leadership Quarterly, 25(4), 746-771.

Anwar, A., Abid, G., \& Waqas, A. (2019). Authentic Leadership and Creativity: Moderated Meditation Model of Resilience and Hope in the Health Sector*. European Journal of Investigation in Health, Psychology and Education, 10(1), 18-29.

Asif, M., Miao, Q., Jameel, A., Manzoor, F., \& Hussain, A. (2020). How ethical leadership influence employee creativity: A parallel multiple mediation model*. Current Psychology.

Asif, M., Qing, M., Hwang, J., \& Shi, H. (2019). Ethical leadership, affective commitment,work engagement, and creativity: Testing a multiple mediation approach*. Sustainability (Switzerland), 11(16). 
Atinc, G., Simmering, M. J., \& Kroll, M. J. (2012). Control variable use and reporting in macro and micro management research. Organizational Research Methods, 15(1), 57-74.

Avolio, B. J., Walumbwa, F. O., \& Weber, T. J. (2009). Leadership: Current theories, research, and future directions. Annual Review of Psychology, 60, 421-449.

Awang, A. H., Haron, M., Zainuddin Rela, I., \& Saad, S. (2020). Formation of civil servants' creativity through transformative leadership*. Journal of Management Development, 39(4), 499-515.

Bagheri, A., \& Akbari, M. (2018). The Impact of Entrepreneurial Leadership on Nurses' Innovation Behavior. Journal of Nursing Scholarship, 50(1), 28-35.

Bagheri, A., Akbari, M., \& Artang, A. (2020). How does entrepreneurial leadership affect innovation work behavior? The mediating role of individual and team creativity self-efficacy. European Journal of Innovation Management.

Bagheri, A., Lope Pihie, Z. A., \& Krauss, S. E. (2013). Entrepreneurial leadership competencies among Malaysian university student entrepreneurial leaders. In Asia Pacific Journal of Education (Vol. 33, Issue 4, pp. 493-508). Taylor \& Francis.

Bagheri, A., Newman, A., \& Eva, N. (2020). Entrepreneurial leadership of CEOs and employees' innovative behavior in high-technology new ventures. Journal of Small Business Management, 00(00), 1-23.

Bak, H. U. (2020). Supervisor Feedback and Innovative Work Behavior: The Mediating Roles of Trust in Supervisor and Affective Commitment*. Frontiers in Psychology, 11(September).

Bakker, A. B., Schaufeli, W. B., Leiter, M. P., \& Taris, T. W. (2008). Work engagement: An emerging concept in occupational health psychology. Work and Stress, 22(3), 187-200.

Bandura, A. (1977). Self-efficacy: Toward a Unifying Theory of Behavioral Change. Psychological Review, 84(2), 191-215.

Bandura, A. (1986). Social foundations of thought and action: A social cognitive theory. In Social foundations of thought and action: A social cognitive theory. Prentice-Hall, Inc.

Bandura, A. (2001). Social Cognitive Theory: An Agentic Perspective. Annual Review of Psychology, 52(1), 1-26.

Bandura, A. (2005). The Evolution of Social Cognitive Theory. In K. G. Smith \& M. A. Hitt (Eds.), Great Minds in Management (pp. 9-35). Oxford University Press.

Bandura, A., \& Azzi, R. G. (2017). Teoria social cognitiva: diversos enfoques (Psicologia). Mercado das Letras.

Basadur, M. (2004). Leading others to think innovatively together: Creative leadership. Leadership Quarterly, 15(1), 103-121.

Bavik, A. (2020). A systematic review of the servant leadership literature in management and hospitality. International Journal of Contemporary Hospitality Management, 32(1), 347-382.

Baykal, E., Zehir, C., \& Köle, M. (2018). Effects of Servant Leadership on Gratitude, Empowerment, Innovativeness and Performance: Turkey Example. Journal of Economy Culture and Society, 29-52.

Bhatnagar, J. (2012). Management of innovation: role of psychological empowerment, work engagement and turnover intention in the Indian 
context. International Journal of Human Resource Management, 23(5), 928951.

Bido, D. S., Godoy, A. S., Ferreira, J. F., Kenski, J. M., \& Scartezini, V. N.

(2011). Examining the relationship between individual, group and organizational learning in a financial institution. REAd. Revista Eletrônica de Administração (Porto Alegre), 17(1), 58-85.

Black, K. (2010). Business Statistics for Contemporany Decision Making (Sixth Edit). John Wiley \& Sons, Inc.

Bolden, R., \& O'Regan, N. (2018). Leadership and Creativity in Public Services: An Interview With Lord Michael Bichard, Chair of the National Audit Office*. Journal of Management Inquiry, 27(1), 45-51.

Brasil. (1988). Constituição da República Federativa do Brasil de 1988.

Cai, W., Lysova, E. I., Khapova, S. N., \& Bossink, B. A. G. (2018). Servant leadership and innovative work behavior in Chinese high-tech firms: A moderated mediation model of meaningful work and job autonomy. Frontiers in Psychology, 9(OCT), 1-13.

Cai, W., Lysova, E. I., Khapova, S. N., \& Bossink, B. A. G. (2019). Does Entrepreneurial Leadership Foster Creativity Among Employees and Teams? The Mediating Role of Creative Efficacy Beliefs. Journal of Business and Psychology, 34(2), 203-217.

Castardo, H. F. (2007). O tribunal de contas no ordenamento jurídico brasileiro.

Chaudhary, R., \& Akhouri, A. (2018). Linking corporate social responsibility attributions and creativity: Modeling work engagement as a mediator. Journal of Cleaner Production, 190, 809-821.

Chin, W. W. (1998). The Partial Least Squares approach to structural equation modeling. In G. A. (Ed. . Marcoulides (Ed.), Modern methods for business research (pp. 295-336). Mahwah: Lawrence Erlbaum Associates.

Chiniara, M., \& Bentein, K. (2016). Linking servant leadership to individual performance: Differentiating the mediating role of autonomy, competence and relatedness need satisfaction. The Leadership Quarterly, 27(1), 124-141.

Chiniara, M., \& Bentein, K. (2018). The servant leadership advantage: When perceiving low differentiation in leader-member relationship quality influences team cohesion, team task performance and service OCB. The Leadership Quarterly, 29(2), 333-345.

Christensen, L. J., Mackey, A., \& Whetten, D. (2014). Taking responsibility for corporate social responsibility: The role of leaders in creating, implementing, sustaining, or avoiding socially responsible firm behaviors. Academy of Management Perspectives, 28(2), 164-178.

Clausen, T. H., Demircioglu, M. A., \& Alsos, G. A. (2020). Intensity of innovation in public sector organizations: The role of push and pull factors. Public Administration, 98(1), 159-176.

Cohen, J. (1988). Statistical Power Analysis for the Behavioral Sciences. In Statistical Power Analysis for the Behavioral Sciences (Second Edi). Routledge.

Colares, J. C. de S., Neves, H. de C., Santos, J. C. S. dos, Cavalcante, M. J. M., Silva, R. A. da, \& Filho, F. de S. P. (2020). Efficiency in Public Administration Focusing on Strategic Alignment. International Journal of Business Administration, 11(5), 58-70.

Currie, G., Humphreys, M., Ucbasaran, D., \& Mcmanus, S. (2008). Entrepreneurial leadership in the English public sector: Paradox or 
possibility? Public Administration, 86(4), 987-1008.

Dabić, M., Stojčić, N., Simić, M., Potocan, V., Slavković, M., \& Nedelko, Z. (2021). Intellectual agility and innovation in micro and small businesses: The mediating role of entrepreneurial leadership. Journal of Business Research, 123(October 2020), 683-695.

De Jong, J., \& Den Hartog, D. (2010). Measuring innovative work behaviour. Creativity and Innovation Management, 19(1), 23-36.

De Spiegelaere, S., Van Gyes, G., De Witte, H., Niesen, W., \& Van Hootegem, G. (2014). On the relation of job insecurity, job autonomy, innovative work behaviour and the mediating effect of work engagement. Creativity and Innovation Management, 23(3), 318-330.

De Spiegelaere, S., Van Gyes, G., \& Van Hootegem, G. (2016). Not All Autonomy is the Same. Different Dimensions of Job Autonomy and Their Relation to Work Engagement \& Innovative Work Behavior. Human Factors and Ergonomics In Manufacturing, 26(4), 515-527.

Deci, E. L., \& Ryan, R. M. (2008). Self-determination theory: A macrotheory of human motivation, development, and health. Canadian Psychology, 49(3), 182-185.

Eisenbeiss, S. A. (2012). Re-thinking ethical leadership: An interdisciplinary integrative approach. The Leadership Quarterly, 23(5), 791-808.

Eva, N., Robin, M., Sendjaya, S., van Dierendonck, D., \& Liden, R. C. (2019). Servant Leadership: A systematic review and call for future research. The Leadership Quarterly, 30(1), 111-132.

Faul, F., Erdfelder, E., \& Lang, A. B. A. A.-G. (2009). Statistical power analyses using G*Power 3.1: Tests for correlation and regression analyses. Behavior Research Methods, 41(4), 1149-1160.

Fontana, A., \& Musa, S. (2017). The impact of entrepreneurial leadership on innovation management and its measurement validation. International Journal of Innovation Science, 9(1), 2-19.

Franco, M., \& Antunes, A. (2020). Understanding servant leadership dimensions: Theoretical and empirical extensions in the Portuguese context. Nankai Business Review International, 11(3), 345-369.

Gagné, M., \& Deci, E. L. (2005). Self-determination theory and work motivation. Jounal of Organizational Behavior, 26(January), 331-362.

Garg, S., \& Dhar, R. (2017). Employee service innovative behavior: The roles of leader-member exchange (LMX), work engagement, and job autonomy*. International Journal of Manpower, 38(2), 242-258.

Gillet, J., Cartwright, E., \& Vugt, M. van. (2011). Selfish or servant leadership? Evolutionary predictions on leadership personalities in coordination games. Personality and Individual Differences, 51(3), 231-236.

Gilson, L. L., \& Shalley, C. E. (2004). A little creativity goes a long way: An examination of teams' engagement in creative processes. Journal of Management, 30(4), 453-470.

Giolito, V. J., Liden, R. C., van Dierendonck, D., \& Cheung, G. W. (2020). Servant Leadership Influencing Store-Level Profit: The Mediating Effect of Employee Flourishing. Journal of Business Ethics.

Gkorezis, P. (2016). Principal empowering leadership and teacher innovative behavior: a moderated mediation model*. International Journal of Educational Management, 30(6), 1030-1044.

González-Romá, V., Schaufeli, W. B., Bakker, A. B., \& Lloret, S. (2006). 
Burnout and work engagement: Independent factors or opposite poles? Journal of Vocational Behavior, 68(1), 165-174.

Gottman, J. M., Coan, J., Carrere, S., Swanson, C., Gottman, J. M., Coan, J., Carrere, S., \& Swanson, C. (2010). Transformational and transactional leadership and innovative behavior: The moderating role of psychological empowerment*. Journal of Organizational Behavior, 31(1), 609-623.

Greenleaf, R. K. (1970). The servant as leader. Indianapolis: The Robert K. Greenleaf Center.

Greenleaf, R. K. (1972a). The institution as servant. Indianapolis: The Robert K. Greenleaf Center.

Greenleaf, R. K. (1972b). Trustees as servants. Indianapolis: The Robert K. Greenleaf Center.

Greenleaf, R. K. (1977). Servant Leadership: A Journey Into the Nature of Legitimate Power and Greatness.

Gregory Stone, A., Russell, R. F., \& Patterson, K. (2004). Transformational versus servant leadership: A difference in leader focus. Leadership \& Organization Development Journal, 25(4), 349-361.

Günzel-Jensen, F., Hansen, J. R., Jakobsen, M. L. F., \& Wulff, J. (2018). A TwoPronged Approach? Combined Leadership Styles and Innovative Behavior. International Journal of Public Administration, 41(12), 957-970.

Gupta, V., MacMillan, I. C., \& Surie, G. (2004). Entrepreneurial leadership: Developing and measuring a cross-cultural construct. Journal of Business Venturing, 19(2), 241-260.

Hair, J. F., Hult, G. T. M., Ringle, C. M., \& Sarstedt, M. (2017). A Primer on Partial Least Squares Structural Equation Modeling (PLS-SEM) (2 ed.). Thousand Oaks, CA: Sage.

Hair, J. F., Risher, J. J., Sarstedt, M., \& Ringle, C. M. (2019). When to use and how to report the results of PLS-SEM. European Business Review, 31(1), 224.

Hair, J. F., Sarstedt, M., Ringle, C. M., \& Gudergan, S. P. (2018). Advanced Issues in Partial Least Squares Structural Equation Modeling (PLS-SEM). Thousand Oaks, CA: Sage.

He, L., Standen, P., \& Coetzer, A. (2017). The perceived personal characteristics of entrepreneurial leaders. Small Enterprise Research, 24(2), 97-119.

Hernández-Perlines, F., \& Araya-Castillo, L. A. (2020). Servant Leadership, Innovative Capacity and Performance in Third Sector Entities. Frontiers in Psychology, 11(February), 1-15.

Hiebl, M. R. W. (2021). Sample Selection in Systematic Literature Reviews of Management Research. Organizational Research Methods, 1-33.

Hoch, J. E., Bommer, W. H., Dulebohn, J. H., \& Wu, D. (2018). Do Ethical, Authentic, and Servant Leadership Explain Variance Above and Beyond Transformational Leadership? A Meta-Analysis. Journal of Management, 44(2), 501-529.

Hu, J., \& Liden, R. C. (2011). Antecedents of Team Potency and Team Effectiveness: An Examination of Goal and Process Clarity and Servant Leadership. Journal of Applied Psychology, 96(4), 851-862.

Huang, S., Ding, D., \& Chen, Z. (2014). Entrepreneurial leadership and performance in chinese new ventures: A moderated mediation model of exploratory innovation, exploitative innovation and environmental dynamism. Creativity and Innovation Management, 23(4), 453-471. 
Hughes, D. J., Lee, A., Tian, A. W., Newman, A., \& Legood, A. (2018). Leadership, creativity, and innovation: A critical review and practical recommendations. The Leadership Quarterly, 29(5), 549-569.

Iqbal, A., Latif, K. F., \& Ahmad, M. S. (2020). Servant leadership and employee innovative behaviour: exploring psychological pathways. Leadership and Organization Development Journal, 41(6), 813-827.

Iqbal, A., Nazir, T., \& Ahmad, M. S. (2020). Entrepreneurial leadership and employee innovative behavior: an examination through multiple theoretical lenses. European Journal of Innovation Management.

Jaiswal, N. K., \& Dhar, R. L. (2017). The influence of servant leadership, trust in leader and thriving on employee creativity. Leadership and Organization Development Journal, 38(1), 2-21.

Janssen, O. (2000). Job demands, perceptions of effort-reward fairness and innovative work behaviour. Journal of Occupational and Organizational Psychology, 73(3), 287-302.

Kalyar, M. N., Usta, A., \& Shafique, I. (2019). When ethical leadership and LMX are more effective in prompting creativity: The moderating role of psychological capital*. Baltic Journal of Management, 15(1), 61-80.

Karatepe, O. M., Aboramadan, M., \& Dahleez, K. A. (2020). Does climate for creativity mediate the impact of servant leadership on management innovation and innovative behavior in the hotel industry? International Journal of Contemporary Hospitality Management, 32(8), 2497-2517.

Kaur, P. (2018). Mediator Analysis of Job Satisfaction: Relationship between Servant Leadership and Employee Engagement. Metamorphosis: A Journal of Management Research, 17(2), 76-85.

Kaya, B., \& Karatepe, O. M. (2020). Does servant leadership better explain work engagement, career satisfaction and adaptive performance than authentic leadership? International Journal of Contemporary Hospitality Management, 32(6), 2075-2095.

Khan, M. M., Khan, N. A., Bodla, A. A., \& Gul, S. (2020). Impact on employee creativity via work engagement and negative socioemotional behavior in public health sector: Role of abusive supervision*. Personnel Review, 49(8), 1655-1675.

Khan, M. M., Mubarak, S., \& Islam, T. (2020). Leading the innovation: role of trust and job crafting as sequential mediators relating servant leadership and innovative work behavior. European Journal of Innovation Management.

Khan, M. M., Mubarik, M. S., Islam, T., Rehman, A., Ahmed, S. S., Khan, E., \& Sohail, F. (2021). How servant leadership triggers innovative work behavior: exploring the sequential mediating role of psychological empowerment and job crafting. European Journal of Innovation Management.

Khedhaouria, A., Gurău, C., \& Torrès, O. (2015). Creativity, self-efficacy, and small-firm performance: the mediating role of entrepreneurial orientation. Small Business Economics, 44(3), 485-504.

Kim, J., \& Song, C. (2020). The relationship between R\&D team diversity and team creativity*. Management Decision, 59(2), 175-189.

Kim, S., \& Yoon, G. (2015). An innovation-driven culture in local government: Do senior manager's transformational leadership and the climate for creativity matter?*. Public Personnel Management, 44(2), 147-168.

Kim, W., \& Park, J. (2017). Examining structural relationships between work engagement, organizational procedural justice, knowledge sharing, and 
innovative work behavior for sustainable organizations. Sustainability (Switzerland), 9(2).

Kremer, H., Villamor, I., \& Aguinis, H. (2019). Innovation leadership: Bestpractice recommendations for promoting employee creativity, voice, and knowledge sharing. Business Horizons, 62(1), 65-74.

Krog, C. L., \& Govender, K. (2015). The relationship between servant leadership and employee empowerment, commitment, trust and innovative behaviour: A project management perspective. SA Journal of Human Resource Management, 13(1), 1-12.

Kundu, S. C., Kumar, S., \& Lata, K. (2019). Effects of perceived role clarity on innovative work behavior: a multiple mediation model. RAUSP Management Journal, ahead-of-p(ahead-of-print).

Laguna, M., \& Razmus, W. (2019). When I Feel My Business Succeeds, I Flourish: Reciprocal Relationships Between Positive Orientation, Work Engagement, and Entrepreneurial Success. Journal of Happiness Studies, 20(8), 2711-2731.

Langelaan, S., Bakker, A. B., van Doornen, L. J. P., \& Schaufeli, W. B. (2006). Burnout and work engagement: Do individual differences make a difference? Personality and Individual Differences, 40(3), 521-532.

Lapuente, V., \& Suzuki, K. (2020). Politicization, Bureaucratic Legalism, and Innovative Attitudes in the Public Sector. Public Administration Review, 80(3), 454-467.

Latif, K. F., \& Marimon, F. (2019). Development and validation of servant leadership scale in Spanish higher education. Leadership and Organization Development Journal, 40(4), 499-519.

Lee, A., Legood, A., Hughes, D., Tian, A. W., Newman, A., \& Knight, C. (2020). Leadership, creativity and innovation: a meta-analytic review. European Journal of Work and Organizational Psychology, 29(1), 1-35.

Leitch, C. M., Mcmullan, C., \& Harrison, R. T. (2013). The Development of Entrepreneurial Leadership: The Role of Human, Social and Institutional Capital. British Journal of Management, 24(3), 347-366.

Lewis, J. M., Ricard, L. M., \& Klijn, E. H. (2018). How innovation drivers, networking and leadership shape public sector innovation capacity. International Review of Administrative Sciences, 84(2), 288-307.

Li, C., Makhdoom, H. U. R., \& Asim, S. (2020). Impact of entrepreneurial leadership on innovative work behavior: Examining mediation and moderation mechanisms. Psychology Research and Behavior Management, $13,105-118$.

Li, Y., Mehmood, K., Zhang, X., \& Crossin, C. M. (2019). A multilevel study of leaders' emotional labor on servant leadership and job satisfaction. In Emotions and Leadership (Research on Emotion in Organizations) (Vol. 15, pp. 47-67). Emerald Publishing Limited.

Liden, R. C., Panaccio, A., Meuser, J. D., Hu, J., \& Sandy, J. (2014). Servant leadership: Antecedents, processes, and outcomes. In D. V. Day (Ed.), The Oxford Handbook of Leadership and Organizations (pp. 1-41). Oxford handbooks online.

Liden, R. C., Wayne, S. J., Liao, C., \& Meuser, J. D. (2014). Servant leadership and serving culture: Influence on individual and unit performance. Academy of Management Journal, 57(5), 1434-1452.

Liden, R. C., Wayne, S. J., Meuser, J. D., Hu, J., Wu, J., \& Liao, C. (2015). 
Servant leadership: Validation of a short form of the SL-28. The Leadership Quarterly, 26(2), 254-269.

Liden, R. C., Wayne, S. J., Zhao, H., \& Henderson, D. (2008). Servant leadership: Development of a multidimensional measure and multi-level assessment. The Leadership Quarterly, 19(2), 161-177.

Ling, Q., Liu, F., \& Wu, X. (2017). Servant Versus Authentic Leadership: Assessing Effectiveness in China's Hospitality Industry. Cornell Hospitality Quarterly, 58(1), 53-68.

Lingo, E. L. (2020). Entrepreneurial Leadership as Creative Brokering: The Process and Practice of Co-creating and Advancing Opportunity. Journal of Management Studies, 57(5), 962-1001.

Liu, B., Hu, W., \& Cheng, Y. C. (2015). From the west to the east: Validating servant leadership in the Chinese public sector. Public Personnel Management, 44(1), 25-45.

Luu, T. T., Rowley, C., Dinh, C. K., Qian, D., \& Le, H. Q. (2019). Team Creativity in Public Healthcare Organizations: The Roles of Charismatic Leadership, Team Job Crafting, and Collective Public Service Motivation. Public Performance and Management Review, 42(6), 1448-1480.

Makri, M., \& Scandura, T. A. (2010). Exploring the effects of creative CEO leadership on innovation in high-technology firms. The Leadership Quarterly, 21(1), 75-88.

Malik, O. F., Shahzad, A., Waheed, A., \& Yousaf, Z. (2020). Abusive supervision as a trigger of malevolent creativity: do the Light Triad traits matter?*. Leadership and Organization Development Journal, 41(8), 1119-1137.

Malik, S., Awan, T. M., \& Nisar, A. (2020). Entrepreneurial Leadership and Employee Innovative Behavior in Software Industry. Journal of Business \& Economics, 12(1), 63-76.

Masood, M., \& Afsar, B. (2017). Transformational leadership and innovative work behavior among nursing staff*. Nursing Inquiry, 24(4), 1-14.

Matta, F. K., Scott, B. A., Koopman, J., \& Conlon, D. (2015). Does Seeing "Eye To Eye" Affect Work Engagement and OCB? A Role Theory Perspective on LMX Agreement. Academy of Management Journal, 58(6), 2-60.

Mehmood, M. S., Jian, Z., \& Akram, U. (2020). Be so creative they can't ignore you! How can entrepreneurial leader enhance the employee creativity? Thinking Skills and Creativity, 38(August), 100721.

Mehmood, M. S., Jian, Z., Akram, U., \& Tariq, A. (2021). Entrepreneurial leadership: the key to develop creativity in organizations. Leadership and Organization Development Journal, 71771022.

Mehmood, M. S., Jian, Z., \& Gilal, F. G. (2020). Entrepreneurial leadership and employee innovative behavior: Intervening role of creative self-efficacy. Human Systems Management, 39(3), 367-379.

Menter, M. (2020). Entrepreneurial universities and innovative behavior: the impact of gender diversity. Economics of Innovation and New Technology, $O(0), 1-15$.

Miao, Q., Newman, A., Schwarz, G., \& Cooper, B. (2018). How Leadership and Public Service Motivation Enhance Innovative Behavior. Public Administration Review, 78(1), 71-81.

Mittal, R., \& Dorfman, P. W. (2012). Servant leadership across cultures. Journal of World Business, 47(4), 555-570.

Mokhber, M., Wan Ismail, W. K., Vakilbashi, A., Abdul Rasid, S. Z., \& Tan, G. 
(2015). Towards Understanding the Influence of Entrepreneurial Leadership on Organization Demand for Innovation. In Advanced Science Letters (Vol. 21, Issue 5, pp. 1481-1484).

Mutonyi, B. R., Slåtten, T., \& Lien, G. (2020). Organizational climate and creative performance in the public sector. European Business Review, 32(4), 615-631.

Naeem, R. M., Weng, Q., Hameed, Z., \& Rasheed, M. I. (2020). Ethical leadership and work engagement: A moderated mediation model. Ethics and Behavior, 30(1), 63-82.

Nazir, S., Qun, W., Hui, L., \& Shafi, A. (2018). Influence of social exchange relationships on affective commitment and innovative behavior: Role of perceived organizational support*. Sustainability (Switzerland), 10(12).

Newman, A., Schwarz, G., Cooper, B., \& Sendjaya, S. (2017). How Servant Leadership Influences Organizational Citizenship Behavior: The Roles of LMX, Empowerment, and Proactive Personality. Journal of Business Ethics, 145(1), 49-62.

Newman, A., Tse, H. H. M., Schwarz, G., \& Nielsen, I. (2018). The effects of employees' creative self-efficacy on innovative behavior: The role of entrepreneurial leadership. Journal of Business Research, 89(September 2016), 1-9.

Nullens, P. (2019). The Will to Serve: An Anthropological and Spiritual Foundation for Leadership. In L. Bouckaert \& S. C. van den Heuvel (Eds.), Servant Leadership, Social Entrepreneurship and the Will to Serve: Spiritual Foundations and Business Applications (pp. 3-28). Palgrave Macmillan.

Odoardi, C., Montani, F., Boudrias, J. S., \& Battistelli, A. (2015). Linking managerial practices and leadership style to innovative work behavior: The role of group and psychological processes. Leadership and Organization Development Journal, 36(5), 545-569.

Oldham, G. R., \& Cummings, A. (1996). Employee creativity: Personal and contextual factors at work. Academy of Management Journal, 39(3), 607634.

Opoku, M. A., Choi, S. B., \& Kang, S. W. (2019). Servant leadership and innovative behaviour: An empirical analysis of Ghana's manufacturing sector. Sustainability (Switzerland), 11(22).

Osborne, S. P., \& Brown, L. (2011). Innovation, public policy and public services delivery in the UK. The word that would be king? Public Administration, 89(4), 1335-1350.

Paesen, H., Wouters, K., \& Maesschalck, J. (2019). Servant leaders, ethical followers? The effect of servant leadership on employee deviance. Leadership \& Organization Development Journal, 40(5), 624-646.

Panaccio, A., Henderson, D. J., Liden, R. C., Wayne, S. J., \& Cao, X. (2015). Toward an Understanding of When and Why Servant Leadership Accounts for Employee Extra-Role Behaviors. Journal of Business and Psychology, 30(4), 657-675.

Papalexandris, N., \& Galanaki, E. (2009). Leadership's impact on employee engagement: Differences among entrepreneurs and professional CEOs. Leadership and Organization Development Journal, 30(4), 365-385.

Park, S., \& Jo, S. J. (2018). The impact of proactivity, leader-member exchange, and climate for innovation on innovative behavior in the Korean government sector*. Leadership and Organization Development Journal, 39(1), 130-149. 
Parris, D. L., \& Peachey, J. W. (2013). A Systematic Literature Review of Servant Leadership Theory in Organizational Contexts. Journal of Business Ethics, 113(3), 377-393.

Peng, Y. P. (2020). Relationship between job involvement, leader-member exchange, and innovative behavior of public librarians*. Journal of Librarianship and Information Science, 52(2), 441-450.

Peterson, S. J., Galvin, B. M., \& Lange, D. (2012). CEO servant leadership: Exploring executive characteristics and firm performance. Personnel Psychology, 65(3), 565-596.

Phuong, T. H., \& Takahashi, K. (2021). The impact of authentic leadership on employee creativity in Vietnam: a mediating effect of psychological contract and moderating effects of subcultures*. Asia Pacific Business Review, 27(1), $77-100$.

Pietraszewski, D. (2020). The evolution of leadership: Leadership and followership as a solution to the problem of creating and executing successful coordination and cooperation enterprises. The Leadership Quarterly, 31(2), 101299.

Podsakoff, P. M., MacKenzie, S. B., Lee, J. Y., \& Podsakoff, N. P. (2003). Common Method Biases in Behavioral Research: A Critical Review of the Literature and Recommended Remedies. Journal of Applied Psychology, 88(5), 879-903.

Qiu, H., \& Chreim, S. (2021). A tension lens for understanding public innovation diffusion processes. Public Management Review.

Qiu, S., \& Dooley, L. (2019). Servant leadership: Development and validation of a multidimensional measure in the Chinese hospitality industry. Leadership and Organization Development Journal, 40(2), 193-212.

Reiter, R., \& Klenk, T. (2019). The manifold meanings of 'post-New Public Management' - a systematic literature review. International Review of Administrative Sciences, 85(1), 11-27.

Renko, M. (2017). Entrepreneurial leadership. In D. V. Day \& J. Antonakis (Eds.), The Nature of Leadership (3rd editio, pp. 1-46). SAGE Publications.

Renko, M., El Tarabishy, A., Carsrud, A. L., \& Brännback, M. (2015). Understanding and measuring entrepreneurial leadership style. Journal of Small Business Management, 53(1), 54-74.

Ringle, C. M., \& Sarstedt, M. (2016). Gain more insight from your PLS-SEM results the importance-performance map analysis. Industrial Management and Data Systems, 116(9), 1865-1886.

Ringle, C. M., Silva, D., \& Bido, D. D. S. (2014). Modelagem de Equações Estruturais com Utilização do SmartPLS. Revista Brasileira de Marketing, 13(2), 56-73.

Rodríguez-Sánchez, A. M., Devloo, T., Rico, R., Salanova, M., \& Anseel, F. (2017). What Makes Creative Teams Tick? Cohesion, Engagement, and Performance Across Creativity Tasks: A Three-Wave Study. Group and Organization Management, 42(4), 521-547.

Rusliati, E., Mulyaningrum, M., Wibowo, A., \& Narmaditya, B. S. (2020). Does entrepreneurial leadership matter for micro-enterprise development?: Lesson from west java in Indonesia. Journal of Asian Finance, Economics and Business, 7(8), 445-450.

Russell, R. F., \& Stone, A. G. (2002). A review of servant leadership attributes: developing a practical model. Leadership \& Organization Development 
Journal, 23(3), 145-157.

Ruvio, A., Rosenblatt, Z., \& Hertz-Lazarowitz, R. (2010). Entrepreneurial leadership vision in nonprofit vs. for-profit organizations. The Leadership Quarterly, 21(1), 144-158.

Ryan, R. M., \& Deci, E. L. (2000). Self-determination theory and the facilitation of intrinsic motivation, social development, and well-being. American Psychologist, 55(1), 68-78.

Salanova, M., \& Schaufeli, W. B. (2008). A cross-national study of work engagement as a mediator between job resources and proactive behaviour. International Journal of Human Resource Management, 19(1), 116-131.

Saleem, F., Zhang, Y. Z., Gopinath, C., \& Adeel, A. (2020). Impact of Servant Leadership on Performance: The Mediating Role of Affective and Cognitive Trust. SAGE Open, 10(1).

Schaufeli, W. B., \& Bakker, A. B. (2004). Job demands, job resources, and their relationship with burnout and engagement: A multi-sample study. Journal of Organizational Behavior, 25(3), 293-315.

Schaufeli, W. B., Bakker, A. B., \& Rhenen, W. Van. (2009). How changes in job demands and resources predict burnout, work engagement, and sickness absenteeism. Journal of Organizational Behavior, 30, 893-917.

Schaufeli, W. B., Bakker, A. B., \& Salanova, M. (2006). The measurement of work engagement with a short questionnaire: A cross-national study. Educational and Psychological Measurement, 66(4), 701-716.

Schaufeli, W. B., Salanova, M., Gonzalez-Roma, V., \& Bakker, A. B. (2002). The Measurement of Engagement and Burnout: A Two Sample Confirmatory Factor Analytic Approach. Journal of Happiness Studies, 3, 71-92.

Scott, S. G., \& Bruce, R. A. (1994). Determinants of Innovative Behavior: A Path Model of Individual Innovation in the Workplace. The Academy of Management Journal, 37(3), 580-607.

Semedo, A. S. D., Coelho, A. F. M., \& Ribeiro, N. M. P. (2016). Effects of authentic leadership, affective commitment and job resourcefulness on employees' creativity and individual performance*. Leadership and Organization Development Journal, 37(8), 1038-1055.

Semedo, A. S. D., Coelho, A. F. M., \& Ribeiro, N. M. P. (2017). Authentic leadership and creativity: the mediating role of happiness*. International Journal of Organizational Analysis, 25(3), 395-412.

Sendjaya, S. (2015). Personal and Organizational Excellence through Servant Leadership: Learning to Serve, Serving to Lead, Leading to Transform. In Personal and Organizational Excellence through Servant Leadership.

Sendjaya, S., Eva, N., Butar Butar, I., Robin, M., \& Castles, S. (2019). SLBS-6: Validation of a Short Form of the Servant Leadership Behavior Scale. Journal of Business Ethics, 156(4), 941-956.

Sendjaya, S., Eva, N., Robin, M., Sugianto, L., ButarButar, I., \& Hartel, C. (2019). Leading others to go beyond the call of duty: A dyadic study of servant leadership and psychological ethical climate. Personnel Review, 49(2), 620-635.

Sendjaya, S., Sarros, J. C., \& Santora, J. C. (2008). Defining and measuring servant leadership behaviour in organizations. Journal of Management Studies, 45(2), 402-424.

Senjaya, S., \& Pekerti, A. (2010). Servant leadership as antecedent of trust in organizations. Leadership and Organization Development Journal, 31(7), 
643-663.

Shane, S., \& Venkataraman, S. (2000). The promise of entrepreneurship as a field of research. The Academy of Management Review, 25(1), 217-226.

Shim, D. C., \& Park, H. H. (2019). Public Service Motivation in a Work Group: Role of Ethical Climate and Servant Leadership. Public Personnel Management, 48(2), 203-225.

Sklaveniti, C. (2017). Processes of entrepreneurial leadership: Co-acting creativity and direction in the emergence of new SME ventures. International Small Business Journal: Researching Entrepreneurship, 35(2), 197-213.

Sousa, M., \& van Dierendonck, D. (2017). Servant Leadership and the Effect of the Interaction Between Humility, Action, and Hierarchical Power on Follower Engagement. Journal of Business Ethics, 141(1), 13-25.

Sousa, M., \& Van Dierendonck, D. (2014). Servant leadership and engagement in a merge process under high uncertainty. Journal of Organizational Change Management, 27(6), 877-899.

Souza, S. A. de. (2016). O que é um tribunal de contas? Estudo sob a perspectiva popular, em Curitiba (PR). Cadernos Gestão Pública e Cidadania, 21(70), 284-307.

Spears, L. C. (2004). Practicing Servant-Leadership. Leader to Leader, 34, 7-11.

Spreitzer, G. M. (1995). Psychological, Empowerment in the Workplace: Dimensions, Measurement and Validation. Academy of Management Journal, 38(5), 1442-1465.

Spreitzer, G. M. (1996). Social structural characteristics of psychological empowerment. Academy of Management Journal, 39(2), 483-504.

Steffens, N. K., Yang, J., Jetten, J., Haslam, S. A., \& Lipponen, J. (2018). The unfolding impact of leader identity entrepreneurship on burnout, work engagement, and turnover intentions. Journal of Occupational Health Psychology, 23(3), 373-387.

Strobl, A., Bauer, F., \& Matzler, K. (2020). The impact of industry-wide and target market environmental hostility on entrepreneurial leadership in mergers and acquisitions. Journal of World Business, 55(2), 100931.

Su, W., Lyu, B., Chen, H., \& Zhang, Y. (2020). How does servant leadership influence employees' service innovative behavior? The roles of intrinsic motivation and identification with the leader. Baltic Journal of Management, 15(4), 571-586.

Sun, P. Y. T. (2013). The servant identity: Influences on the cognition and behavior of servant leaders. The Leadership Quarterly, 24(4), 544-557.

Suseno, Y., Standing, C., Gengatharen, D., \& Nguyen, D. (2020). Innovative work behaviour in the public sector: The roles of task characteristics, social support, and proactivity. Australian Journal of Public Administration, 79(1), 41-59.

Tierney, P., Farmer, S. M., \& Graen, G. B. (1999). An examination of leadership and employee creativity: The relevance of traits and relationships. Personnel Psychology, 52(3), 591-620.

Tong, Z., Zhu, L., Zhang, N., Livuza, L., \& Zhou, N. (2019). Employees’ perceptions of corporate social responsibility and creativity: Employee engagement as a mediator. Social Behavior and Personality, 47(12).

Tripathi, D., Priyadarshi, P., Kumar, P., \& Kumar, S. (2020). Does servant leadership affect work role performance via knowledge sharing and psychological empowerment? Journal of Information and Knowledge 
Management Systems.

Vallerand, R. J., Koestner, R., \& Pelletier, L. G. (2008). Reflections on selfdetermination theory. Canadian Psychology, 49(3), 257-262.

van Acker, W., Wynen, J., \& Op de Beeck, S. (2018). Illuminating the Gender Divide in Public Sector Innovation: Evidence From the Australian Public Service. Public Personnel Management, 47(2), 175-194.

van Dierendonck, D. (2011). Servant leadership: A review and synthesis. Journal of Management, 37(4), 1228-1261.

van Dierendonck, D., \& Nuijten, I. (2011). The Servant Leadership Survey: Development and Validation of a Multidimensional Measure. Journal of Business and Psychology, 26(3), 249-267.

van Dierendonck, D., \& Patterson, K. (2010). Servant Leadership: Developments in Theory and Research. In Servant Leadership. Palgrave Macmillan UK.

van Dierendonck, D., \& Patterson, K. (2015). Compassionate Love as a Cornerstone of Servant Leadership: An Integration of Previous Theorizing and Research. Journal of Business Ethics, 128(1), 119-131.

Van Dierendonck, D., Stam, D., Boersma, P., de Windt, N., \& Alkema, J. (2014). Same difference? Exploring the differential mechanisms linking servant leadership and transformational leadership to follower outcomes. The Leadership Quarterly, 25(3), 544-562.

Venkataraman, S. (1997). The distinctive domain of entrepreneurship research: An editor's perspective. In J. Katz \& R. Brockhaus (Ed.), Advances in entrepreneurship, firm emergence, and growth (vol. 3:119). Greenwich, CT: JAI Press.

Venkataramani, V., Richter, A. W., \& Clarke, R. (2014). Creative benefits from well-connected leaders: Leader social network ties as facilitators of employee radical creativity*. Journal of Applied Psychology, 99(5), 966-975.

Volery, T., \& Tarabashkina, L. (2021). The impact of organisational support, employee creativity and work centrality on innovative work behaviour. Journal of Business Research, 129, 295-303.

Waheed, A., Abbas, Q., \& Malik, O. F. (2018). 'Perceptions of performance appraisal quality' and employee innovative behavior: Do psychological empowerment and 'perceptions of HRM system strength' matter?*. Behavioral Sciences, 8(12).

Wang, Y., Chen, Y., \& Zhu, Y. (2021). Promoting Innovative Behavior in Employees: The Mechanism of Leader Psychological Capital. Frontiers in Psychology, 11(January).

Wang, Z., Meng, L., \& Cai, S. (2019). Servant leadership and innovative behavior: a moderated mediation. Journal of Managerial Psychology, 34(8), 505-518.

Wiliams, W. A., Brandon, R. S., Hayek, M., Haden, S. P., \& Atinc, G. (2017). Servant leadership and followership creativity: The influence of workplace spirituality and political skill*. Leadership and Organization Development Journal, 38(2), 178-193.

Williams, L. J., Hartman, N., \& Cavazotte, F. (2010). Method variance and marker variables: A review and comprehensive cfa marker technique. Organizational Research Methods, 13(3), 477-514.

Wipulanusat, W., Panuwatwanich, K., Stewart, R. A., Parnphumeesup, P., \& Sunkpho, J. (2020). Unraveling key drivers for engineer creativity and meaningfulness of work: Bayesian network approach*. Management and 
Production Engineering Review, 11(2), 26-37.

Woods, S. A., Mustafa, M. J., Anderson, N., \& Sayer, B. (2018). Innovative work behavior and personality traits: Examining the moderating effects of organizational tenure. Journal of Managerial Psychology, 33(1), 29-42.

Wu, T. J., \& Wu, Y. J. (2019). Innovative work behaviors, employee engagement, and surface acting: A delineation of supervisor-employee emotional contagion effects. Management Decision, 57(11), 3200-3216.

Ximenes, M., Supartha, W. G., Manuati Dewi, I. G. A., \& Sintaasih, D. K. (2019). Entrepreneurial leadership moderating high performance work system and employee creativity on employee performance. Cogent Business and Management, 6(1).

Yang, J., Gu, J., \& Liu, H. (2019). Servant leadership and employee creativity: The roles of psychological empowerment and work-family conflict. Current Psychology, 38(6), 1417-1427.

Yoshida, D. T., Sendjaya, S., Hirst, G., \& Cooper, B. (2014). Does servant leadership foster creativity and innovation? A multi-level mediation study of identification and prototypicality. Journal of Business Research, 67(7), 1395-1404.

Zampetakis, L. A. (2008). The role of creativity and proactivity on perceived entrepreneurial desirability. Thinking Skills and Creativity, 3(2), 154-162.

Zhang, W., Jex, S. M., Peng, Y., \& Wang, D. (2017). Exploring the Effects of Job Autonomy on Engagement and Creativity: The Moderating Role of Performance Pressure and Learning Goal Orientation. Journal of Business and Psychology, 32(3), 235-251.

Zhang, X., \& Bartol, K. M. (2010). Linking empowering leadership and employee creativity: The influence of psychological empowerment, intrinsic motivation, and creative process engagement. Academy of Management Journal, 53(1), 107-128.

Zhou, J., \& George, J. M. (2001). When Job Dissatisfaction Leads to Creativity: Encouraging the Expression of Voice. Academy of Management Journal, 44(4), 682-696.

Zhu, C., \& Zhang, F. (2020). How does servant leadership fuel employee innovative behavior? A moderated mediation framework. Asia Pacific Journal of Human Resources, 58(3), 356-377.

Zhu, J., Song, L. J., Zhu, L., \& Johnson, R. E. (2019). Visualizing the landscape and evolution of leadership research. The Leadership Quarterly, 30(2), 215232. 


\section{Anexo}

\section{Engajamento}

1. Em meu trabalho, sinto-me cheio de energia.

2. No trabalho, sinto-me forte e com vigor.

3. Estou entusiasmado com meu trabalho.

4. Meu trabalho me inspira.

5. Quando me levanto pela manhã, tenho vontade de ir trabalhar.

6. Sinto-me feliz quando trabalho intensamente.

7. Estou orgulhoso com o trabalho que realizo.

8. Fico imerso no meu trabalho.

9. Sou encantado pelo meu trabalho.

Nunca a Sempre (7 pontos)

\section{Comportamento inovador no trabalho}

Com que frequência você se sente à vontade para:

1. Criar novas ideias para questões difíceis.

2. Pesquisar novos métodos de trabalho, técnicas ou instrumentos.

3. Gerar soluções originais para problemas.

Com que frequência você busca:

1. Mobilizar apoio para ideias inovadoras.

2. Obter aprovação para ideias inovadoras.

3. Fazer com que membros importantes da organização fiquem entusiasmados com ideias inovadoras.

Com que frequência efetivamente você:

1. Transforma ideias inovadoras em aplicações úteis.

2. Introduz ideias inovadoras no ambiente de trabalho de forma sistemática.

3. Avalia a utilidade de ideias inovadoras.

Nunca a Sempre (7 pontos)

\section{Liderança Servidora}

1. Meu (minha) líder sabe quando algo relacionado ao trabalho não está indo bem.

2. Meu (minha) líder faz o desenvolvimento da minha carreira uma prioridade.

3. Eu posso pedir a ajuda de meu (minha) líder se eu tiver um problema pessoal.

4. Meu (minha) líder enfatiza a importância de retribuir à comunidade.

5. Meu (minha) líder dá mais prioridade aos meus interesses do que aos seus próprios

6. Meu (minha) líder me dá liberdade para lidar com situações difíceis da maneira que considero melhor.

7. Meu (minha) líder NÃO comprometeria princípios éticos para alcançar sucesso.

Discordar totalmente a concordar totalmente (7 pontos).

\section{Liderança Empreendedora}

1. Frequentemente, surge com ideias ousadas de melhoria para os serviços que realizamos.

2. Frequentemente, surge com ideias de serviços completamente novos que poderíamos realizar. 
3. Assume riscos.

4. Tem soluções criativas para problemas.

5. Demonstra paixão pelo seu trabalho.

6. Tem uma visão do futuro da nossa organização.

7. Desafia-me e incentiva-me a agir de forma mais inovadora.

8. Quer que eu desafie as formas atuais de realizar o trabalho.

Discordar totalmente a concordar totalmente ( 7 pontos).

\section{Empoderamento Psicológico}

1. O trabalho que realizo é muito importante para mim.

2. As atividades que executo em meu trabalho me proporcionam autorrealização.

3. Sou capaz de perceber o propósito do trabalho que desempenho.

4. Confio nas minhas habilidades para desempenhar o meu trabalho.

5. Tenho autoconsciência das minhas competências para desempenhar as atividades do meu trabalho.

6. Domino totalmente as competências necessárias para desempenhar o meu trabalho.

7. Tenho autonomia para determinar como faço o meu trabalho.

8. Posso decidir por conta própria como realizar o meu trabalho.

9. Tenho considerável independência e liberdade para realizar meu trabalho.

10. O impacto do meu trabalho no que ocorre no meu departamento é alto.

11. Tenho capacidade de controlar o que ocorre no meu departamento.

12. Tenho significativa influência no que ocorre no meu departamento.

Discordar totalmente a concordar totalmente (7 pontos).

\section{Variáveis marcadoras}

1. Eu gosto da cidade onde vivo

2. Eu gosto das escolas que frequentei

3. Eu gosto da qualidade da comida que consumo

4. Eu gosto da qualidade de meu momento de descanso

5. Eu gosto de programas de televisão

6. Eu gosto, em geral, das campanhas publicitárias que vejo

7. Eu gosto de música popular

8. Eu gosto, em geral, das comidas dos restaurantes

Discordar totalmente a concordar totalmente (5 pontos).

\section{Variáveis demográficas e organizacionais}

1. Idade

2. Gênero

3. Formação

4. Há quanto tempo você trabalha na organização? (Em anos)

5. Por quanto tempo você trabalhou com a liderança imediata a qual esteve subordinado(a) até dezembro de 2020 ?

6. Qual o gênero da liderança a qual esteve subordinado(a) até dezembro de 2020?

7. Quão confortável você se sente/sentiu no teletrabalho?

8. Qual a probabilidade de você desejar permanecer no teletrabalho após a pandemia?

9. Vínculo organizacional e Estado da Federação 